Supporting Information

\title{
Electrocatalytic Hydrogen Evolution by Cobalt Complexes with a Redox Non-Innocent Polypyridine Ligand
}

Jiale Liu, ${ }^{a}$ Rongzhen Liao, ${ }^{b}$ Frank W. Heinemann, ${ }^{c}$ Karsten Meyer, ${ }^{c}$ Randolph P. Thummel, ${ }^{d}$ Yaqiong Zhang, ${ }^{* b}$ Lianpeng Tong*a

a School of Chemistry and Chemical Engineering/Institute of Clean Energy and Materials, Guangzhou University, No. 230 Wai Huan Xi Road, Higher Education Mega Center, Guangzhou, 510006, P. R. China.

${ }^{\mathrm{b}}$ Key Laboratory of Material Chemistry for Energy Conversion and Storage, Ministry of Education, Hubei Key Laboratory of Bioinorganic Chemistry and Materia Medica, Hubei Key Laboratory of Materials Chemistry and Service Failure, School of Chemistry and Chemical Engineering, Huazhong University of Science and Technology, Wuhan 430074, China

${ }^{c}$ Department of Chemistry and Pharmacy, Inorganic Chemistry, Friedrich-Alexander-Universität Erlangen-Nürnberg (FAU), Egerlandstraße 1, 91058 Erlangen, Germany.

${ }^{\mathrm{d}}$ Department of Chemistry, 112 Fleming Building, University of Houston, Houston, TX 77204-5003.

*E-mail: yaqiongzhang@hust.edu.cn (Y. Z.); 1tong@gzhu.edu.cn (L. T.) 


\section{Table of Contents}

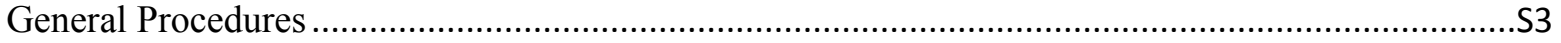

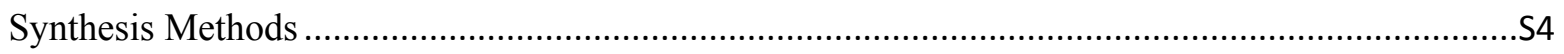

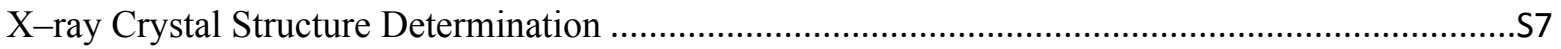

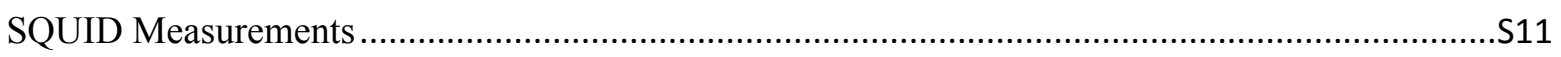

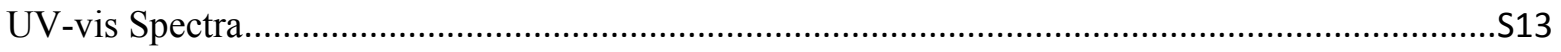

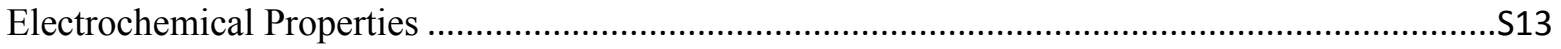

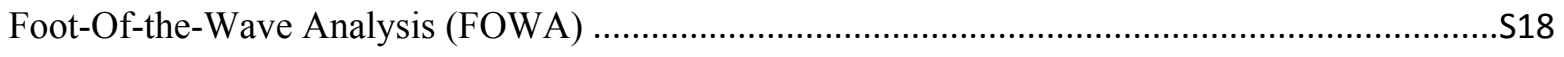

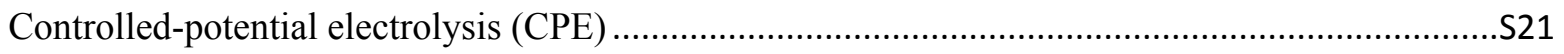

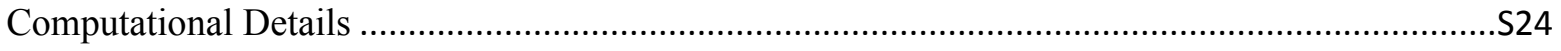

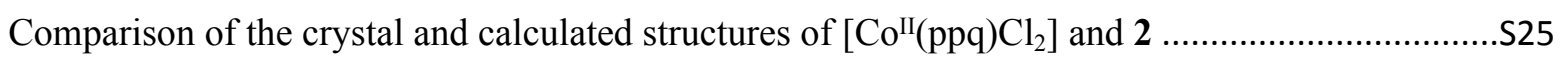

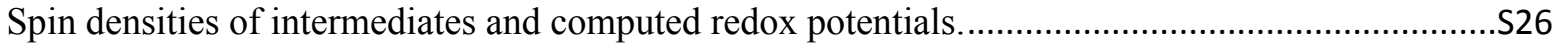

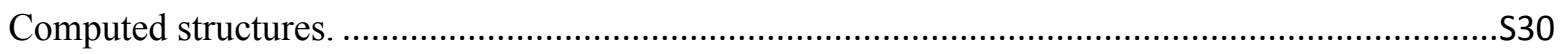

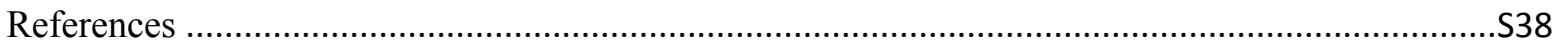

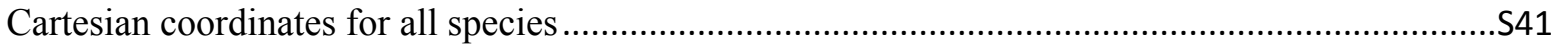




\section{General Procedures}

All air- and moisture-sensitive experiments were performed under a dry nitrogen atmosphere using standard Schlenk techniques or a MBraun glovebox containing an atmosphere of purified dinitrogen. Tetra$n$-butylammonium hexafluorophosphate $\left(\mathrm{TBAPF}_{6}, 99.9 \%\right)$ and ferrocene were purchased from SigmaAldrich and used as received. 2-(pyrid-2'-yl)-8-(1",10"-phenanthrolin-2"-yl)-quinoline (ppq) ${ }^{1}$, $\left[\mathrm{Co}{ }^{\mathrm{I}} \mathrm{Cl}\left(\mathrm{PPh}_{3}\right)_{3}\right]$ and $\left[\mathrm{Co}^{\mathrm{II}}(\mathrm{MeCN})_{2}\left(\mathrm{CF}_{3} \mathrm{SO}_{3}\right)_{2}\right]$ were prepared according to literature methods. ${ }^{2}$ Solvents for air- and moisture-sensitive experiments were purified using a two-column solid-state purification system (Glasscontour System, Irvine, CA) and transferred to the glovebox without exposure to air. NMR solvents were packaged under argon and stored over activated molecular sieves and sodium (where appropriate) prior to use.

${ }^{1} \mathrm{H}$ NMR and ${ }^{13} \mathrm{C}$ NMR spectra were recorded on a JEOL 270 (400 MHz) or Bruker Avance NEO $(600 \mathrm{MHz})$ instrument, operating at a probe temperature of room temperature. Chemical shifts, $\delta$, are reported in ppm relative to the peak of $\mathrm{SiMe}_{4}$, using ${ }^{1} \mathrm{H}$ chemical shifts of the residual solvents as references. ${ }^{3}$ Elemental analysis results were obtained from the Analytical Laboratories at the FriedrichAlexander-University Erlangen-Nuremberg (Erlangen, Germany). Electronic absorption spectra were recorded with a MAPADA UV-vis Spectrophotometer (UV-6300). Electrochemical voltammetry measurements were conducted on a Metrohm Autolab TYPE III or Chinstruments CHI700E potentiostat/galvanostat with a glass carbon working electrode $(\varnothing=3 \mathrm{~mm})$, a Pt counter electrode, and a Ag pseudo reference electrode (a silver wire suspended in a $0.1 \mathrm{M} \mathrm{DMF}$ solution of $\mathrm{TBAPF}_{6}$ and separated from the analyte solution by a frit). Tetra- $n$-butylammonium hexafluorophosphate was used as supporting electrolyte $(0.1 \mathrm{M})$ and ferrocene was applied as an internal reference. All reported potentials in organic electrolytes were converted versus the $\mathrm{Fe}{ }^{\mathrm{III} / \mathrm{II}}$ redox potential of ferrocene $\left(\mathrm{FeCp}_{2}{ }^{+/ 0}\right)$.

Bulk electrolysis was performed in DMF using a glassy carbon working electrode $(\varnothing=5 \mathrm{~cm}), \mathrm{Ag}$ pseudo reference electrode, and a platinum rod counter electrode in a gas-tight $\mathrm{H}$-shape electrochemical cell. An anhydrous 0.1 M DMF solution $\mathrm{TBAPF}_{6}$ was used as the electrolyte. The potential was applied versus $\mathrm{FeCp}_{2}{ }^{+/ 0}$ in the presence of acid. The residual ohmic drop was compensated by following the iR compensation function of the potentiostat. Gas chromatography measurements were used to quantify the amount of $\mathrm{H}_{2}$ gas evolution, and Faradaic efficiencies were determined according to the calibration curve derived from $\mathrm{H}_{2}$ gas standards. The applied gas chromatography (GC) instrument was SHIMADZU GC2018 equipped with a $5 \AA$ molecular sieve column $(2 \times 3 \mathrm{~mm}, 60-80 \mathrm{mesh})$, Ar carrier gas, and a TCD detector. 
Magnetism data of crystalline, finely powdered samples $(15-20 \mathrm{mg})$, contained within a polycarbonate gel capsule/film, were recorded with a Quantum Design MPMS-XL SQUID magnetometer. DC magnetization data were collected in the temperature range of 2-300 K with an applied DC field of 0.1 or $1.0 \mathrm{~T}$. Values of the magnetic susceptibility were corrected for core diamagnetism of the sample estimated using tabulated Pascal's constants. ${ }^{4}$ The chemical composition and purity of samples used for magnetization measurements were checked by elemental analysis $(\mathrm{C}, \mathrm{H}$, and $\mathrm{N})$. Data reproducibility was carefully checked by repeating measurements on independently synthesized samples. The program 'julX' (developed by Dr. E. Bill, Max-Planck-Institute for Chemical Energy Conversion, Mülheim/Ruhr, Germany) was used for the simulation and analysis of magnetic susceptibility data.

EPR spectra were recorded on a JEOL continuous wave spectrometer JES-FA200 equipped with an X-band Gunn oscillator bridge, a cylindrical mode cavity, and a helium cryostat. Co complex samples were freshly dissolved as a solution of approximately $1 \mathrm{mM}$ concentration in an air-tight J. Young quartz epr tube. The EPR spectra were simulated and analyzed using program 'esimX' and 'eview4w' (developed by Dr. E. Bill, Max-Planck-Institute for Chemical Energy Conversion, Mülheim/Ruhr, Germany).

\section{Synthesis Methods}

Synthesis of $\left[\mathrm{Co}(\mathrm{ppq})(\mathrm{MeCN})\left(\mathrm{CF}_{3} \mathrm{SO}_{3}\right)\right]\left(\mathrm{CF}_{3} \mathrm{SO}_{3}\right)(\mathbf{1})$.

A solution of $\left[\mathrm{Co}(\mathrm{MeCN})_{2}\left(\mathrm{CF}_{3} \mathrm{SO}_{3}\right)_{2}\right](43.9 \mathrm{mg}, 0.1 \mathrm{mmol})$ in about $3 \mathrm{~mL} \mathrm{MeCN}$ was slowly added into a suspension of ppq ligand $(38.4 \mathrm{mg}, 0.1 \mathrm{mmol})$ in about $3 \mathrm{~mL} \mathrm{MeCN}$ under stirring. The color of the mixture solution turned to reddish instantly. The reaction mixture was kept stirring overnight at room temperature. Insoluble solid was removed by filtration through a plug of celite. The volume of the filtrate was reduced under vacuum until the appearance of a reddish precipitate. It was then kept in the fridge ( -35 ${ }^{\circ} \mathrm{C}$ ) of the glovebox overnight. The Reddish precipitate was collected by filtration and dried under vacuum. The crude product was dissolved in small amount of $\mathrm{MeCN}$ again and slow vapor diffusion of $\mathrm{Et}_{2} \mathrm{O}$ into the $\mathrm{MeCN}$ solution afforded complex 1 as dark reddish prism crystals (46 mg, yield $=58 \%$ ). EA (\%) calcd. for $\mathrm{C}_{30} \mathrm{H}_{19} \mathrm{CoF}_{6} \mathrm{~N}_{5} \mathrm{O}_{6} \mathrm{~S}_{2}(\mathbf{1})$ : N, 8.95; C, 46.05; H, 2.45; S, 8.19; found: N, 9.46; C, 46.01; H, 2.22; S, 7.82.

Synthesis of $\left[\mathrm{Co}(\mathrm{ppq})\left(\mathrm{PPh}_{3}\right)\right]\left(\mathrm{PF}_{6}\right)(2)$.

$\left[\mathrm{Co}{ }^{\mathrm{I}} \mathrm{Cl}\left(\mathrm{PPh}_{3}\right)_{3}\right](88.1 \mathrm{mg}, 0.1 \mathrm{mmol})$, ppq ligand $(38.4 \mathrm{mg}, 0.1 \mathrm{mmol})$ and $5 \mathrm{~mL} \mathrm{MeCN}$ were added in a glass vial. After stirring overnight at room temperature, the mixture became a homogeneous dark green solution. $\mathrm{Tl}\left(\mathrm{PF}_{6}\right)$ (34.9 mg, $0.1 \mathrm{mmol}$ ) was then added into the solution, and the mixture was stirred for another 24 hours. White precipitate was removed by filtration through a plug of celite. Removal of the 
$\mathrm{MeCN}$ solvent under vacuum resulted in a dark green solid, which was dissolved in small amount of $\mathrm{MeCN}$, filtrated through a plug of celite, and dried again, in order to remove $\mathrm{TlCl}$ residue. The dark green solid was washed with $\sim 5 \mathrm{~mL}$ toluene and $\sim 5 \mathrm{~mL}$ diethyl ether, sequentially. This washing procedure was repeated once in order to remove $\mathrm{PPh}_{3}$. The volatile organic solvent was removed under vacuum and the crude product was dissolved in small amount of $\mathrm{MeCN}$. Slow vapor diffusion of $\mathrm{Et}_{2} \mathrm{O}$ into the $\mathrm{MeCN}$ solution afforded complex 2 as dark green needle crystals (64 mg, yield $=75 \%$ ). EA (\%) calcd. for $\mathrm{C}_{44} \mathrm{H}_{31} \mathrm{CoF}_{6} \mathrm{~N}_{4} \mathrm{P}_{2}$ (2): N, 6.59; C, 62.13; H, 3.67; found: N, 6.64; C, 62.87; H, 3.84.

Synthesis of $\left[\mathrm{Zn}(\mathrm{ppq})\left(\mathrm{CF}_{3} \mathrm{SO}_{3}\right)_{2}\right](\mathbf{3})$.

A solution of $\mathrm{Zn}\left(\mathrm{CF}_{3} \mathrm{SO}_{3}\right)_{2}(36.3 \mathrm{mg}, 0.1 \mathrm{mmol})$ in about $3 \mathrm{~mL} \mathrm{MeCN}$ was slowly added into a suspension of ppq ligand $(38.4 \mathrm{mg}, 0.1 \mathrm{mmol})$ in about $3 \mathrm{~mL} \mathrm{MeCN}$ under stirring. The mixture slurry turned to a homogenous colorless solution gradually. The reaction mixture was kept stirring overnight at room temperature. Insoluble solid was removed by filtration through a plug of celite. The volume of the filtrate was reduced to about $3 \mathrm{~mL}$ under vacuum. Laying $\mathrm{Et}_{2} \mathrm{O}(\sim 8 \mathrm{~mL})$ on the top of the solution precipitated a pale white solid in several hours. The bulk organic solvent was decanted and the precipitate was dried under vacuum to give a pale white powder. The crude product was dissolved in small amount of $\mathrm{MeCN}$ again and slow vapor diffusion of $\mathrm{Et}_{2} \mathrm{O}$ into the $\mathrm{MeCN}$ solution afforded complex $\mathbf{3}$ as white prism crystals $(48 \mathrm{mg}$, yield $=65 \%) .{ }^{1} \mathrm{H}$ NMR $\left(600 \mathrm{MHz}, d_{6}\right.$-DMSO) $\delta 9.54(\mathrm{dd}, J=4.8,1.5 \mathrm{~Hz}, 1 \mathrm{H}), 9.07(\mathrm{~d}, J$ $=8.7 \mathrm{~Hz}, 1 \mathrm{H}), 9.04(\mathrm{dt}, J=5.3,1.2 \mathrm{~Hz}, 1 \mathrm{H}), 9.00(\mathrm{~d}, J=8.7 \mathrm{~Hz}, 1 \mathrm{H}), 8.99(\mathrm{dd}, J=8.2,1.5 \mathrm{~Hz}, 1 \mathrm{H}), 8.82$ $(\mathrm{dd}, J=7.6,1.4 \mathrm{~Hz}, 1 \mathrm{H}), 8.78 \sim 8.71(\mathrm{~m}, 2 \mathrm{H}), 8.68(\mathrm{~d}, J=8.7 \mathrm{~Hz}, 1 \mathrm{H}), 8.54 \sim 8.43(\mathrm{~m}, 2 \mathrm{H}), 8.36 \sim 8.24(\mathrm{~m}$, $3 \mathrm{H}), 8.12(\mathrm{t}, J=7.8 \mathrm{~Hz}, 1 \mathrm{H}), 7.97$ (ddd, $J=7.7,5.2,1.1 \mathrm{~Hz}, 1 \mathrm{H}) ;{ }^{13} \mathrm{C}$ NMR (150 MHz, $d_{6}$-DMSO) $\delta 156.5$, 152.0, 150.6, 150.0, 149.0. 144.2, 143.2, 142.8, 141.7, 141.4, 140.6, 140.1, 139.5, 133.9, 130.5, 130.0, $129.8,129.4,128.7,128.4,128.3,128.1,127.6,126.7,125.8,122.2,121.2$, 120.1. EA (\%) calcd. for $\mathrm{C}_{28} \mathrm{H}_{16} \mathrm{ZnF}_{6} \mathrm{~N}_{4} \mathrm{O}_{6} \mathrm{~S}_{2}(3)$ : N, 7.49; C, 44.96; H, 2.16; found: N, 7.11; C, 45.33; H, 2.24. 


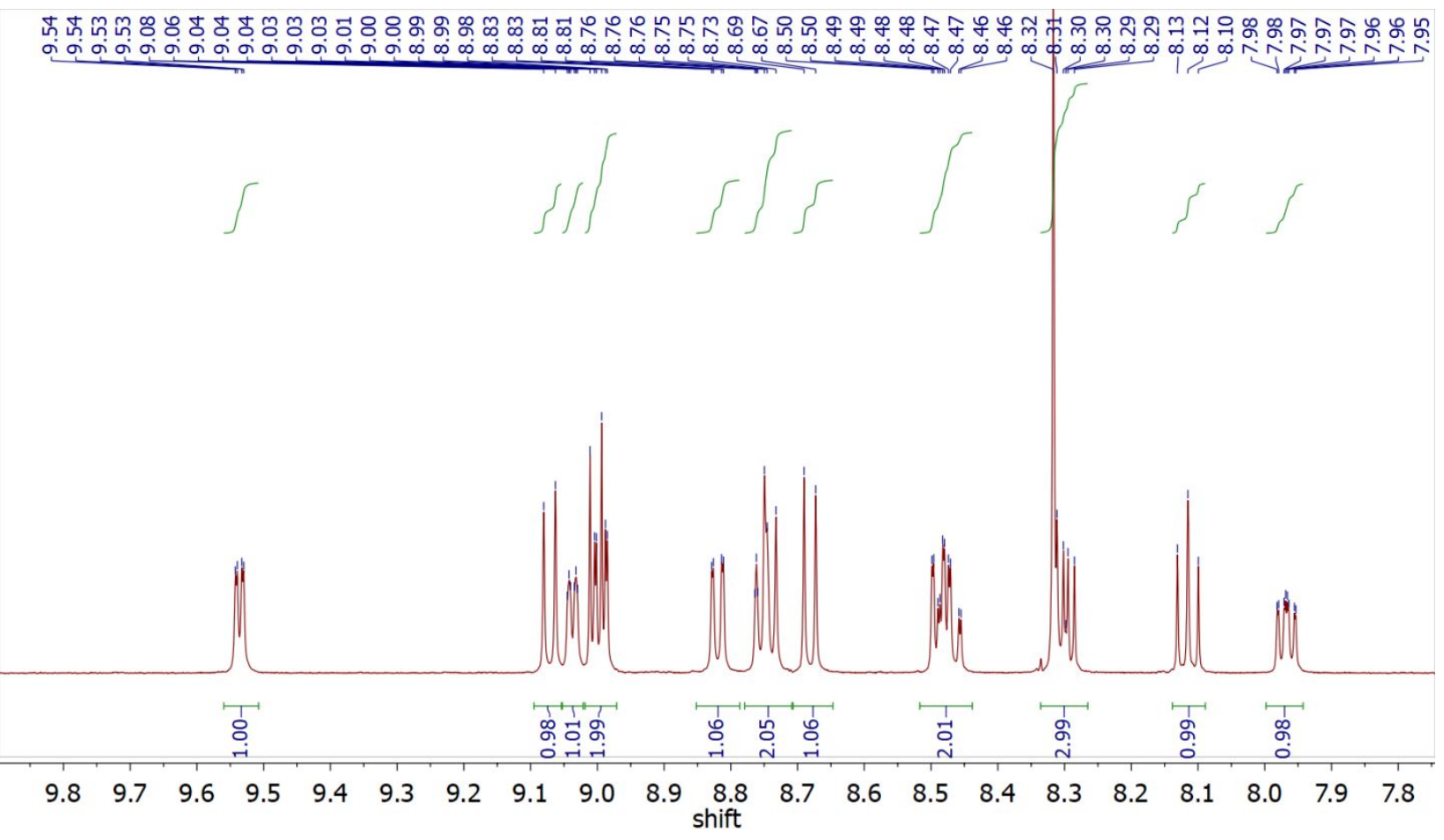

Figure S1. ${ }^{1} \mathrm{H}$ NMR of 3 in $d_{6}$-DMSO.

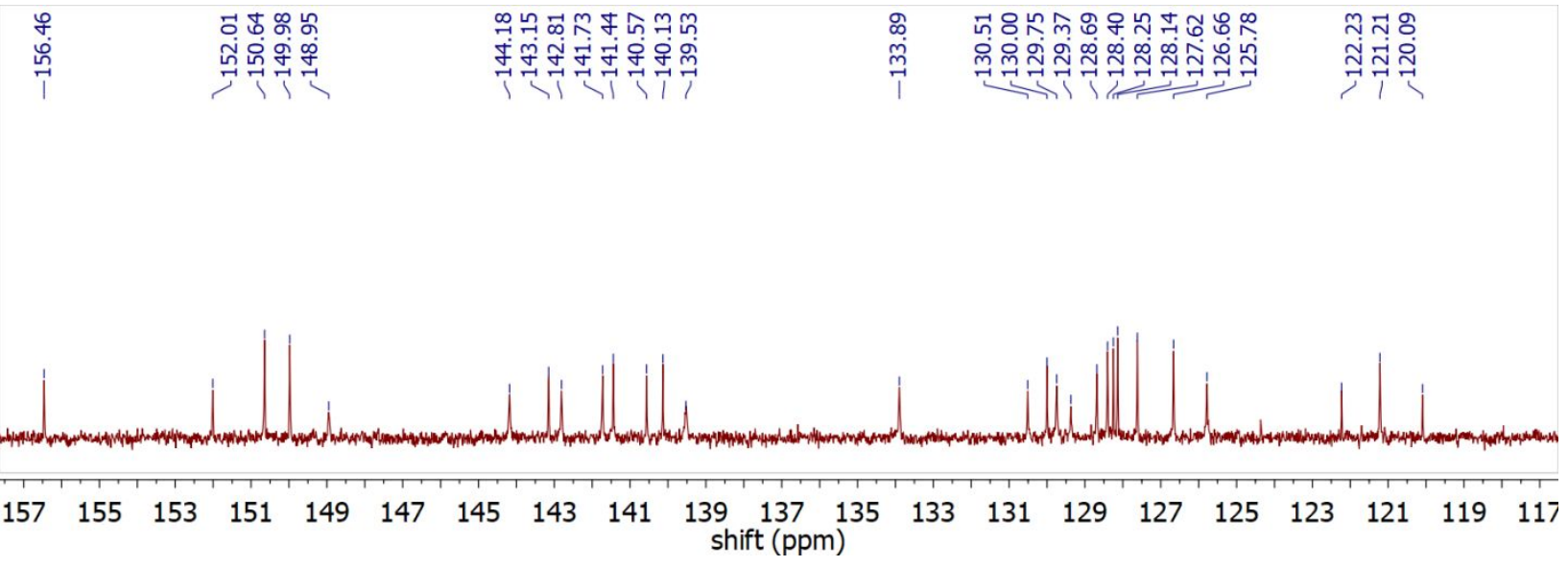

Figure S2. ${ }^{13} \mathrm{C}$ NMR of 3 in $d_{6}$-DMSO. 


\section{X-ray Crystal Structure Determination}

CCDC-2018561 (1, recorded at $100 \mathrm{~K})$, CCDC-2018563 (1, recorded at $295 \mathrm{~K})$, CCDC-2018558 (2), and CCDC-2018789 (3) contain the supplementary crystallographic data for this paper. The data can be obtained free of charge from Cambridge Crystallographic Data Centre, 12 Union Road, Cambridge, CB2 1EZ, UK (fax: ++44-1223-336-033; e-mail: deposit@,ccdc.cam.ac.uk).

Red prism-shaped crystals of $\mathbf{1}$ suitable for single crystal X-ray analysis were obtained by slow diffusion of $\mathrm{Et}_{2} \mathrm{O}$ into a MeCN solution of $\mathbf{1}$. Dark green plate-shaped crystals of $\mathbf{2}$ suitable for single crystal $\mathrm{X}$-ray analysis were obtained by slow diffusion of $\mathrm{Et}_{2} \mathrm{O}$ into a $\mathrm{MeCN}$ solution of $\mathbf{2}$. White prism-shaped crystals of 3 suitable for single crystal X-ray analysis were obtained by slow diffusion of $\mathrm{Et}_{2} \mathrm{O}$ into a $\mathrm{MeCN}$ solution of 3. X-ray intensity data were collected using $\operatorname{Mo} K_{\alpha}$ radiation $(\lambda=0.71073 \AA)$ on a Bruker Kappa APEX2 I $\mu S$ duo diffractometer equipped with QUAZAR focusing Montel optics (for $1 @ 100 \mathrm{~K}, 1 @$ 295K and 2) or using $\mathrm{CuK \alpha}$ radiation ( $\lambda=1.54178 \AA$ ) on a Rigaku XtaLAB Synergy diffractometer (3). Data of 1 and 2 were corrected for Lorentz and polarization effects, semiempirical absorption corrections were performed on the basis of multiple scans using $S A D A B S$. Cell refinement and data reduction were performed using the software SAINT from Bruker. The structures were solved by direct methods and refined by fullmatrix least-squares procedures on $F^{2}$ using SHELXL-2018/3.5 The structure of 3 was solved using SHELXT structure solution program (Intrinsic Phasing) and refined by least-squares procedures on $F^{2}$ using SHELXL. ${ }^{6}$ Anisotropic thermal parameters were applied to all non-hydrogen atoms. All Crystallographic data, data collection, and structure refinement details are given in Table S2.

Table S1. Metrical parameters for the solid-state structures of complexes 1, 2, 3, and [Co $\left.{ }^{\mathrm{II}}(\mathrm{ppq}) \mathrm{Cl}_{2}\right]$.

\begin{tabular}{ccccc}
\hline Bond distance $(\AA)$ & {$\left[\mathrm{Co}^{\mathrm{II}}(\mathrm{ppq}) \mathrm{Cl}_{2}\right]^{a}$} & $\mathbf{1}$ & $\mathbf{2}$ & $\mathbf{3}$ \\
\hline${ }^{b} \mathrm{M}-\mathrm{N} 1$ & $2.004(3)$ & $1.9730(12)$ & $1.9324(16)$ & $2.0809(27)$ \\
$\mathrm{M}-\mathrm{N} 2$ & $1.997(2)$ & $1.9378(12)$ & $1.8870(16)$ & $2.1334(32)$ \\
$\mathrm{M}-\mathrm{N} 3$ & $1.972(2)$ & $1.9335(12)$ & $1.9026(16)$ & $2.1061(28)$ \\
$\mathrm{M}-\mathrm{N} 4$ & $2.021(2)$ & $1.9779(12)$ & $1.9500(17)$ & $2.1270(31)$ \\
$\mathrm{M}$-N5 & & $2.1509(13)$ & & \\
M-O1 & & $2.3814(11)$ & & $2.02108(20)$ \\
$\mathrm{M}$-O2 & & & $2.2577(20)$ \\
$\mathrm{M}-\mathrm{P} 1$ & & & $2.3186(6)$ & \\
C5-C6 & $1.474(4)$ & $1.472(2)$ & $1.439(3)$ & $1.496(4)$ \\
C13-C15 & $1.486(4)$ & $1.478(2)$ & $1.459(3)$ & $1.491(4)$ \\
Bond angle (deg) & & & & \\
N1-M-N2 & $83.13(9)$ & $83.27(5)$ & $82.59(7)$ & $79.91(4)$ \\
N2-M-N3 & $92.93(9)$ & $93.23(5)$ & $92.27(7)$ & $88.76(8)$ \\
N3-M-N4 & $81.72(10)$ & $83.69(5)$ & $84.28(7)$ & $80.72(5)$ \\
N1-M-N4 & $103.11(10)$ & $99.88(5)$ & $96.33(7)$ & $110.55(7)$ \\
Dihedral angle (deg) & & & & \\
N1-C5-C6-N2 & $7.0(4)$ & $8.08(19)$ & $-4.3(2)$ & $2.6(0)$ \\
\hline
\end{tabular}




\begin{tabular}{ccccc}
$\mathrm{C} 14-\mathrm{C} 13-\mathrm{C} 15-\mathrm{N} 3$ & $-20.2(4)$ & $-24.5(2)$ & $18.1(3)$ & $-20.0(0)$ \\
$\mathrm{N} 4-\mathrm{C} 25-\mathrm{C} 26-\mathrm{N} 3$ & $3.7(4)$ & $2.49(18)$ & $-2.0(2)$ & $2.4(0)$ \\
\hline
\end{tabular}

${ }^{a}$ Data were cited from the reference. ${ }^{7 b} \mathrm{M}=\mathrm{Co}$ or $\mathrm{Zn}$.

Table S2. Crystallographic data, data collection and refinement details of complexes 1-3.

\begin{tabular}{|c|c|c|c|}
\hline & 1 & 2 & 3 \\
\hline formula & $\begin{array}{c}\mathrm{C}_{30} \mathrm{H}_{19} \mathrm{CoF}_{6} \mathrm{~N}_{5} \mathrm{O}_{6} \mathrm{~S}_{2} \bullet \\
\mathrm{C}_{2} \mathrm{H}_{3} \mathrm{~N}\end{array}$ & $\mathrm{C}_{44} \mathrm{H}_{31} \mathrm{CoF}_{6} \mathrm{~N}_{4} \mathrm{P}_{2}$ & $\mathrm{C}_{28} \mathrm{H}_{16} \mathrm{ZnF}_{6} \mathrm{~N}_{4} \mathrm{O}_{6} \mathrm{~S}_{2}$ \\
\hline formula weight & 823.60 & 850.60 & 747.95 \\
\hline space group & $P_{1}^{-}$ & $P_{1}^{-}$ & $P \overline{1}$ \\
\hline $\mathrm{a} / \AA ̊$ & $9.3758(7)$ & $11.4538(10)$ & $9.6479(3)$ \\
\hline $\mathrm{b} / \AA$ & $13.105(1)$ & $11.9723(11)$ & $10.2499(3)$ \\
\hline $\mathrm{c} / \AA ̊$ & $14.6321(12)$ & $13.8727(12)$ & $14.6331(4)$ \\
\hline$\alpha / \operatorname{deg}$ & $74.0215(17)$ & $86.357(2)$ & $73.127(3)$ \\
\hline$\beta / \mathrm{deg}$ & $72.6258(16)$ & $73.676(2)$ & $88.726(2)$ \\
\hline$\gamma / \operatorname{deg}$ & $78.8119(17)$ & $87.147(2)$ & $89.397(3)$ \\
\hline$V / \AA^{3}$ & $1637.2(2)$ & $1821.0(3)$ & $1384.42(7)$ \\
\hline$Z$ & 2 & 2 & 2 \\
\hline$D_{c} / \mathrm{mg} \mathrm{cm}^{-3}$ & 1.671 & 1.551 & 1.794 \\
\hline$T / \mathrm{K}$ & 100 & 100 & 100 \\
\hline $\mathrm{F}(000)$ & 834 & 868 & 752 \\
\hline refl. unique & 8455 & 9444 & 5522 \\
\hline $\operatorname{refl} .[I>2 \sigma(I)]$ & 7292 & 7504 & 4591 \\
\hline radiation wavelength / $\AA$ & 0.71073 & 0.71073 & 1.54184 \\
\hline refl. collected & 55172 & 63129 & 18087 \\
\hline goodness-of-fit on $F^{2}$ & 1.05 & 1.06 & 1.017 \\
\hline$R_{I}[I>2 \sigma(I)]$ (observed) & 0.029 & 0.041 & 0.0635 \\
\hline$w R_{2}$ (all data) & 0.074 & 0.102 & 0.1689 \\
\hline$w R_{2}=\left[\frac{\Sigma\left[w\left(F_{o}^{2}-F_{c}^{2}\right)^{2}\right]}{\Sigma\left[w\left(F_{o}^{2}\right)^{2}\right]}\right]$ & {$\left[\frac{\Sigma|| F_{o}|-| F_{c} \|}{\Sigma\left|F_{o}\right|}\right.$} & \multicolumn{2}{|c|}{$S=\left[\frac{\Sigma\left[w\left(F_{o}^{2}-F_{c}^{2}\right)^{2}\right]}{(n-p)}\right]^{\frac{1}{2}}$} \\
\hline
\end{tabular}



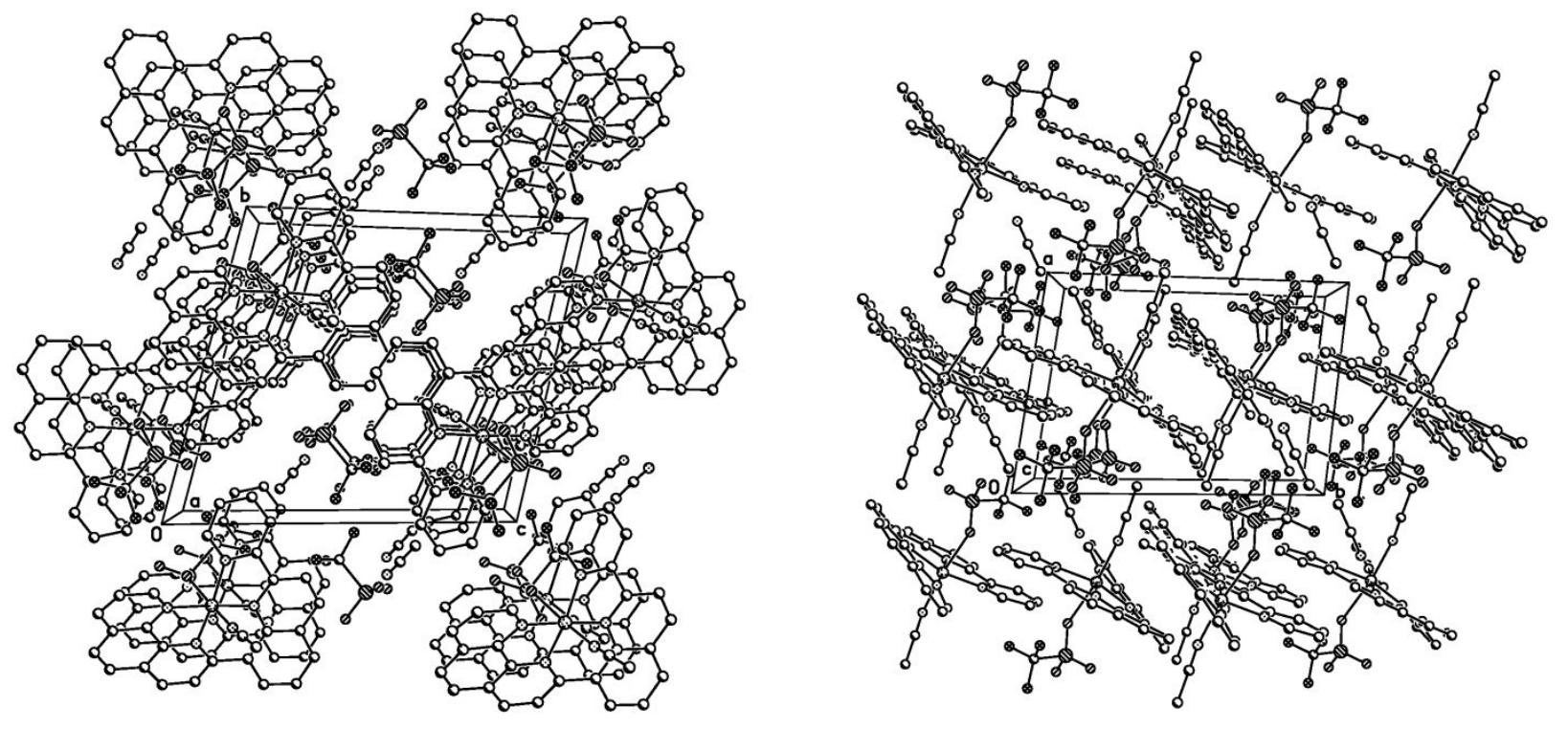

Figure S3. Crystal packing diagram of $\mathbf{1}$ viewed along the $a$ (left) and $c$ (right) axis.
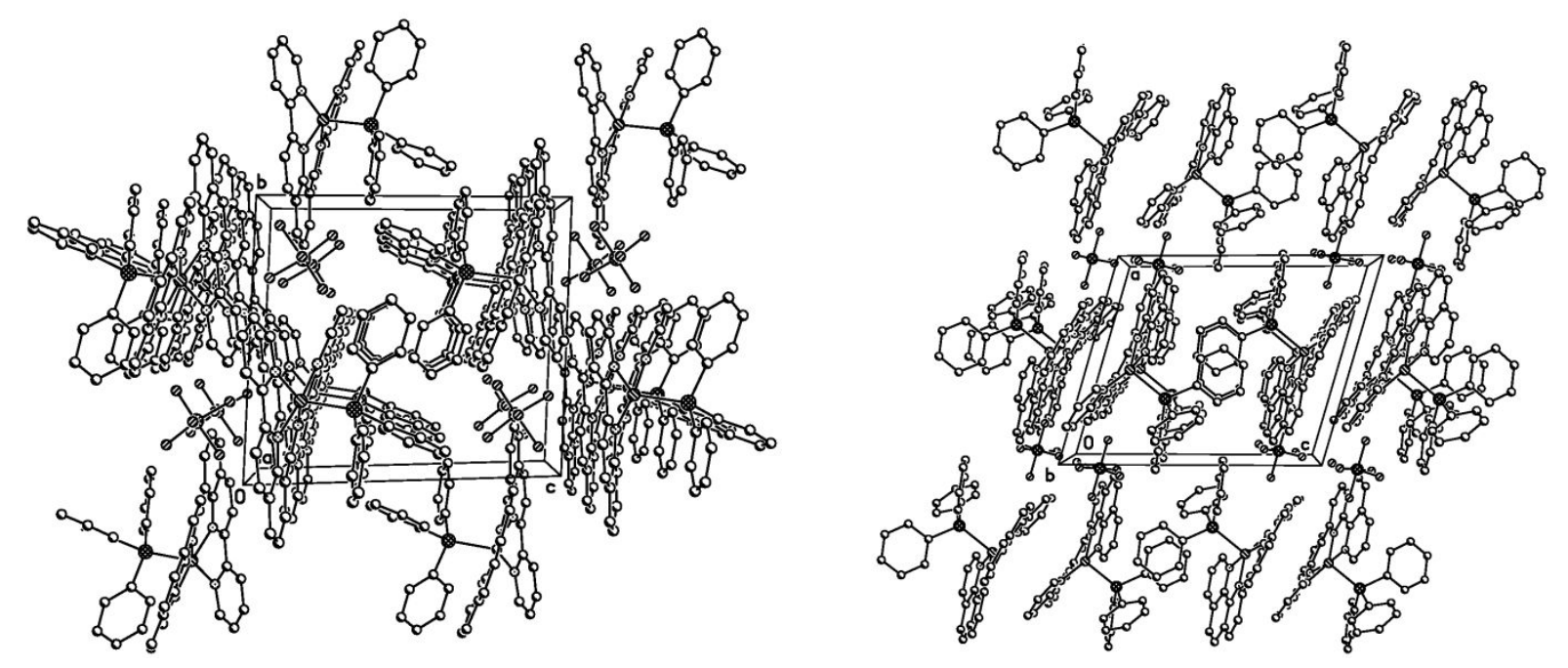

Figure S4. Crystal packing diagram of 2 viewed along the $a$ (left) and $b$ (right) axis. 


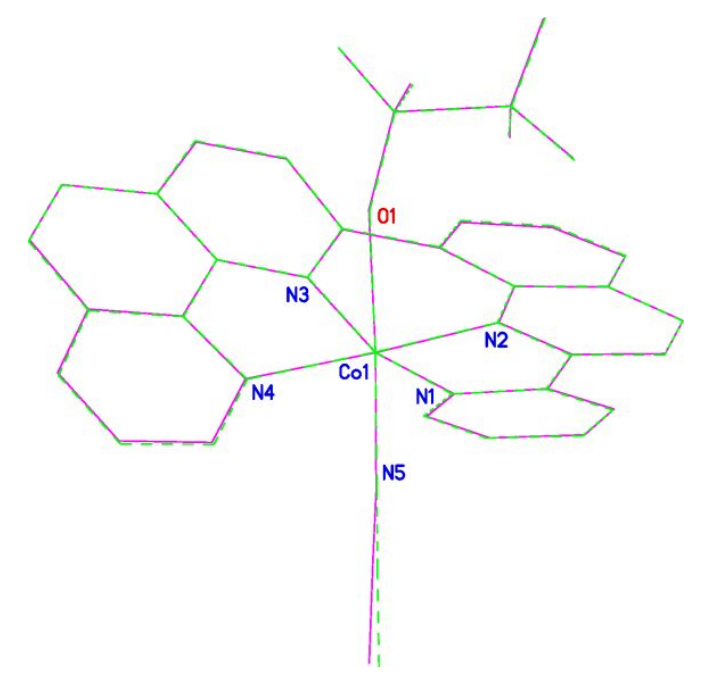

Figure S5. Overlay wireframe plots of the crystal structure of 1 at $100 \mathrm{~K}$ (green dashed line) and $295 \mathrm{~K}$ (purple solid line); nonpolar hydrogen atoms, noncoordinating counterion, and fractional solvent molecules are omitted for clarity.

Table S3. Selected bond lengths and angles for 1 at 100 and $295 \mathrm{~K}$, including the standard deviation $3 \sigma$.

\begin{tabular}{llll}
\hline Bond distance $(\AA)$ & $100 \mathrm{~K}$ & $295 \mathrm{~K}$ & $3 \sigma(\AA)$ \\
\hline Co1-N1 & $1.9730(12)$ & $1.9868(17)$ & 0.005 \\
Co1-N2 & $1.9378(12)$ & $1.9551(16)$ & 0.005 \\
Co1-N3 & $1.9335(12)$ & $1.9523(15)$ & 0.005 \\
Co1-N4 & $1.9779(12)$ & $1.9969(16)$ & 0.005 \\
Co1-N5 & $2.1509(13)$ & $2.1607(17)$ & 0.005 \\
Co1-O1 & $2.3814(11)$ & $2.3965(15)$ & 0.005 \\
& & & \\
Angle (deg) & $100 \mathrm{~K}$ & $295 \mathrm{~K}$ & $3 \sigma(\mathrm{deg})$ \\
N1-Co1-N2 & $83.27(5)$ & $82.70(7)$ & 0.2 \\
N2-Co1-N3 & $93.23(5)$ & $93.04(6)$ & 0.2 \\
N3-Co1-N4 & $83.69(5)$ & $83.10(6)$ & 0.2 \\
N1-Co1-N4 & $99.88(5)$ & $101.14(6)$ & 0.2 \\
O1-Co1-N5 & $171.83(4)$ & $172.64(6)$ & 0.2 \\
C28-N5-Co1 & $170.81(12)$ & $171.64(17)$ & 0.5 \\
& & & \\
Dihedral angle (deg) & $100 \mathrm{~K}$ & $295 \mathrm{~K}$ & $3 \sigma(\mathrm{deg})$ \\
N1-C5-C6-N2 & $8.08(19)$ & $8.1(3)$ & 1.0 \\
C14-C13-C15-N3 & $-24.5(2)$ & $-24.8(3)$ & 1.0 \\
N4-C25-C26-N3 & $2.49(18)$ & $2.1(2)$ & 0.6 \\
\hline
\end{tabular}




\section{SQUID Measurements}

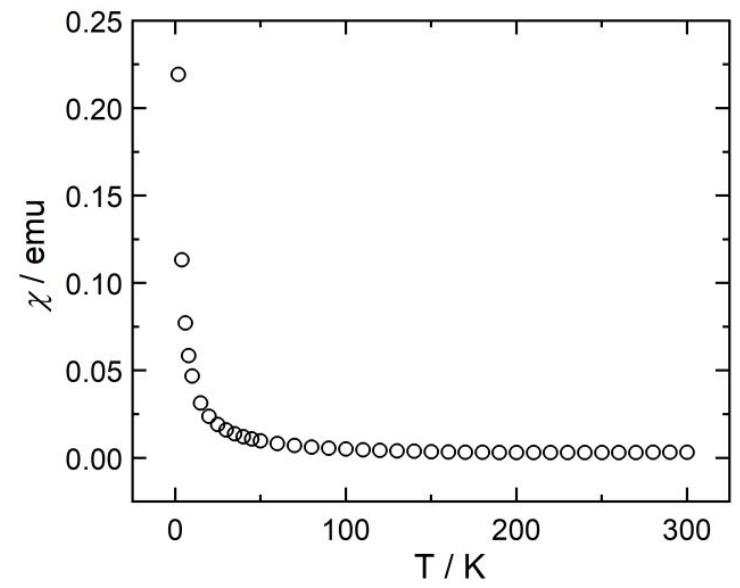

Figure S6. VT SQUID data ( $\chi$ versus temperature) of $\mathbf{1}$ as a microcrystalline solid sample.

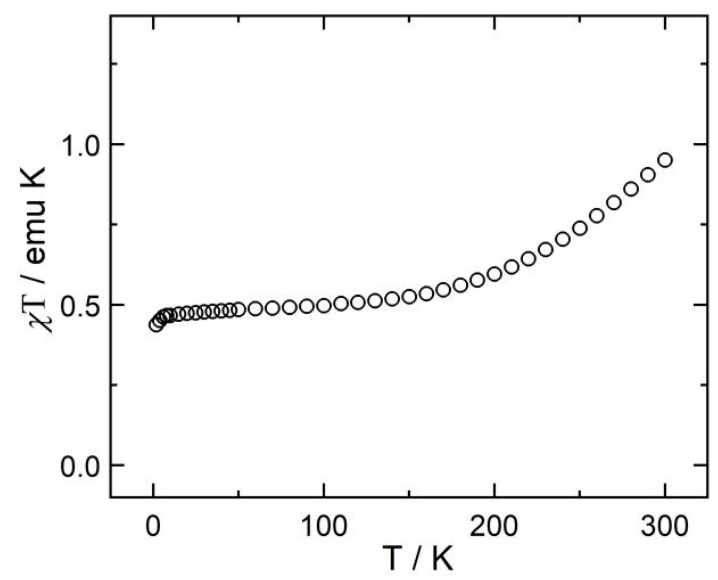

Figure S7. VT SQUID data ( $\chi \mathrm{T}$ versus temperature) of $\mathbf{1}$ as a microcrystalline solid sample. 


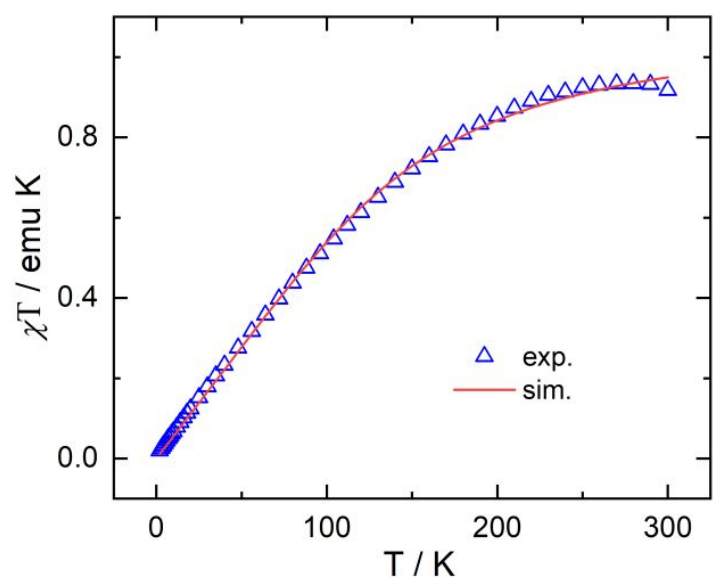

Figure S8. VT SQUID data ( $\chi$ T versus temperature) of $\mathbf{2}$ as a microcrystalline solid sample. Simulation (red line) parameters: $S=1, g=2.05, D=266.14 \mathrm{~cm}^{-1},|E / D|=0.1, \mathrm{TIP}=2000 \times 10^{-6} \mathrm{~cm}^{3} \mathrm{~mol}^{-1}$.

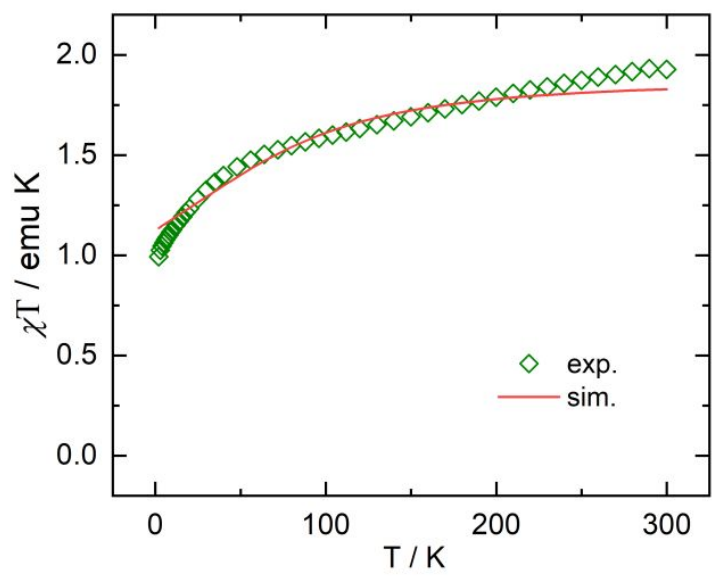

Figure S9. VT SQUID data ( $\chi \mathrm{T}$ versus temperature) of $\left[\mathrm{Co}^{\mathrm{II}}(\mathrm{ppq}) \mathrm{Cl}_{2}\right]$ as a microcrystalline solid sample. Simulation (red line) parameters: $S=3 / 2, D=90.86 \mathrm{~cm}^{-1},|E / D|=0.15$. 


\section{UV-vis Spectra}

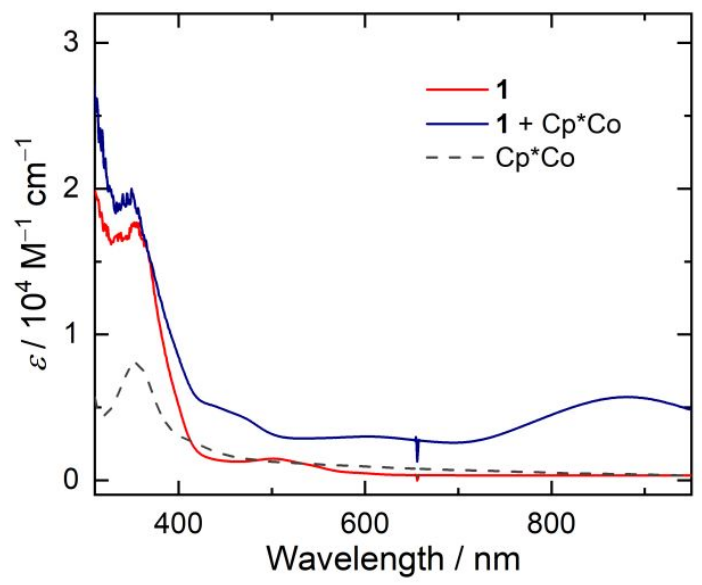

Figure S10. Electronic absorption spectra of 1 in acetonitrile before and after addition of one equivalent bis(pentamethylcyclopentadienyl)cobalt $(\mathrm{Cp} * \mathrm{Co})$.

\section{Electrochemical Properties}

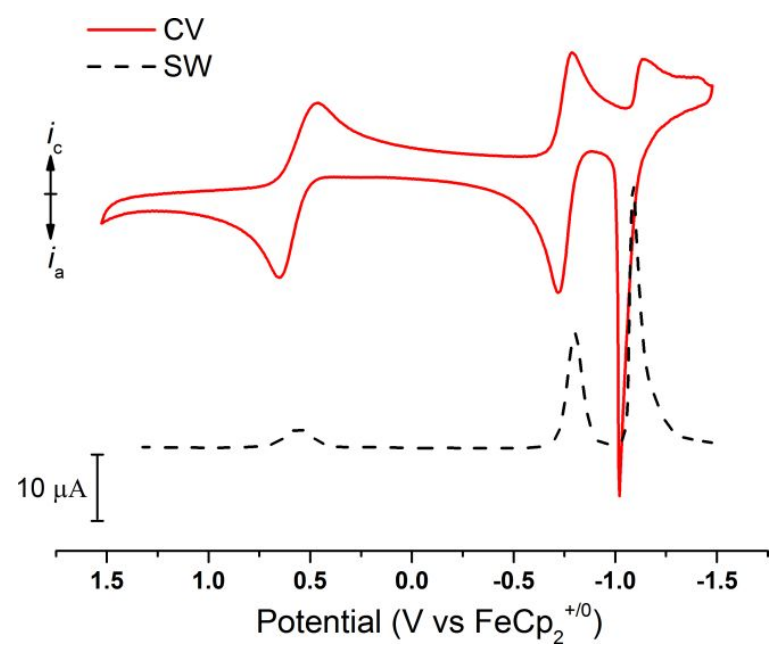

Figure S11. Cyclic and square wave voltammograms of 1 recorded in acetonitrile. Conditions: $1 \mathrm{mM} 1$ in DMF containing $0.1 \mathrm{M} \mathrm{TBANPF}_{6}$, glass carbon electrode $(d=3 \mathrm{~mm})$, and scan rate $=100 \mathrm{mV} / \mathrm{s}$. 


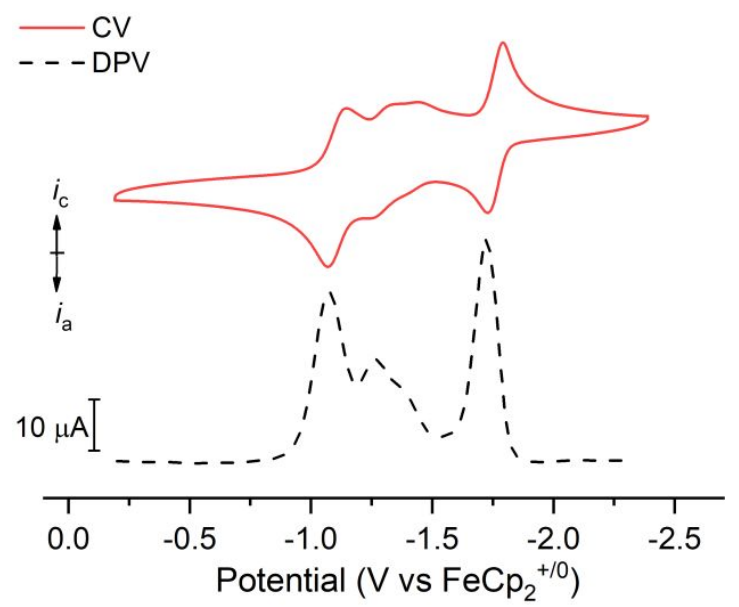

Figure S12. Cyclic and differential pulse voltammograms of 1 recorded in DMF. Conditions: $1 \mathrm{mM} 1$ in DMF containing $0.1 \mathrm{M} \mathrm{TBANPF}_{6}$, glass carbon electrode $(d=3 \mathrm{~mm})$, and scan rate $=100 \mathrm{mV} / \mathrm{s}$.
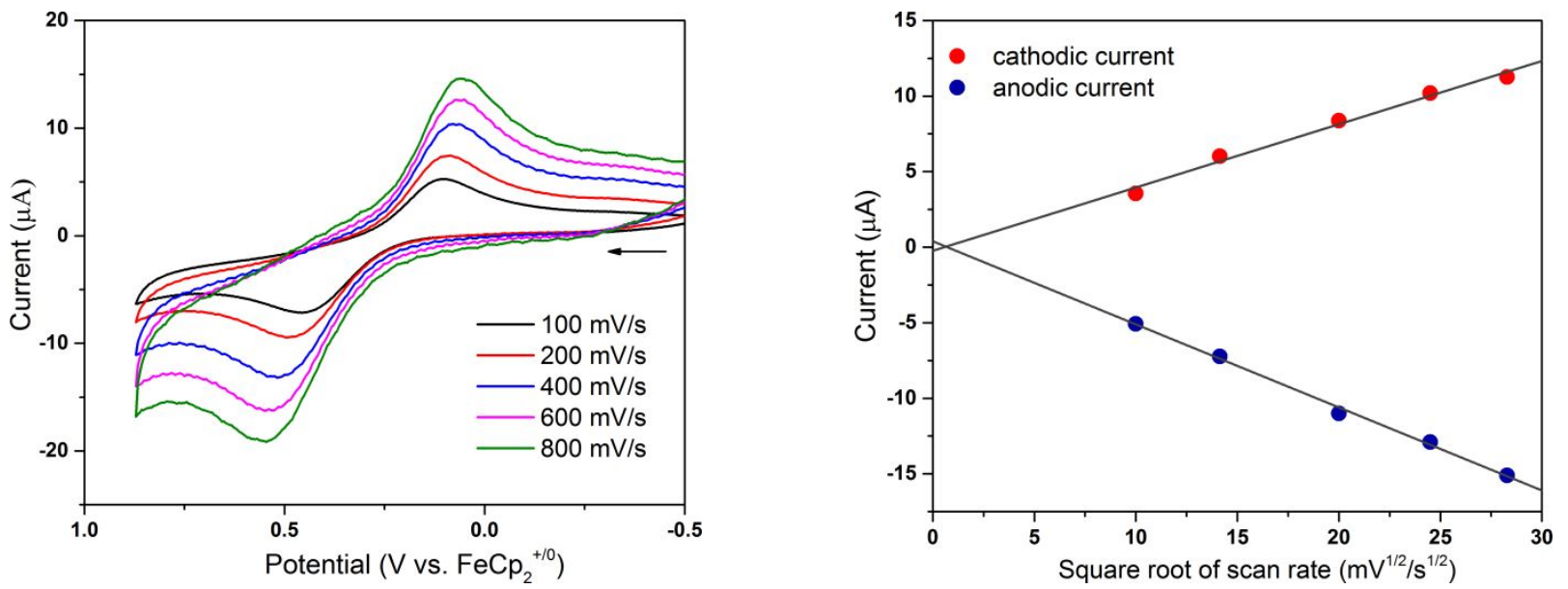

Figure S13. Left: cyclic voltammograms for $1 \mathrm{mM} 1$ in DMF containing $0.1 \mathrm{M} \mathrm{TBAPF}_{6}$ at different scan rates. Right: dependence of cathodic current and anodic current on the square root of scan rates. 

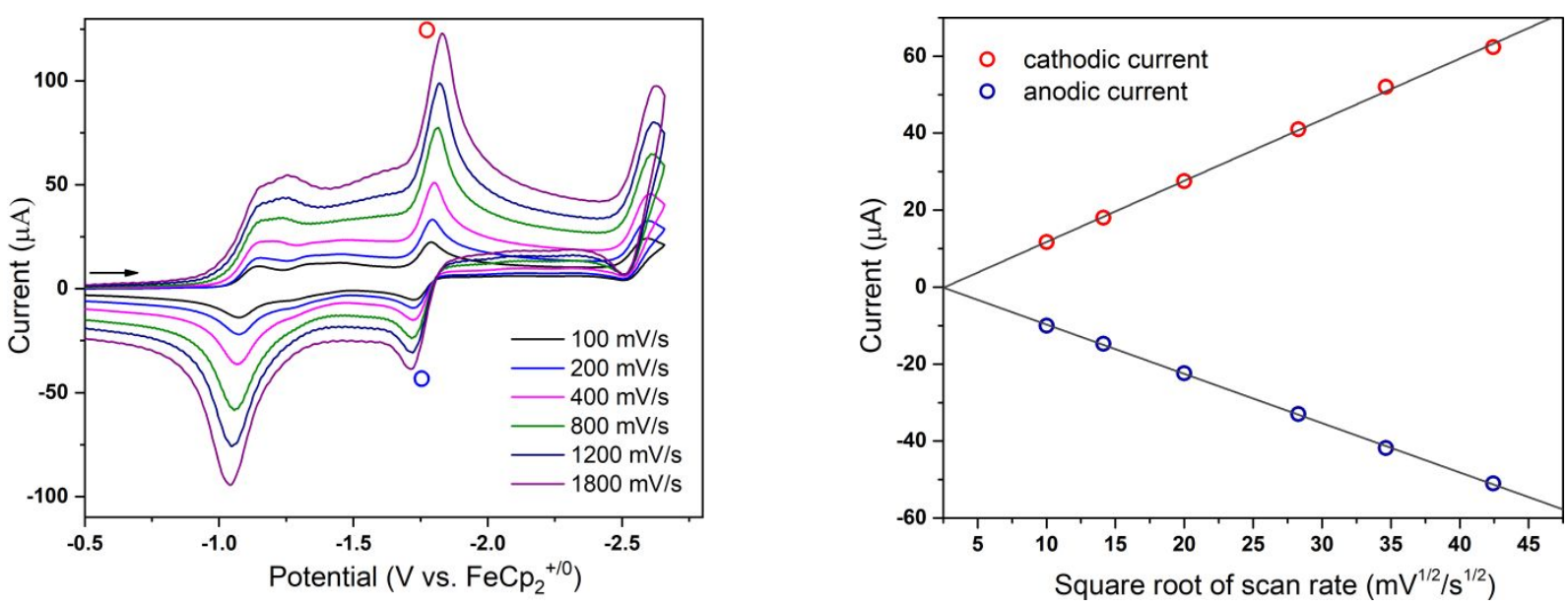

Figure S14. Left: cyclic voltammograms for $1 \mathrm{mM} 1$ in DMF containing $0.1 \mathrm{M} \mathrm{TBAPF}_{6}$ at different scan rates. Right: dependence of cathodic current and anodic current on the square root of scan rates.

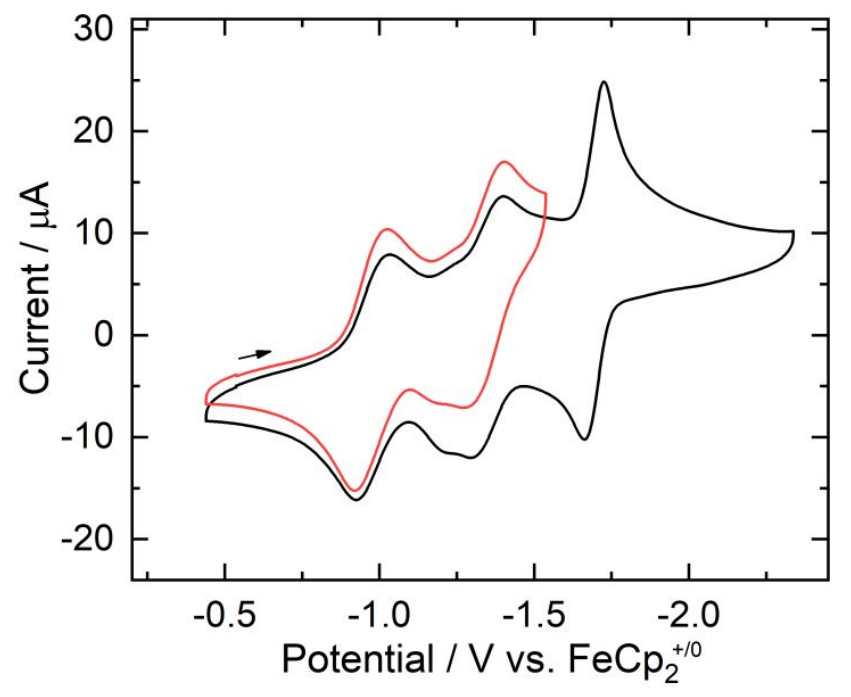

Figure S15. CVs of $1 \mathrm{mM} 2$ in DMF containing $0.1 \mathrm{M} \mathrm{TBAPF}_{6}$ at different ranges of potential scan. 

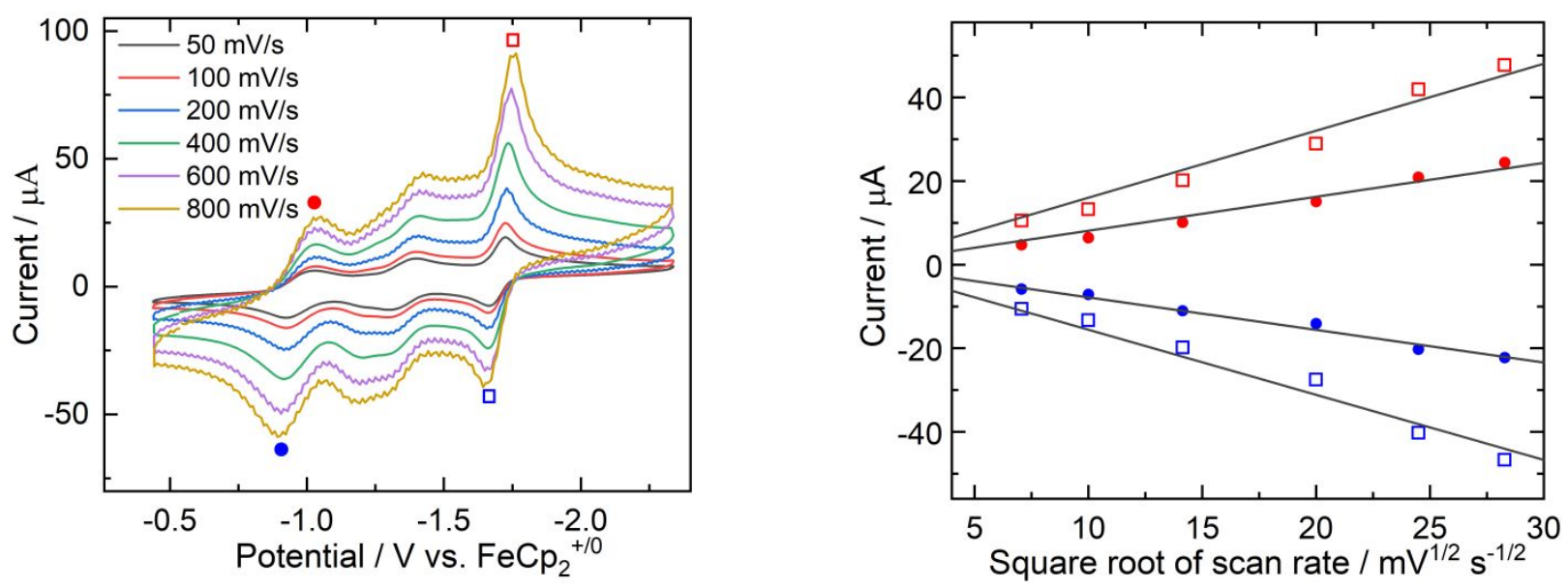

Figure S16. Left: cyclic voltammograms for $1 \mathrm{mM} 2$ in DMF containing $0.1 \mathrm{M} \mathrm{TBAPF}_{6}$ at different scan rates. Right: dependence of cathodic current and anodic current on the square root of scan rates.

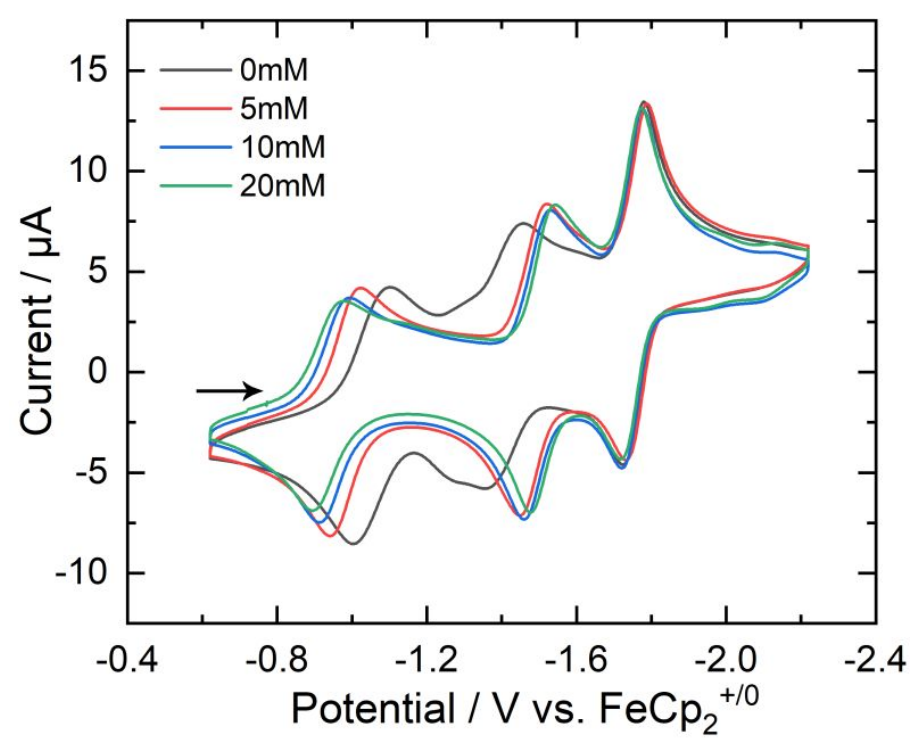

Figure S17. CVs of $0.5 \mathrm{mM} 2$ in DMF containing $0.1 \mathrm{M} \mathrm{TBAPF}_{6}$ and various amounts of triphenylphosphine. 


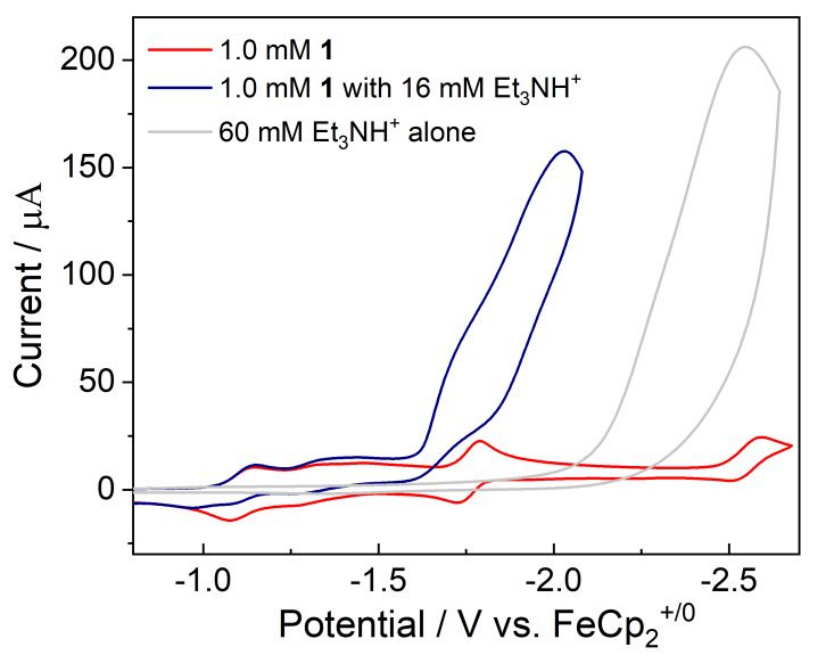

Figure S18. CVs of $1.0 \mathrm{mM} 1$ in the absence and presences of $16 \mathrm{mM}$ triethylammonium tetrafluoroborate. Conditions: $0.1 \mathrm{M} \mathrm{TBAPF}_{6}$, glass carbon electrode $(d=3 \mathrm{~mm})$, and scan rate $=100$ $\mathrm{mV} / \mathrm{s}$.

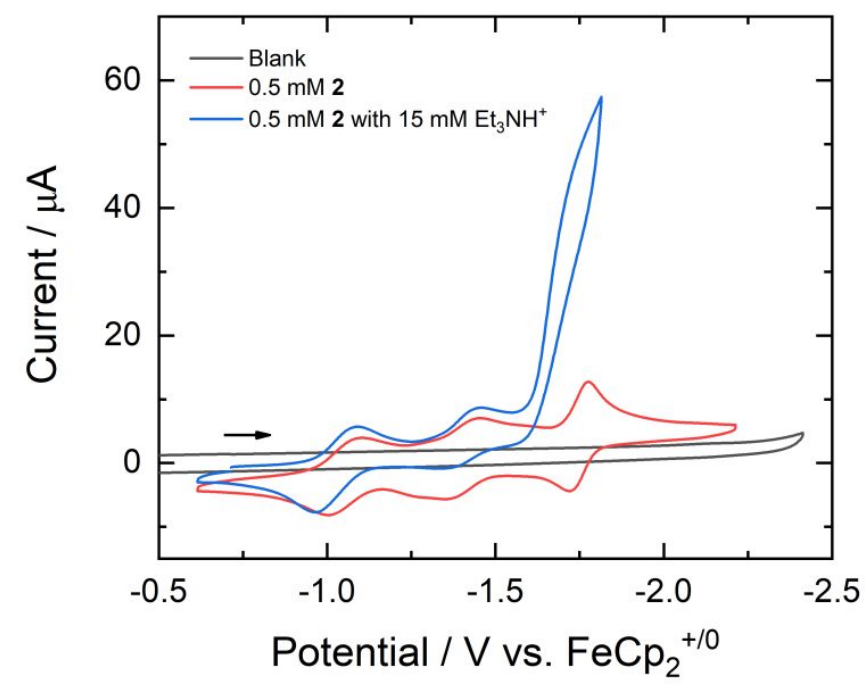

Figure S19. CVs of $0.5 \mathrm{mM} 2$ in the absence and presences of $15 \mathrm{mM}$ triethylammonium tetrafluoroborate. Conditions: $0.1 \mathrm{M} \mathrm{TBAPF}_{6}$, glass carbon electrode $(d=3 \mathrm{~mm})$, and scan rate $=100$ $\mathrm{mV} / \mathrm{s}$. 


\section{Foot-Of-the-Wave Analysis (FOWA)}

The FOWA was conducted according to the established methodology. ${ }^{8-11}$ Applied voltammograms in the presence of various concentration of acids were background-subtracted by extrapolation of the nonFaradaic charging current of the potential scan. The equations are briefly described below. The equation derived for FOWA of an EECC mechanism divided by the Randles-Sevcik Equation affords the $i_{\mathrm{c}} / i_{\mathrm{p}}$ relationship depending on the experimentally observed parameters. Linearly fitting the initial section of the $i_{\mathrm{c}} / i_{\mathrm{p}}$ plot yields a slope value, from which the rate constant $k_{\mathrm{obs}}$ can be obtained. $E$ represents the applied potential during scanning, $v$ represents the scanning rate of $C V s$, and $D_{\text {cat }}$ represents the diffusion coefficient of the catalyst. The half potential of $[\mathrm{Co}(\mathrm{ppq}) \mathrm{DMF}]^{0 /-1}$ couple is used as the $E_{\mathrm{cat} / 2}$ values in the FOWA.

$i_{\mathrm{c}}$ expression for a $E E C C$ mechanism:

$$
i_{c}=\frac{2 F A C_{c a t} \sqrt{k_{o b s} D_{c a t}}}{1+\exp \left[\frac{F}{R T}\left(E-E_{c a t / 2}\right)\right]}
$$

Randles-Sevcik equation:

$$
\begin{aligned}
& i_{p}=0.4463 n F A C_{c a t} \sqrt{\frac{n F v D_{c a t}}{R T}} \\
& \frac{i_{c}}{i_{p}}=\frac{4.48}{n \sqrt{\frac{R T k_{o b s}}{n F v}}} \\
& 1+\exp \left[\frac{F}{R T}\left(E-E_{c a t / 2}\right)\right]
\end{aligned}
$$

Inserting the numerical values of $\mathrm{R}=8.3145 \mathrm{~J} \mathrm{~mol}^{-1} \mathrm{~K}^{-1}, \mathrm{~T}=298 \mathrm{~K}, \mathrm{~F}=96485 \mathrm{C} \mathrm{mol}^{-1}$, generates the expression of slope containing $k_{\text {obs. }}$.

$$
\begin{aligned}
& \text { slope }=\frac{0.718}{n} \sqrt{\frac{k_{o b s}}{n v}} \\
& k_{o b s}=n v\left(\frac{n * \text { slope }}{0.718}\right)^{2}
\end{aligned}
$$

In the above equation, $n$ equals1, because this parameter derives from the Randles-Sevcik equation and corresponds to the one-electron $[\mathrm{Co}(\mathrm{ppq})]^{0 /-1}$ redox process in our analysis. A scan rate of $v=0.1 \mathrm{~V} / \mathrm{s}$ was set for all FOWA experiments.

$$
k_{\text {obs }}=\left(\frac{\text { slope }}{2.27}\right)^{2}
$$




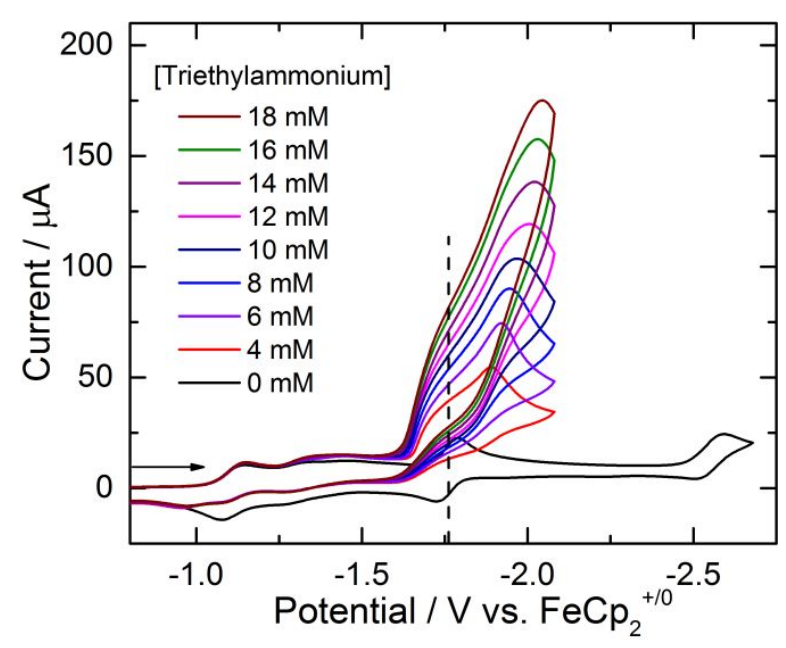

Figure S20. CVs of $1 \mathrm{mM} 1$ in the presences of $0 \sim 18 \mathrm{mM}$ triethylammonium tetrafluoroborate. Conditions: $0.1 \mathrm{M} \mathrm{TBAPF}_{6}$, glass carbon electrode $(d=3 \mathrm{~mm})$, and scan rate $=100 \mathrm{mV} / \mathrm{s}$.
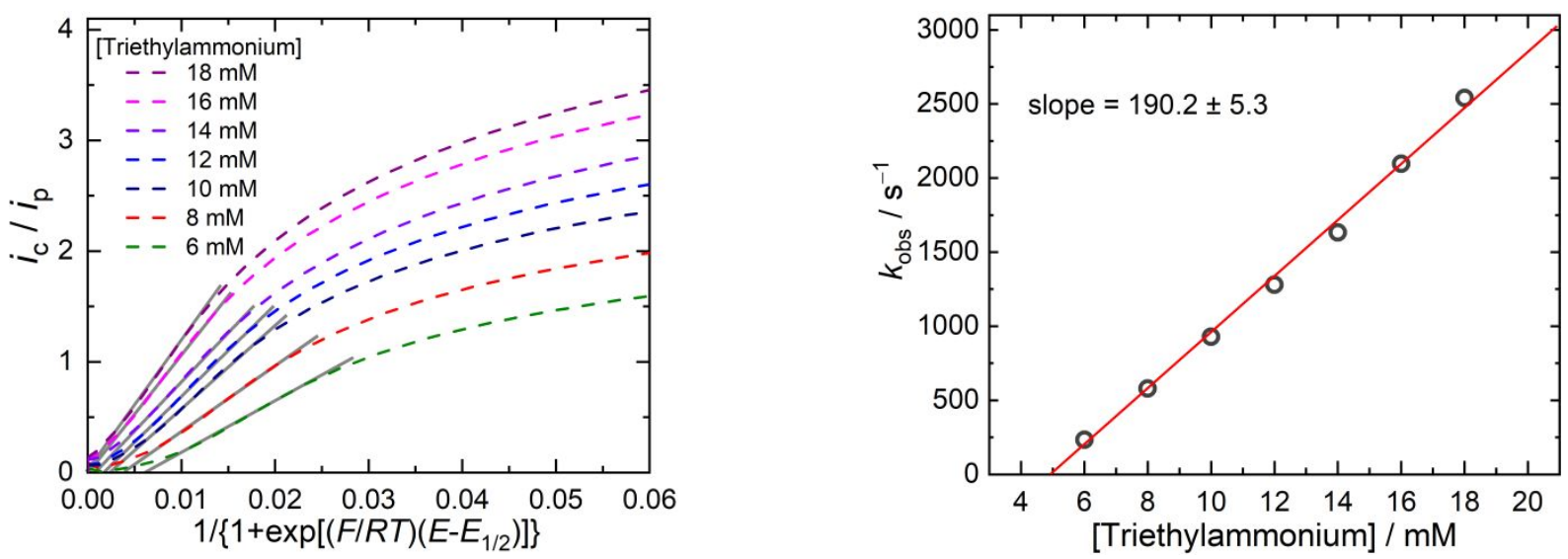

Figure S21. Left: plots of $i_{\mathrm{c}} / i_{\mathrm{p}}$ versus $1 /\left\{1+\exp \left[F / R T\left(E-E_{1 / 2}\right)\right]\right\}$ for FOWA. The data are derived from $\mathrm{CVs}$ of 1 at various concentration of $\mathrm{HNEt}_{3} \mathrm{BF}_{4}$ (Figure S20). Right: the pseudo-first-order rate constants ( $k_{\text {obs }}$, obtained from the FOWA) depending on the concentration of $\mathrm{HNEt}_{3} \mathrm{BF}_{4}$. 


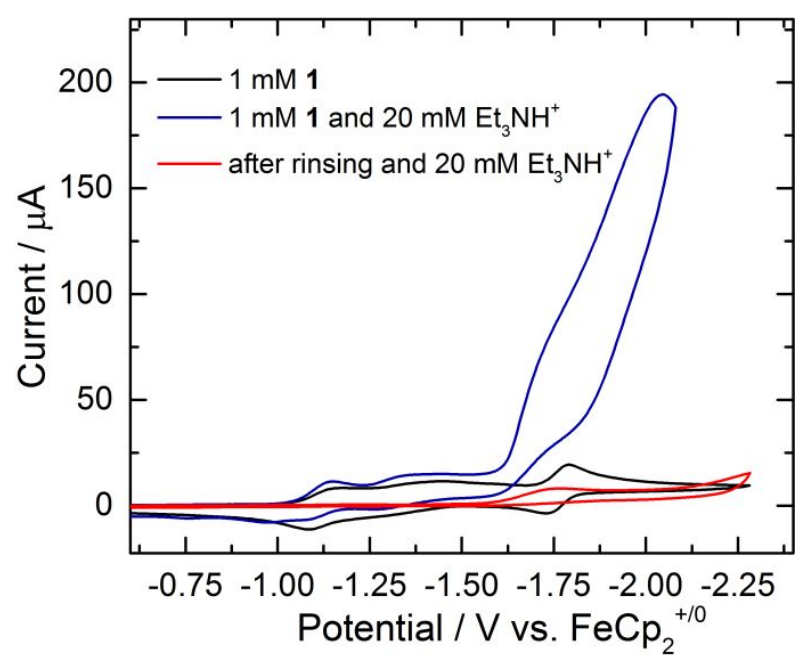

Figure S22. Rinsing experiment of $\mathbf{1}$. CV was first recorded in the electrolyte with 1 and $\mathrm{Et}_{3} \mathrm{NH}^{+}$. After the working electrode was rinsed with fresh DMF, CV was recorded again in a catalyst-free electrolyte with $\mathrm{Et}_{3} \mathrm{NH}^{+}$under the same conditions. Experimental conditions: glass carbon working electrode $(d=3$ $\mathrm{mm}$ ), scan rate $=100 \mathrm{mV} / \mathrm{s}$, and $0.1 \mathrm{M} \mathrm{TBAPF}_{6} \mathrm{DMF}$ solution.

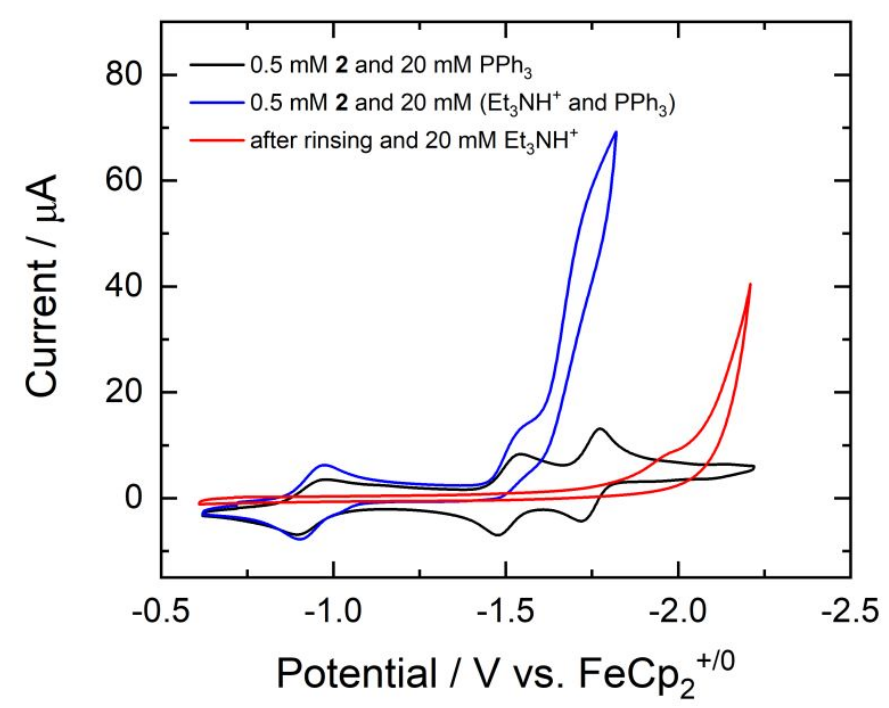

Figure S23. Rinsing experiment of 2. CV was first recorded in the electrolyte with 1 and $\mathrm{Et}_{3} \mathrm{NH}^{+}$. After the working electrode was rinsed with fresh DMF, CV was recorded again in a catalyst-free electrolyte with $\mathrm{Et}_{3} \mathrm{NH}^{+}$under the same conditions. Experimental conditions: glass carbon working electrode $(d=3$ $\mathrm{mm})$, scan rate $=100 \mathrm{mV} / \mathrm{s}$, and $0.1 \mathrm{M} \mathrm{TBAPF}_{6} \mathrm{DMF}_{\text {solution. }}$ 

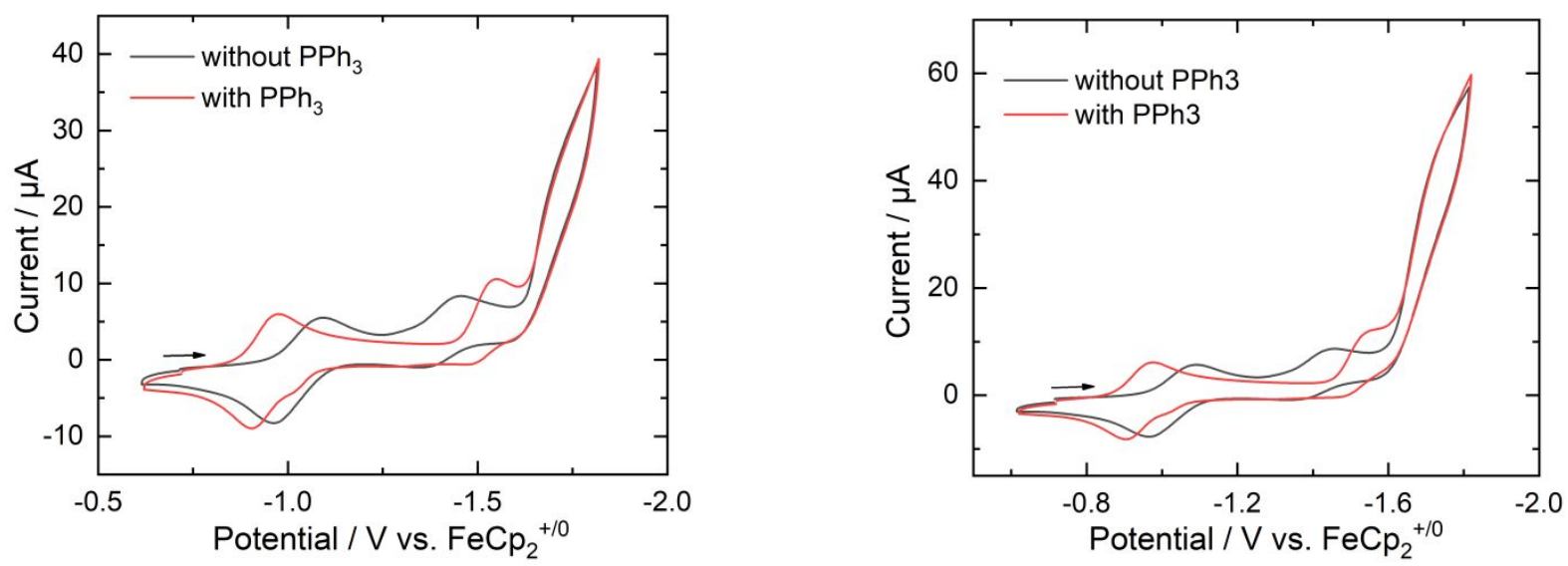

Figure S24. Left: CVs of 2 in DMF containing $15 \mathrm{mM}$ triethylammonium with (red) or without (black) $20 \mathrm{mM}$ triphenylphosphine. Right: CVs of 2 in DMF containing $15 \mathrm{mM}$ triethylammonium with (red) or without (black) $20 \mathrm{mM}$ triphenylphosphine. Conditions: $0.5 \mathrm{mM}$ complex 2 in $0.1 \mathrm{M}^{\mathrm{n}} \mathrm{Bu}_{4} \mathrm{NPF}_{6} \mathrm{DMF}$ solutions, glass carbon electrode $(d=3 \mathrm{~mm})$, and scan rate $=100 \mathrm{mV} / \mathrm{s}$.

\section{Controlled-potential electrolysis (CPE)}

Previously reported methodology of bulk electrolysis was used to determine the $\mathrm{TOF}_{\max }$ of electrocatalytic HER by $\mathbf{1}$ and 2. ${ }^{8,12-14}$ With respect to a heterolytic $\mathrm{H}-\mathrm{H}$ bond formation step in a EECC electrocatalytic scenario, $\mathrm{TOF}_{\max }$ values were calculated using the following equations, where $\mathrm{A}$ is the surface area of the glass carbon working electrode $\left(A=1.96 \times 10^{-5} \mathrm{~m}^{2}\right),[\mathrm{Cat}]$ is the concentration of the catalyst $([C a t]=0.3 \mathrm{mM})$, and the diffusion coefficient $\left(D_{\text {cat }}\right.$ of $\mathbf{1}=5.6478 \times 10^{-10} \mathrm{~m}^{2} \mathrm{~s}^{-1} ; D_{\text {cat }}$ of $\mathbf{2}=6.8185$ $\times 10^{-10} \mathrm{~m}^{2} \mathrm{~s}^{-1}$ ) that can be measured by cyclitic voltammetry at various potential scanning rates according to the Randles-Sevcik equation. The $[\mathrm{Co}(\mathrm{ppq}) \mathrm{DMF}]^{0 /-1}$ couple potentials of complexes were used as the $E_{\text {cat } / 2}$ values in the CPE study. The average current, $i_{\mathrm{el}}$, was assumed to keep a constant faradaic efficiency (FE) throughout the initial 90 minutes ( $t=5400 \mathrm{~s})$ of electrolysis. The TOFs of 1 and 2 were measured to be $86.80 \mathrm{~s}^{-1}$ and $168.49 \mathrm{~s}^{-1}$ at an electrolysis potential of $-1.80 \mathrm{~V}$ in the presence of $30 \mathrm{mM}$ triethylammonium. $\mathrm{TOF}_{\max }$ numbers were estimated by linearly extrapolating the $\mathrm{TOF} /[\mathrm{acid}]$ relationship to an acid concentration of $1.0 \mathrm{M}$.

$\mathrm{TOF}_{\text {max }}=\frac{i_{e l}{ }^{2}\left(1+\exp \left[\frac{F}{R T}\left(E-E_{\text {cat } / 2)}\right)\right]\right)}{F^{2} A^{2} D_{\text {cat }}[\text { Cat }]^{2}}$

with, $i_{e l}=\frac{Q_{e l} \times F E}{\mathrm{t}}$

TOF- $\eta$ Tafel plots were drawn according to the following equation: 


$$
\mathrm{TOF}=\frac{T O F_{\max }}{1+\exp \left[\frac{F}{R T}\left(E_{H^{+} / H_{2}}^{0}-E_{c a t / 2}\right)\right] \exp \left(-\frac{F}{R T} \eta\right)}
$$

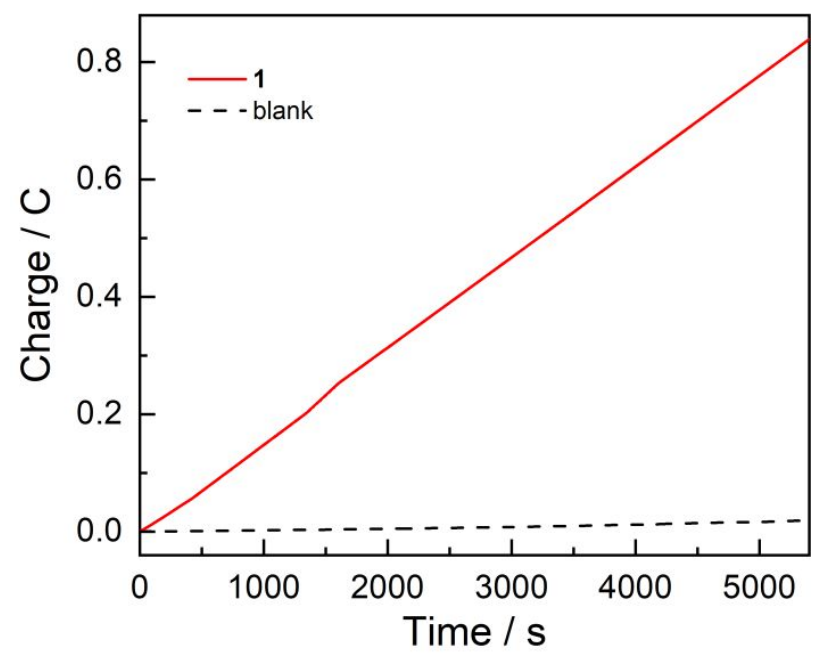

Figure S25. Passed charge versus time plots of bulk electrolysis experiments performed in the absence (blank) and presence of 1 . Conditions: glass carbon working electrode $(d=5 \mathrm{~mm}), 0.3 \mathrm{mM} 1$ and $30 \mathrm{mM}$ triethylammonium in DMF (containing 0.1 $\mathrm{M} \mathrm{TBAPF}_{6}$ as the supporting electrolyte) at an applied potential of $-1.8 \mathrm{~V}$ vs. $\mathrm{FeCp}_{2}{ }^{+/ 0}$. Ferrocene $(0.3 \mathrm{mM})$ was added as an internal reference in the 'blank' experiment.

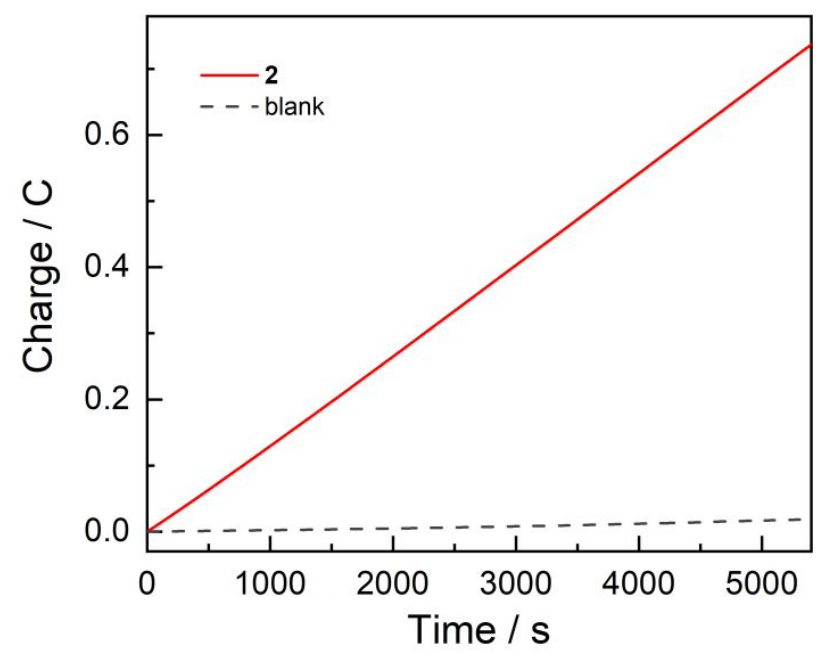

Figure S26. Passed charge versus time plots of bulk electrolysis experiments performed in the absence (blank) and presence of 2 . Conditions: glass carbon working electrode $(d=5 \mathrm{~mm}), 0.3 \mathrm{mM} 2$ and $30 \mathrm{mM}$ triethylammonium in DMF (containing $0.1 \mathrm{M} \mathrm{n}^{\mathrm{n}} \mathrm{Bu}_{4} \mathrm{NPF}_{6}$ as the supporting electrolyte) at an applied 
potential of $-1.8 \mathrm{~V}$ vs. $\mathrm{FeCp}_{2}{ }^{+/ 0}$. Ferrocene $(0.3 \mathrm{mM})$ was added as an internal reference in the 'blank' experiment.

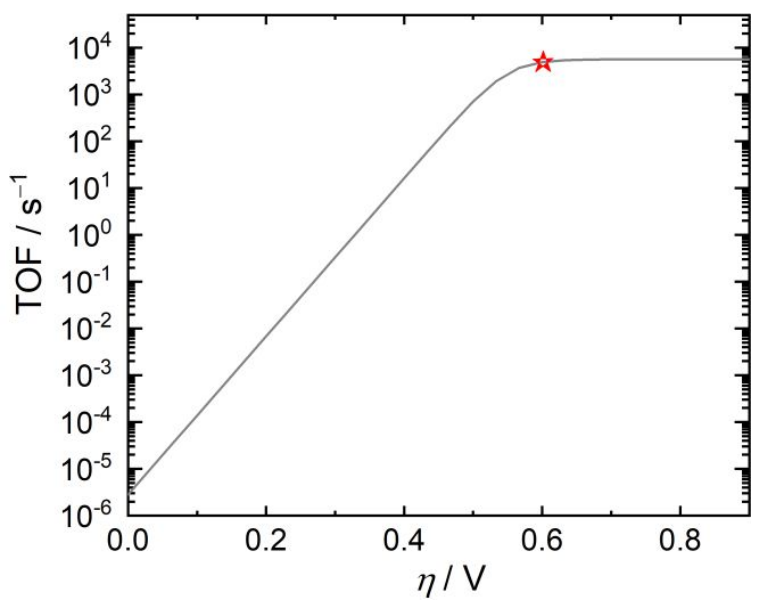

Figure S27. Catalytic Tafel plots of $\mathbf{1}$ based on the $\mathrm{TOF}_{\max }$ value of $\mathbf{1}$ calculated from the CPE experiment. 


\section{Computational Details}

DFT calculations presented herein were accomplished with the B3LYP-D3 functional (with the default D3 dispersion correction proposed by Grimme) ${ }^{15-16}$ as implemented in the Gaussian 16 program package. ${ }^{17}$ For geometry optimization, the $6-31 \mathrm{G}(\mathrm{d}, \mathrm{p})$ basis sets were used for the C, N, H elements, the 6-311+G* for the $\mathrm{P}$ element, and the $\mathrm{SDD}^{18}$ pseudo potential with corresponding basis sets for Co. On the basis of the optimized geometries, the final energy and solvation energy in DMF solvent were determined by singlepoint calculations using the SMD ${ }^{19}$ continuum solvation model and employing larger basis sets, in which all elements, except Co (SDD), were described by the $6-311+\mathrm{G}(2 \mathrm{df}, 2 \mathrm{p})$ basis set. Analytical frequency calculations were carried out at the same level of theory as the geometry optimizations to identify the nature of all stationary points as minima (no imaginary frequency) or transition states (only one imaginary frequency), and to determine the Gibbs free energy corrections at $298.15 \mathrm{~K}$. Unless otherwise mentioned, the energies reported are B3LYP-D3 Gibbs energies including solvation energies, Gibbs free energy corrections, and the D3 dispersion correction.

The redox potentials and $\mathrm{p} K_{\mathrm{a}} \mathrm{s}$ were calculated using the same methodology as that applied in our previous studies, ${ }^{20-23}$ which was also summarized in recent reviews. ${ }^{24-26}$ Therefore, only some key points were mentioned here. The experimental absolute redox potential of the standard hydrogen electrode in DMF (SHE, $4.13 \mathrm{~V}$ ) was used as the reference, ${ }^{27}$ which corresponds to an electron affinity of $95.2 \mathrm{kcal} \mathrm{mol}^{-1}$. The Gibbs free energy of a proton (contribution from translational entropy) is $-6.3 \mathrm{kcal} \mathrm{mol}^{-1}$ in the gas phase. The experimental value of $-267.2 \mathrm{kcal} \mathrm{mol}^{-1}$ was used for a proton's solvation free energy in DMF.

${ }^{28}$ Taken together, the total Gibbs energy of a proton in DMF becomes $-273.5 \mathrm{kcal} \mathrm{mol}^{-1}$, which was utilized as the reference for the calculations of the $\mathrm{p} K_{\mathrm{a}} \mathrm{s}$. The corrections for DMF (standard concentration of 13.0 mol L${ }^{-1}$ ) and $\mathrm{Et}_{3} \mathrm{NH}^{+}$(standard concentration of $0.03 \mathrm{~mol} \mathrm{~L}^{-1}$ ) are 3.4 and $-0.2 \mathrm{kcal} \mathrm{mol}^{-1}$, respectively. ${ }^{29}$ The correction originates from the free energy change from $1 \mathrm{~atm}\left(24.5 \mathrm{~L} \mathrm{~mol}^{-1}\right.$ for ideal gas) to $1 \mathrm{M}$ (1 mol L ${ }^{-1}$ in DMF solution) at $298.15 \mathrm{~K}$. 


\section{Comparison of the crystal and calculated structures of $\left[\mathrm{Co}^{\mathrm{II}}(\mathrm{ppq}) \mathrm{Cl}_{2}\right]$ and 2}

Table S4. Comparison of the crystal and calculated structures of [ $\left.\mathrm{Co}^{\mathrm{II}}(\mathrm{ppq}) \mathrm{Cl}_{2}\right]$.

\begin{tabular}{ccccc}
\hline Bond distance $(\AA)$ & X-ray $(\AA)^{\mathrm{a}}$ & $\begin{array}{c}\text { Calc. }(\AA)- \\
\text { doublet }\end{array}$ & $\begin{array}{c}\text { Calc. }(\AA)- \\
\text { quartet }\end{array}$ & Calc. $(\AA)$-sexter \\
\hline M-N1 & $2.004(3)$ & 1.95 & 2.02 & 2.08 \\
M-N2 & $1.997(2)$ & 1.93 & 2.04 & 2.07 \\
M-N3 & $1.972(2)$ & 1.93 & 2.03 & 2.02 \\
M-N4 & $2.021(2)$ & 1.98 & 2.08 & 2.14 \\
RSMD & & 0.003 & 0.002 & 0.007 \\
Bond angle (deg) & & & & \\
N1-M-N2 & $83.13(9)$ & 84.0 & 81.9 & 78.2 \\
N2-M-N3 & $92.93(9)$ & 94.0 & 90.5 & 88.5 \\
N3-M-N4 & $81.72(10)$ & 84.3 & 82.3 & 80.7 \\
N1-M-N4 & $103.11(10)$ & 99.9 & 107.4 & 101.2 \\
RSMD & & 4.8 & 6.5 & 12.2 \\
Dihedral angle (deg) & & & & 4.0 \\
N1-C5-C6-N2 & $7.0(4)$ & 8.3 & 3.7 & -31.4 \\
C14-C13-C15-N3 & $-20.2(4)$ & -21.2 & -22.7 & 1.3 \\
N4-C25-C26-N3 & $3.7(4)$ & 4.5 & 1.0 & 34.8 \\
RSMD & & 0.8 & 6.2 & +49.3 \\
Gibbs free energies & & +2.4 & 0.0 & \\
(kcal/mol) & & & & \\
\hline
\end{tabular}


Table S5. Comparison of the X-ray single crystal and calculated structures of 2.

\begin{tabular}{|c|c|c|c|c|c|}
\hline Bond distance $(\AA)$ & X-ray $(\AA)^{\mathrm{a}}$ & $\begin{array}{c}\text { Calc. }(\AA)- \\
\text { singlet }\end{array}$ & $\begin{array}{c}\text { Calc. }(\AA)- \\
\text { triplet }\end{array}$ & $\begin{array}{l}\text { Calc. }(\AA)- \\
\text { quintet }\end{array}$ & $\begin{array}{l}\text { Calc. }(\AA)- \\
\text { triplet' }\end{array}$ \\
\hline $\mathrm{M}-\mathrm{N} 1$ & $1.9325(16)$ & 1.94 & 1.98 & 2.06 & 2.08 \\
\hline $\mathrm{M}-\mathrm{N} 2$ & $1.8871(16)$ & 1.92 & 1.93 & 2.07 & 2.07 \\
\hline $\mathrm{M}-\mathrm{N} 3$ & $1.9026(16)$ & 1.92 & 1.94 & 2.06 & 2.02 \\
\hline $\mathrm{M}-\mathrm{N} 4$ & $1.9499(17)$ & 1.98 & 1.99 & 2.14 & 2.14 \\
\hline $\mathrm{M}-\mathrm{P} 1$ & $2.3185(6)$ & 2.32 & 2.53 & 2.48 & 2.42 \\
\hline RSMD & & 0.0005 & 0.01 & 0.03 & 0.02 \\
\hline Bond angle (deg) & X-ray $(\AA)^{\mathrm{a}}$ & $\begin{array}{l}\text { Calc. }(\AA)- \\
\text { singlet }\end{array}$ & $\begin{array}{l}\text { Calc. }(\AA)- \\
\text { triplet }\end{array}$ & $\begin{array}{l}\text { Calc. }(\AA)- \\
\text { quintet }\end{array}$ & $\begin{array}{l}\text { Calc. }(\AA)- \\
\text { triplet' }\end{array}$ \\
\hline $\mathrm{N} 1-\mathrm{M}-\mathrm{N} 2$ & $82.58(7)$ & 82.4 & 83.7 & 79.7 & 78.2 \\
\hline $\mathrm{N} 2-\mathrm{M}-\mathrm{N} 3$ & $92.27(7)$ & 91.6 & 92.9 & 88.8 & 88.5 \\
\hline $\mathrm{N} 3-\mathrm{M}-\mathrm{N} 4$ & $84.28(7)$ & 83.5 & 83.6 & 80.3 & 80.7 \\
\hline $\mathrm{N} 1-\mathrm{M}-\mathrm{N} 4$ & $96.33(7)$ & 97.3 & 98.5 & 103.4 & 101.2 \\
\hline RSMD & & 0.5 & 1.7 & 21.7 & 17.6 \\
\hline $\begin{array}{l}\text { Dihedral angle } \\
\text { (deg) }\end{array}$ & X-ray $(\AA)^{\mathrm{a}}$ & $\begin{array}{c}\text { Calc. }(\AA)- \\
\text { singlet }\end{array}$ & $\begin{array}{l}\text { Calc. }(\AA)- \\
\text { triplet }\end{array}$ & $\begin{array}{l}\text { Calc. }(\AA)- \\
\text { quintet }\end{array}$ & $\begin{array}{l}\text { Calc. }(\AA)- \\
\text { triplet' }\end{array}$ \\
\hline $\mathrm{N} 1-\mathrm{C} 5-\mathrm{C} 6-\mathrm{N} 2$ & $4.3(2)$ & 1.4 & 4.2 & 4.3 & 4.1 \\
\hline $\begin{array}{c}\mathrm{C} 14-\mathrm{C} 13- \\
\mathrm{C} 15-\mathrm{N} 3\end{array}$ & $-18.1(3)$ & -25.8 & -24.3 & -29.1 & -31.4 \\
\hline$\frac{\mathrm{N} 4-\mathrm{C} 25-\mathrm{C} 26-}{\mathrm{N} 3}$ & $2.0(2)$ & 2.1 & 3.6 & 1.8 & 1.3 \\
\hline RSMD & & 22.6 & 13.5 & 39.9 & 35.3 \\
\hline $\begin{array}{c}\text { Gibbs free energies } \\
(\mathrm{kcal} / \mathrm{mol})\end{array}$ & & +11.3 & +3.7 & +1.9 & 0.0 \\
\hline
\end{tabular}

${ }^{a}$ Data were cited from the reference. ${ }^{7}$

\section{Spin densities of intermediates and computed redox potentials.}

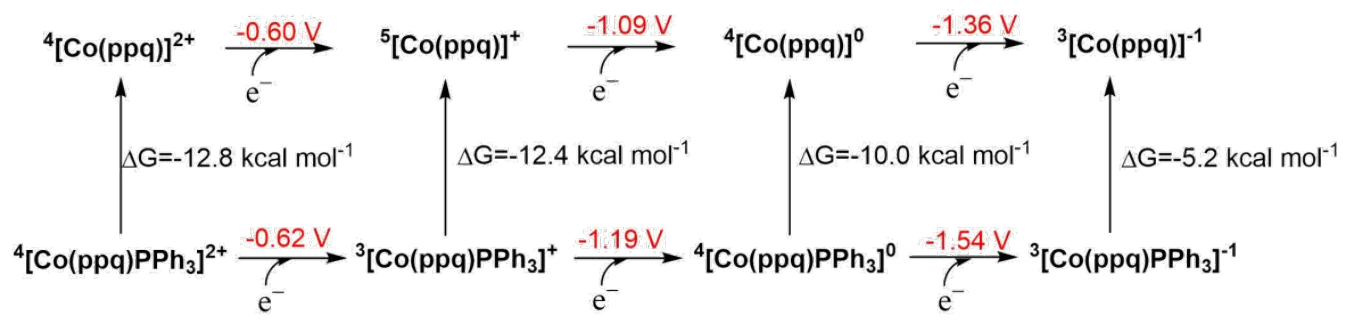

Scheme S1. Calculated redox potentials and dissociation energy of Co-containing species with $\mathrm{PPh}_{3}$ ligand. Left superscript numbers indicate spin multiplicities of the species. Calculated potentials (red) are reported versus SHE. 


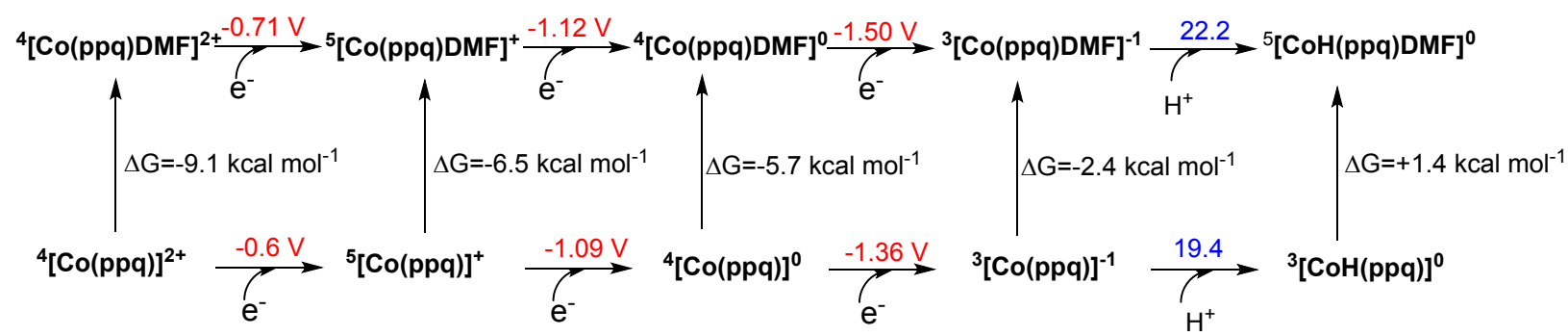

Scheme S2. Calculated redox potentials and association energy of Co-containing species with DMF molecular. Left superscript numbers indicate spin multiplicities of the species, and blue numbers show the $\mathrm{p} K_{\mathrm{a}}$ values in the DMF solvent. Calculated potentials (red) are reported versus SHE.

Table S6. Comparison of redox potentials between the experiment and calculation data. Left superscript numbers indicate spin multiplicities of the species.

\begin{tabular}{ccccc}
\hline Redox couples & $\begin{array}{c}\text { Exp. } \\
\left(\mathrm{V} \mathrm{vs.} \mathrm{FeCp}_{2}{ }^{+/ 0}\right)\end{array}$ & $\begin{array}{c}\text { Exp. } \\
(\mathrm{V} \text { vs. SHE })\end{array}$ & $\begin{array}{c}\text { Cal. } \\
\left(\mathrm{V} \text { vs. FeCp }{ }^{+/ 0}\right)\end{array}$ & $\begin{array}{c}\text { Cal. } \\
(\mathrm{V} \text { vs. SHE })\end{array}$ \\
\hline${ }^{4}[\mathrm{Co}(\mathrm{ppq}) \mathrm{DMF}]^{2+/ 5}[\mathrm{Co}(\mathrm{ppq}) \mathrm{DMF}]^{+}$ & -1.03 & -0.41 & -1.31 & -0.71 \\
${ }^{5}[\mathrm{Co}(\mathrm{ppq}) \mathrm{DMF}]^{+/ 4}[\mathrm{Co}(\mathrm{ppq}) \mathrm{DMF}]^{0}$ & -1.40 & -0.78 & -1.74 & -1.12 \\
${ }^{4}[\mathrm{Co}(\mathrm{ppq}) \mathrm{DMF}]^{0 / 3}[\mathrm{Co}(\mathrm{ppq}) \mathrm{DMF}]^{-1}$ & -1.75 & -1.13 & -2.12 & -1.50 \\
\hline
\end{tabular}

Table S7. The spin density of Co-containing intermediates involved in the reduction processes.

\begin{tabular}{ccccc}
\hline \multirow{2}{*}{ Species } & \multicolumn{2}{c}{ Spin distribution } & \multicolumn{2}{c}{ Charge } \\
\cline { 2 - 5 } & $\mathrm{Co}$ & $0.21(0.21,-0.01)$ & $\mathrm{Co}$ & $\mathrm{ppq}$ \\
\hline${ }^{4}[\mathrm{Co}(\mathrm{ppq}) \mathrm{DMF}]^{a+}$ & 2.73 & $0.25(0.26,-0.01)$ & +0.80 & +1.03 \\
${ }^{2}[\mathrm{Co}(\mathrm{ppq})]^{2+}$ & 2.75 & $1.20(1.44,-0.24)$ & +0.65 & +0.11 \\
${ }^{5}[\mathrm{Co}(\mathrm{ppq}) \mathrm{DMF}]^{+}$ & 2.74 & $1.23(1.48,-0.25)$ & +0.74 & +0.26 \\
${ }^{3}[\mathrm{Co}(\mathrm{ppq})]^{+}$ & 2.77 & $0.36(1.21,-0.85)$ & +0.56 & -0.74 \\
$\left.{ }^{4} \mathrm{Co}(\mathrm{ppq}) \mathrm{DMF}\right]^{0}$ & 2.60 & $0.64(1.30,-0.66)$ & +0.51 & -0.51 \\
${ }^{4}[\mathrm{Co}(\mathrm{ppq})]^{0}$ & 2.36 & $0.89(1.25,-0.36)$ & +0.56 & -1.59 \\
${ }^{3}[\mathrm{Co}(\mathrm{ppq}) \mathrm{DMF}]^{-1}$ & 1.11 & $-0.48(0.34,-0.82)$ & +0.51 & -1.51 \\
${ }^{3}[\mathrm{Co}(\mathrm{ppq})]^{-1}$ & 2.48 & $1.17(1.43,-0.25)$ & +0.22 & -0.16 \\
${ }^{5}[\mathrm{CoH}(\mathrm{ppq}) \mathrm{DMF}]^{0}$ & 2.76 & $-0.72(0.31,-1.02)$ & +0.21 & -0.21 \\
${ }^{3}[\mathrm{CoH}(\mathrm{ppq})]^{0}$ & 2.66 & & &
\end{tabular}

${ }^{a}$ Minus sign in this column stand for $\beta$ spin electron. 


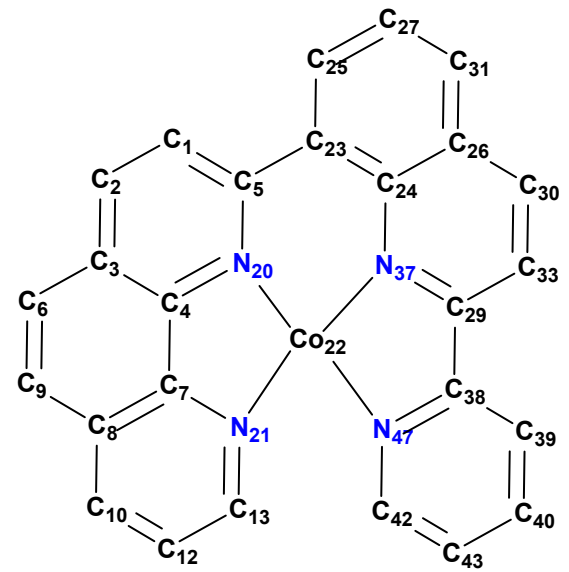

Table S8. Charges and spin densities of atoms in ${ }^{4}[\mathrm{Co}(\mathrm{ppq}) \mathrm{DMF}]^{2+},{ }^{5}[\mathrm{Co}(\mathrm{ppq}) \mathrm{DMF}]^{+}$, and ${ }^{4}[\mathrm{Co}(\mathrm{ppq}) \mathrm{DMF}]^{0}$. Atom labels are shown in the formula above $(\mathrm{H}$ atoms and DMF molecules are omitted for clarity).

\begin{tabular}{|c|c|c|c|c|c|c|}
\hline & \multicolumn{2}{|c|}{${ }^{4}[\mathrm{Co}(\mathrm{ppq}) \mathrm{DMF}]^{2+}$} & \multicolumn{2}{|c|}{${ }^{5}[\mathrm{Co}(\mathrm{ppq}) \mathrm{DMF}]^{+}$} & \multicolumn{2}{|c|}{${ }^{4}[\mathrm{Co}(\mathrm{ppq}) \mathrm{DMF}]^{0}$} \\
\hline & charge & spin & charge & spin & charge & spin \\
\hline $\mathrm{C} 1$ & -0.12003 & -0.001835 & -0.11907 & -0.023381 & -0.1265 & 0.042387 \\
\hline $\mathrm{C} 2$ & -0.08373 & 0.008684 & -0.10313 & 0.053121 & -0.14511 & -0.162952 \\
\hline $\mathrm{C} 3$ & 0.111317 & -0.001295 & 0.106623 & 0.00436 & 0.121388 & 0.06654 \\
\hline $\mathrm{C} 4$ & 0.265667 & 0.003131 & 0.267679 & -0.003016 & 0.257799 & -0.066597 \\
\hline $\mathrm{C} 5$ & 0.25441 & 0.008246 & 0.246708 & 0.058032 & 0.237214 & -0.106037 \\
\hline C6 & -0.11162 & 0.000887 & -0.12042 & 0.001511 & -0.13016 & -0.020056 \\
\hline $\mathrm{C} 7$ & 0.23849 & 0.001063 & 0.216102 & 0.021998 & 0.18557 & -0.078774 \\
\hline $\mathrm{C} 8$ & 0.123066 & 0.000501 & 0.130772 & 0.00047 & 0.145518 & 0.007474 \\
\hline C9 & -0.11738 & -0.000949 & -0.13325 & 0.014612 & -0.14254 & 0.033796 \\
\hline $\mathrm{C} 10$ & -0.08098 & 0.003905 & -0.09161 & -0.000794 & -0.12313 & -0.050186 \\
\hline $\mathrm{C} 12$ & -0.10205 & 0.000706 & -0.10895 & 0.006399 & -0.12127 & -0.045997 \\
\hline $\mathrm{C} 13$ & 0.088943 & 0.002199 & 0.088733 & -0.001143 & 0.080828 & 0.007513 \\
\hline $\mathrm{N} 20$ & -0.57432 & 0.038958 & -0.59725 & 0.088827 & -0.62481 & -0.052768 \\
\hline N21 & -0.52136 & 0.032922 & -0.5011 & 0.031472 & -0.50805 & -0.045102 \\
\hline $\mathrm{Co} 22$ & 0.69151 & 2.734541 & 0.65008 & 2.742743 & 0.56022 & 2.600598 \\
\hline $\mathrm{C} 23$ & 0.055815 & 0.000556 & 0.028654 & 0.05659 & 0.024425 & 0.120472 \\
\hline $\mathrm{C} 24$ & 0.219071 & -0.001118 & 0.223475 & -0.029853 & 0.203737 & -0.06016 \\
\hline $\mathrm{C} 25$ & -0.13803 & 0.002427 & -0.14702 & 0.097912 & -0.15728 & -0.038306 \\
\hline $\mathrm{C} 26$ & 0.108429 & 0.001361 & 0.116007 & -0.028617 & 0.121725 & 0.028811 \\
\hline $\mathrm{C} 27$ & -0.08862 & -0.001499 & -0.1004 & 0.006582 & -0.10384 & 0.076642 \\
\hline $\mathrm{C} 29$ & 0.23912 & 0.00249 & 0.211016 & 0.202614 & 0.189951 & 0.128024 \\
\hline $\mathrm{C} 30$ & -0.10039 & 0.001797 & -0.13988 & 0.194913 & -0.15425 & 0.12203 \\
\hline C31 & -0.1237 & 0.003376 & -0.16239 & 0.127207 & -0.18205 & -0.008661 \\
\hline C33 & -0.11399 & -0.000663 & -0.11392 & -0.095939 & -0.11372 & -0.053439 \\
\hline N37 & -0.51888 & 0.0455 & -0.56922 & 0.158451 & -0.55531 & 0.209525 \\
\hline C38 & 0.28408 & 0.001911 & 0.269176 & 0.019942 & 0.253436 & 0.051572 \\
\hline C39 & -0.10054 & 0.000459 & -0.10738 & 0.042609 & -0.11245 & 0.027152 \\
\hline C40 & -0.05078 & 0.001216 & -0.06942 & 0.010382 & -0.07973 & 0.017062 \\
\hline C42 & 0.115141 & -0.000916 & 0.105642 & -0.030083 & 0.102577 & -0.038735 \\
\hline C43 & -0.08954 & 0.002074 & -0.11003 & 0.099608 & -0.12629 & 0.109365 \\
\hline N47 & -0.5064 & 0.042644 & -0.52657 & 0.136707 & -0.52023 & 0.135994 \\
\hline
\end{tabular}


Table S9. Charge and spin density changes of atoms in ${ }^{4}[\mathrm{Co}(\mathrm{ppq}) \mathrm{DMF}]^{2+},{ }^{5}[\mathrm{Co}(\mathrm{ppq}) \mathrm{DMF}]^{+}$, and ${ }^{4}[\mathrm{Co}(\mathrm{ppq}) \mathrm{DMF}]^{0}$ during redox processes. Atom labels are shown in the formula above (H atoms and DMF molecules are omitted for clarity).

\begin{tabular}{|c|c|c|c|c|}
\hline & \multicolumn{2}{|c|}{${ }^{4}[\mathrm{Co}(\mathrm{ppq}) \mathrm{DMF}]^{2+} /{ }^{5}[\mathrm{Co}(\mathrm{ppq}) \mathrm{DMF}]^{+}$} & \multicolumn{2}{|c|}{${ }^{5}[\mathrm{Co}(\mathrm{ppq}) \mathrm{DMF}]^{+} /{ }^{4}[\mathrm{Co}(\mathrm{ppq}) \mathrm{DMF}]^{0}$} \\
\hline & $\Delta$ charge & $\Delta$ spin & $\Delta$ charge & $\Delta$ spin \\
\hline $\mathrm{C} 1$ & -0.00096 & 0.021546 & 0.007429 & -0.06577 \\
\hline $\mathrm{C} 2$ & 0.019396 & -0.04444 & 0.041983 & 0.216073 \\
\hline $\mathrm{C} 3$ & 0.004694 & -0.00566 & -0.01477 & -0.06218 \\
\hline $\mathrm{C} 4$ & -0.00201 & 0.006147 & 0.00988 & 0.063581 \\
\hline $\mathrm{C} 5$ & 0.007702 & -0.04979 & 0.009494 & 0.164069 \\
\hline C6 & 0.008795 & -0.00062 & 0.009743 & 0.021567 \\
\hline $\mathrm{C} 7$ & 0.022388 & -0.02094 & 0.030532 & 0.100772 \\
\hline $\mathrm{C} 8$ & -0.00771 & 0.000031 & -0.01475 & -0.007 \\
\hline C9 & 0.015873 & -0.01556 & 0.009287 & -0.01918 \\
\hline $\mathrm{C} 10$ & 0.010621 & 0.004699 & 0.031525 & 0.049392 \\
\hline $\mathrm{C} 12$ & 0.006909 & -0.00569 & 0.012315 & 0.052396 \\
\hline $\mathrm{C} 13$ & 0.00021 & 0.003342 & 0.007905 & -0.00866 \\
\hline $\mathrm{N} 20$ & 0.022924 & -0.04987 & 0.027558 & 0.141595 \\
\hline $\mathrm{N} 21$ & -0.02026 & 0.00145 & 0.006954 & 0.076574 \\
\hline $\mathrm{Co} 22$ & 0.041431 & -0.0082 & 0.089861 & 0.142145 \\
\hline $\mathrm{C} 23$ & 0.027161 & -0.05603 & 0.004229 & -0.06388 \\
\hline $\mathrm{C} 24$ & -0.0044 & 0.028735 & 0.019738 & 0.030307 \\
\hline $\mathrm{C} 25$ & 0.008992 & -0.09549 & 0.010264 & 0.136218 \\
\hline $\mathrm{C} 26$ & -0.00758 & 0.029978 & -0.00572 & -0.05743 \\
\hline $\mathrm{C} 27$ & 0.011787 & -0.00808 & 0.003431 & -0.07006 \\
\hline $\mathrm{C} 29$ & 0.028104 & -0.20012 & 0.021065 & 0.07459 \\
\hline $\mathrm{C} 30$ & 0.039491 & -0.19312 & 0.014364 & 0.072883 \\
\hline C31 & 0.038695 & -0.12383 & 0.019656 & 0.135868 \\
\hline $\mathrm{C} 33$ & $-6.6 \mathrm{E}-05$ & 0.095276 & -0.00021 & -0.0425 \\
\hline N37 & 0.050343 & -0.11295 & -0.01391 & -0.05107 \\
\hline C38 & 0.014904 & -0.01803 & 0.01574 & -0.03163 \\
\hline C39 & 0.006837 & -0.04215 & 0.005071 & 0.015457 \\
\hline $\mathrm{C} 40$ & 0.018633 & -0.00917 & 0.010312 & -0.00668 \\
\hline $\mathrm{C} 42$ & 0.009499 & 0.029167 & 0.003065 & 0.008652 \\
\hline $\mathrm{C} 43$ & 0.020491 & -0.09753 & 0.016258 & -0.00976 \\
\hline N47 & 0.020166 & -0.09406 & -0.00634 & 0.000713 \\
\hline SUM & 0.413055 & -1.03096 & 0.381974 & 1.007049 \\
\hline
\end{tabular}




\section{Computed structures.}

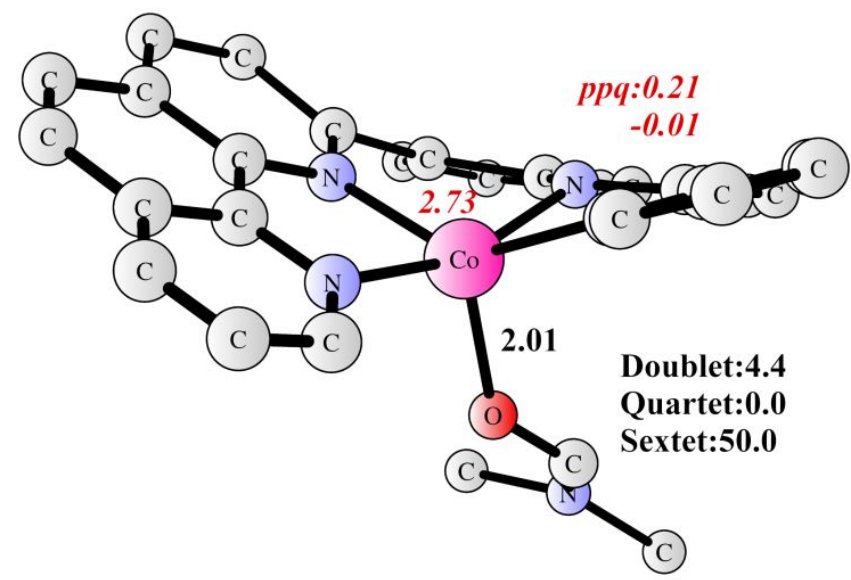

${ }^{4}[\mathrm{Co}(\mathbf{p p q}) \mathrm{DMF}]^{2+}$

Figure S28. Optimized structure of ${ }^{4}[\mathrm{Co}(\mathrm{ppq}) \mathrm{DMF}]^{2+}$ and its relative energy at different spin states. The spin densities on Co and ppq ligand are shown in red italic.

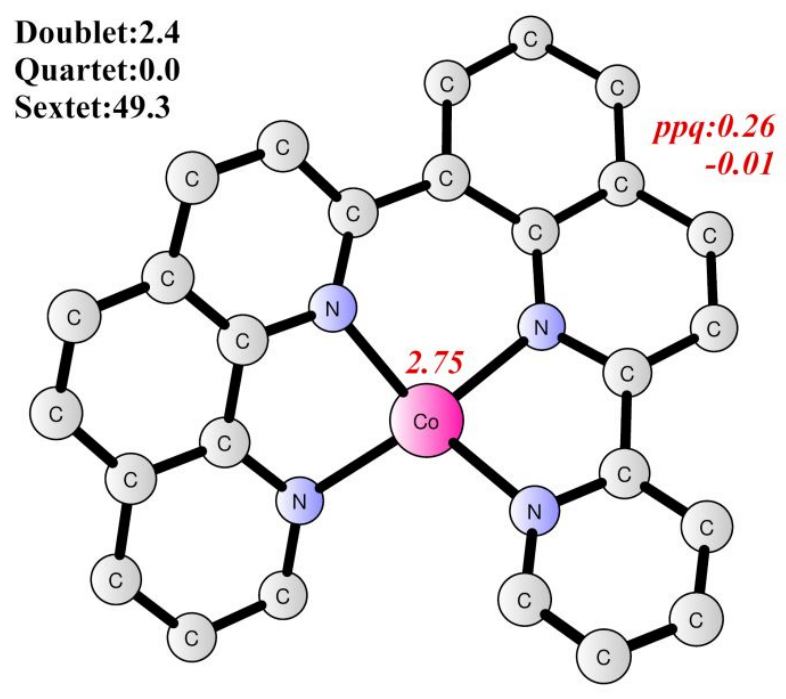

${ }^{4}[\mathrm{Co}(\mathbf{p p q})]^{2+}$

Figure S29. Optimized structure of ${ }^{4}[\mathrm{Co}(\mathrm{ppq})]^{2+}$. The spin densities on Co and ppq ligand are shown in red italic. 


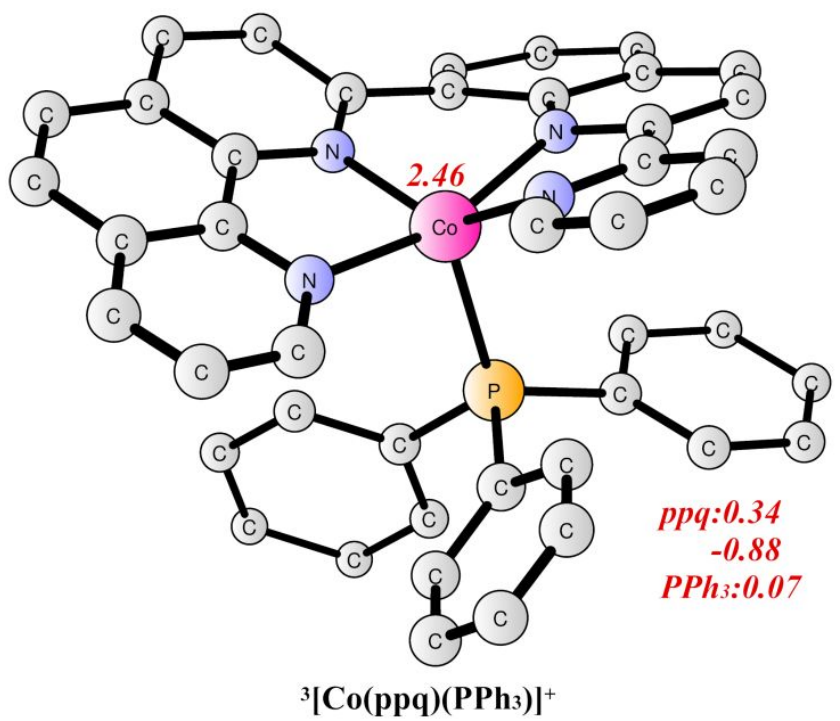

Figure S30. Optimized structure of ${ }^{3}\left[\mathrm{Co}(\mathrm{ppq})\left(\mathrm{PPh}_{3}\right)\right]^{+}$. The spin densities on Co and ppq ligand are shown in red italic.

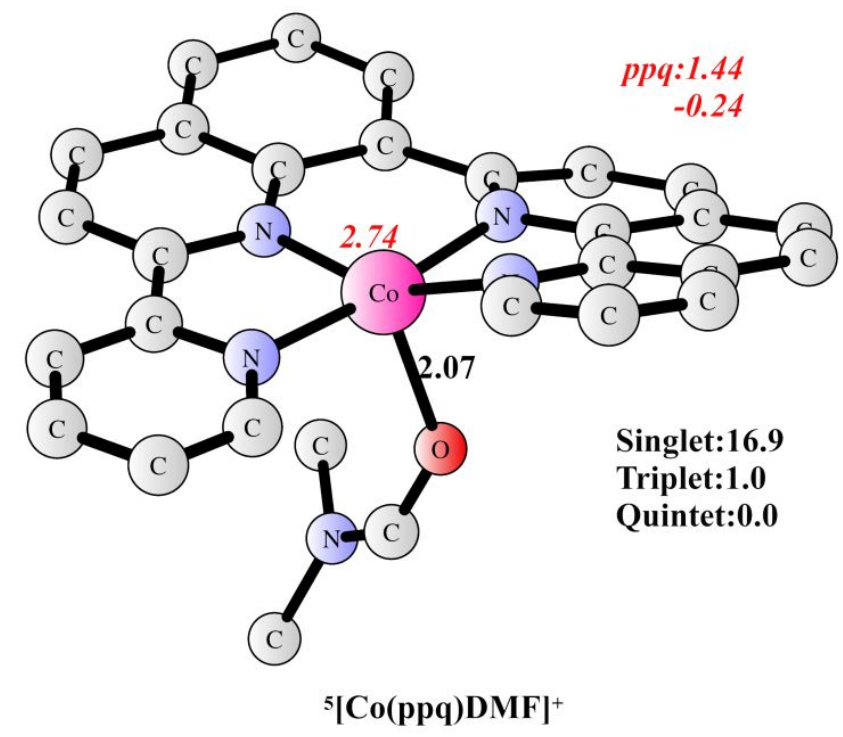

Figure S31. Optimized structure of ${ }^{5}[\mathrm{Co}(\mathrm{ppq}) \mathrm{DMF}]^{+}$and its relative energy at different spin states. The spin densities on Co and ppq ligand are shown in red italic. 


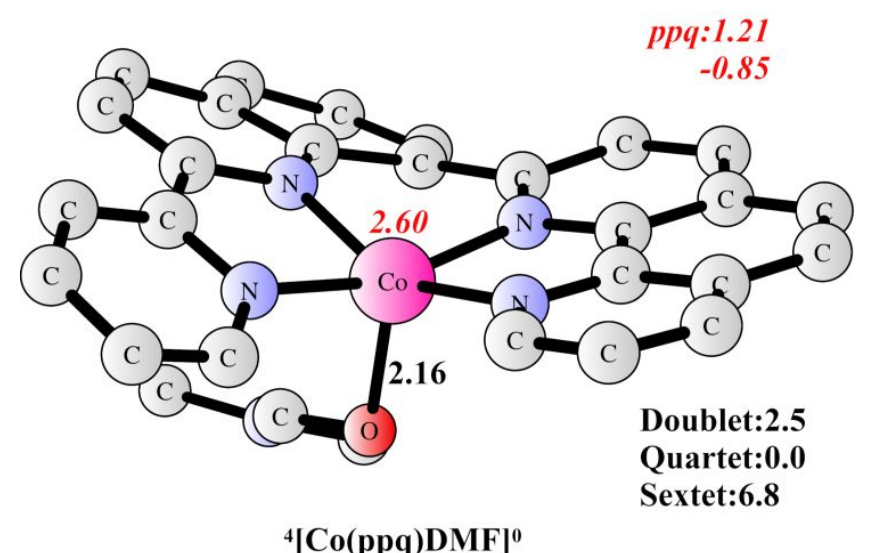

Figure S32. Optimized structure of ${ }^{4}[\mathrm{Co}(\mathrm{ppq}) \mathrm{DMF}]^{0}$ and its relative energy at different spin states. The spin densities on Co and ppq ligand are shown in red italic.

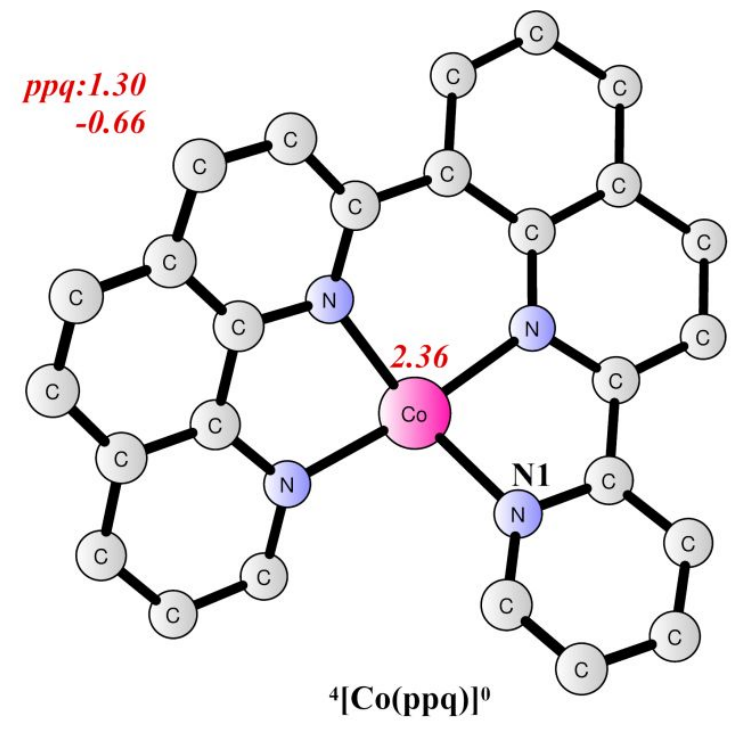

Figure S33. Optimized structure of ${ }^{4}[\mathrm{Co}(\mathrm{ppq})]^{0}$. The spin densities on Co and ppq ligand are shown in red italic. 


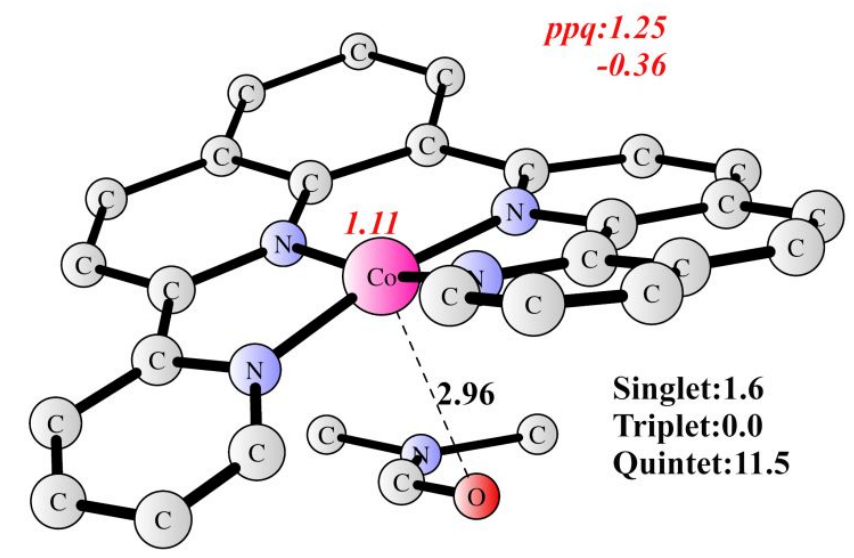

${ }^{3}[\mathrm{Co}(\mathrm{ppq}) \mathrm{DMF}]^{-1}$

Figure S34. Optimized structure of ${ }^{3}[\mathrm{Co}(\mathrm{ppq}) \mathrm{DMF}]^{-1}$ and its relative energy at different spin states. The spin densities on Co and ppq ligand are shown in red italic.

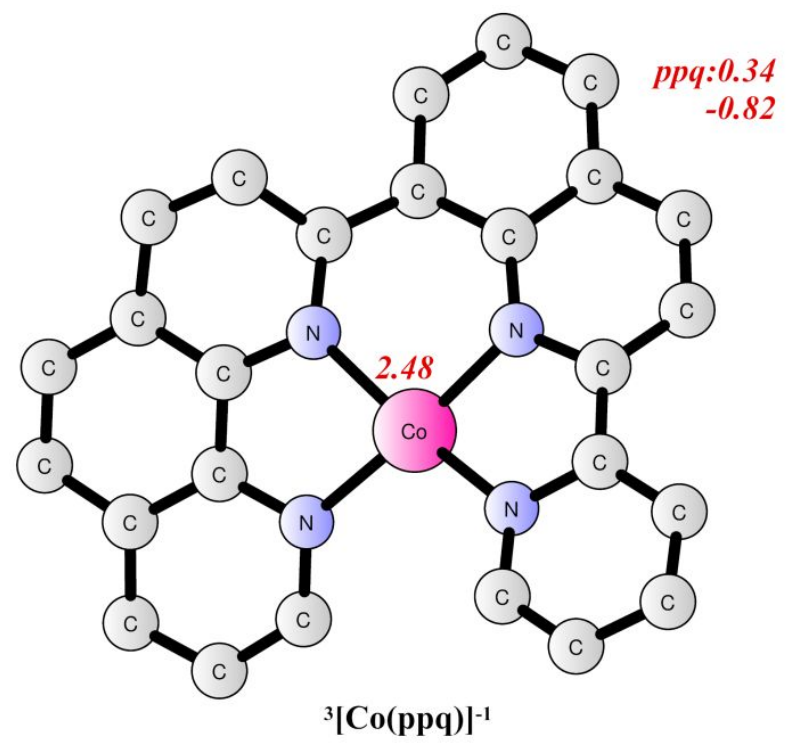

Figure S35. Optimized structure of ${ }^{3}[\mathrm{Co}(\mathrm{ppq})]^{-1}$. The spin densities on Co and ppq ligand are shown in red italic. 


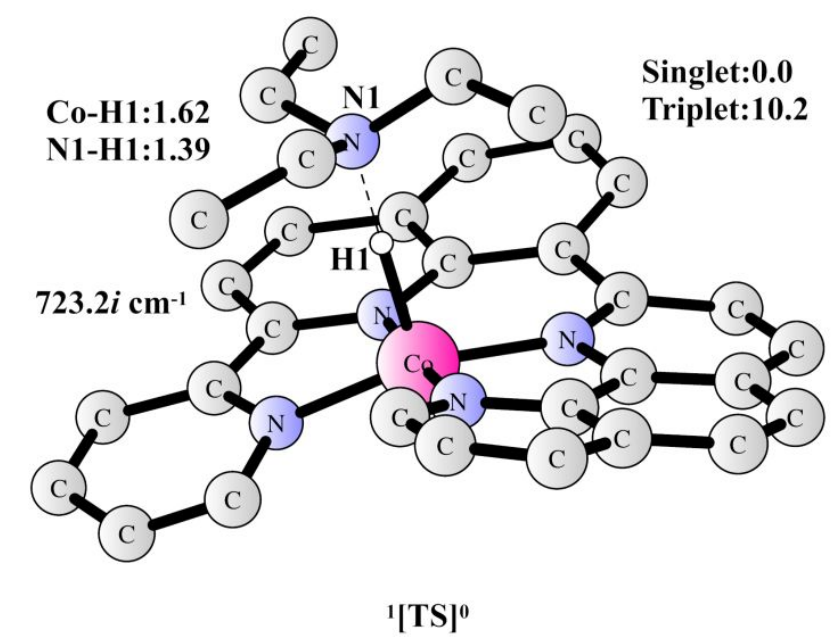

Figure S36. Optimized structure of ${ }^{1}[\mathbf{T S}]^{0}$ and its relative energy at different spin states.

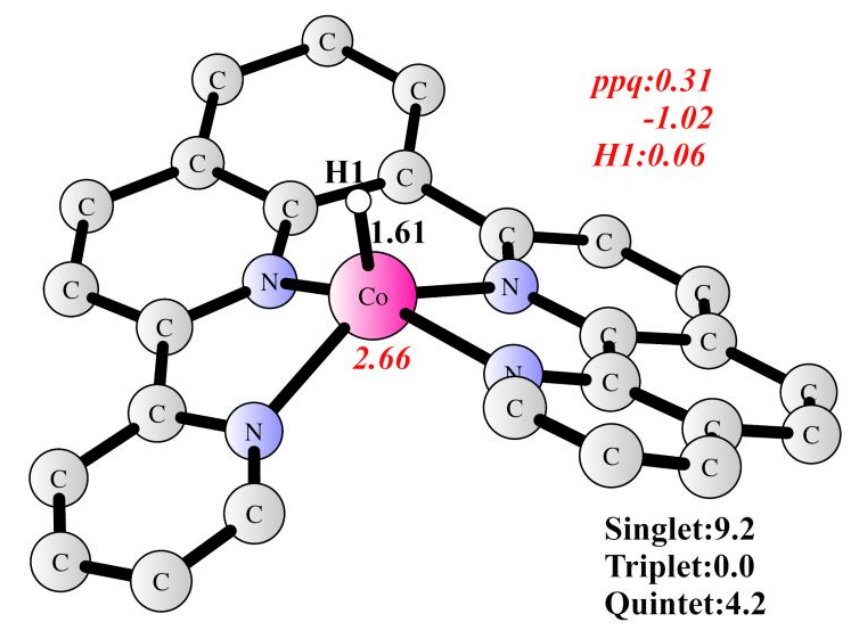

${ }^{3}[\mathrm{CoH}(\mathrm{ppq})]^{0}$

Figure S37. Optimized structure of ${ }^{3}[\mathrm{CoH}(\mathrm{ppq})]^{0}$ and its relative energy at different spin states. 
Table S10. Calculated main optical transition for $\mathbf{2}$ with the largest 10 oscillator strength $f$.

\begin{tabular}{|c|c|c|c|c|c|}
\hline & Excitation & Composition & Energy $(\mathrm{eV})$ & Wavelength (nm) & $f$ \\
\hline Excited State 2 & $\begin{array}{l}176 \mathrm{~B}->177 \mathrm{~B} \\
176 \mathrm{~B}->178 \mathrm{~B} \\
176 \mathrm{~B}->179 \mathrm{~B}\end{array}$ & $\begin{array}{l}39 \% \\
19 \% \\
19 \%\end{array}$ & 0.6889 & 1799.72 & 0.0220 \\
\hline Excited State 6 & $\begin{array}{l}176 \mathrm{~B}->178 \mathrm{~B} \\
176 \mathrm{~B}->179 \mathrm{~B}\end{array}$ & $\begin{array}{l}32 \% \\
31 \%\end{array}$ & 1.2215 & 1015.03 & 0.0620 \\
\hline Excited State 8 & $176 \mathrm{~B}->181 \mathrm{~B}$ & $84 \%$ & 1.6968 & 730.68 & 0.0334 \\
\hline Excited State 15 & $178 \mathrm{~A}->179 \mathrm{~A}$ & $81 \%$ & 2.4900 & 497.94 & 0.0224 \\
\hline Excited State 21 & $\begin{array}{l}177 \mathrm{~A}->179 \mathrm{~A} \\
177 \mathrm{~A}->180 \mathrm{~A}\end{array}$ & $\begin{array}{l}18 \% \\
7 \%\end{array}$ & 2.8715 & 431.77 & 0.0292 \\
\hline Excited State 27 & $\begin{array}{l}176 \mathrm{~B}->191 \mathrm{~B} \\
176 \mathrm{~B}->192 \mathrm{~B} \\
176 \mathrm{~B}->193 \mathrm{~B}\end{array}$ & $\begin{array}{l}25 \% \\
24 \% \\
16 \%\end{array}$ & 3.0773 & 402.91 & 0.0264 \\
\hline Excited State 32 & $\begin{array}{l}175 \mathrm{~A}->179 \mathrm{~A} \\
174 \mathrm{~A}->179 \mathrm{~A}\end{array}$ & $\begin{array}{l}28 \% \\
12 \%\end{array}$ & 3.2965 & 376.11 & 0.0437 \\
\hline Excited State 33 & $\begin{array}{l}173 \mathrm{~B}->177 \mathrm{~B} \\
175 \mathrm{~B}->177 \mathrm{~B} \\
174 \mathrm{~B}->177 \mathrm{~B}\end{array}$ & $\begin{array}{l}12 \% \\
9 \% \\
8 \%\end{array}$ & 3.3801 & 366.81 & 0.0418 \\
\hline Excited State 34 & $\begin{array}{l}173 \mathrm{~B}->177 \mathrm{~B} \\
174 \mathrm{~B}->177 \mathrm{~B}\end{array}$ & $\begin{array}{l}45 \% \\
7 \%\end{array}$ & 3.4238 & 362.13 & 0.0302 \\
\hline Excited State 38 & $\begin{array}{l}175 B->178 B \\
171 B->178 B\end{array}$ & $\begin{array}{l}28 \% \\
11 \%\end{array}$ & 3.5557 & 348.69 & 0.0305 \\
\hline
\end{tabular}




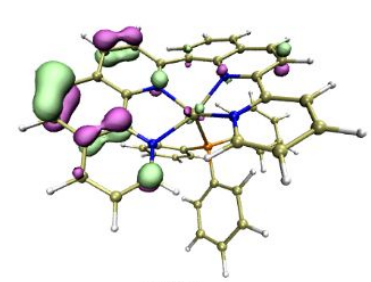

$174 \mathrm{~A}$

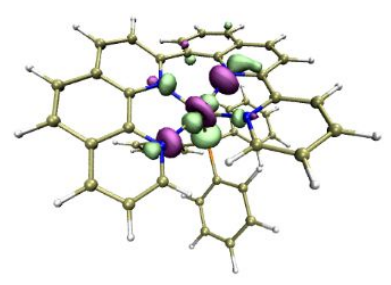

178A

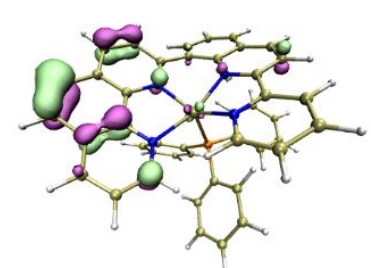

174A

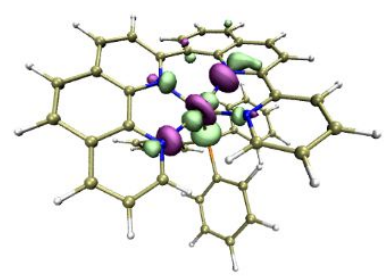

$178 \mathrm{~A}$

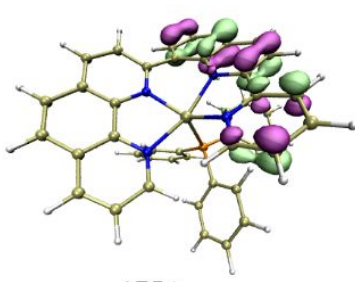

175A

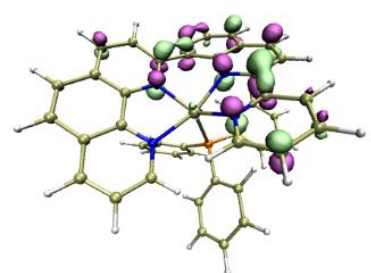

179A

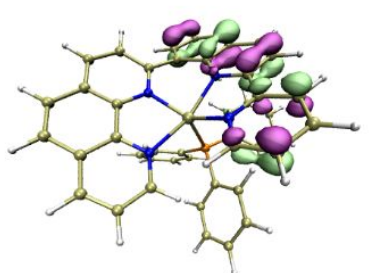

175A

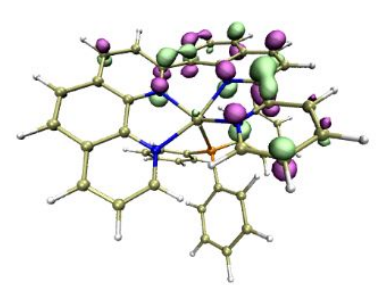

179A

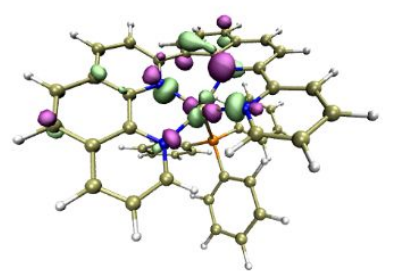

177A

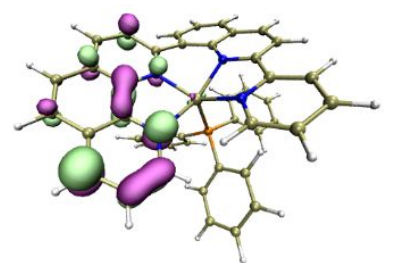

$180 \mathrm{~A}$

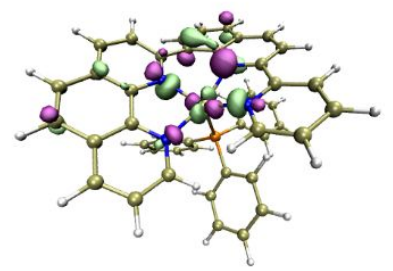

177A

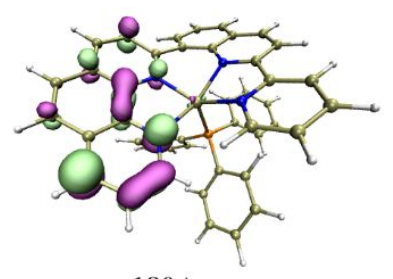

$180 \mathrm{~A}$

Figure S38. Calculated main frontier molecular orbitals (FMO) for complex 2 (isosurface value of 0.06). 


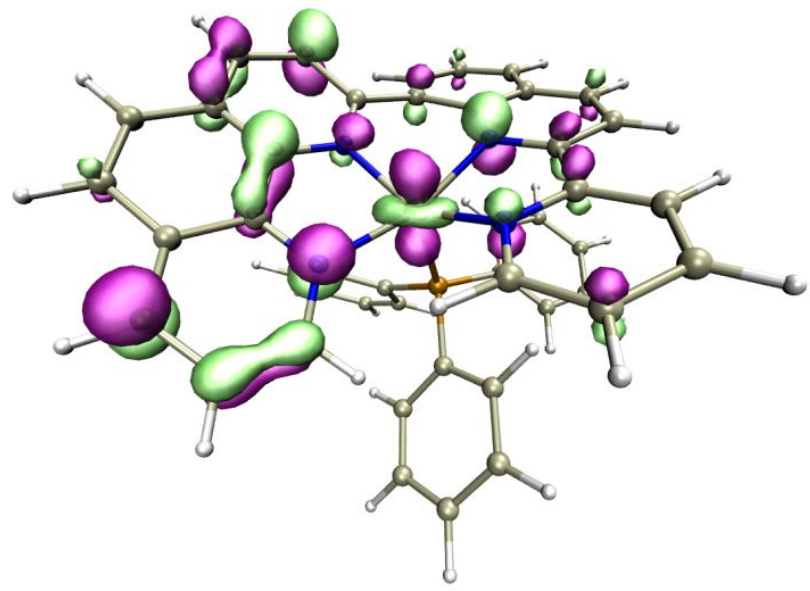

Beta NTO 177

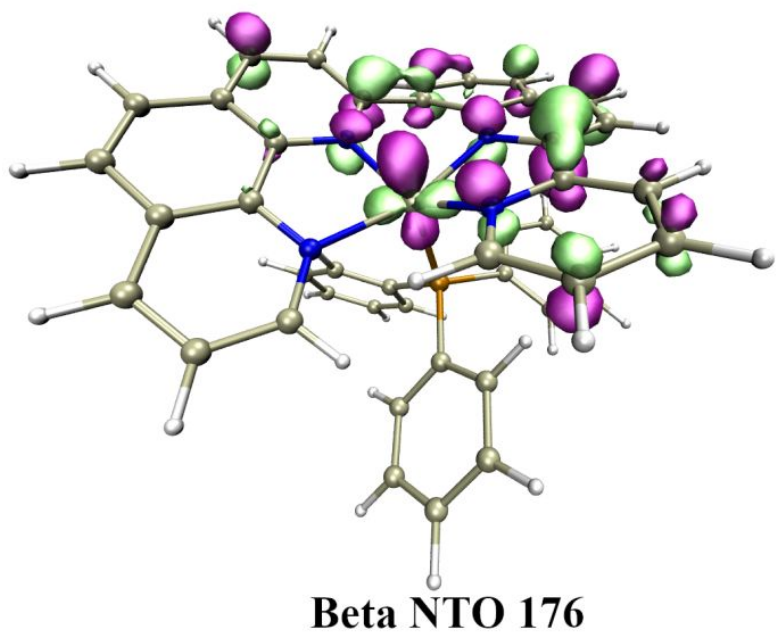

Figure S39. Natural transition orbitals (NTO) for complex 2 (isosurface value of 0.06). 


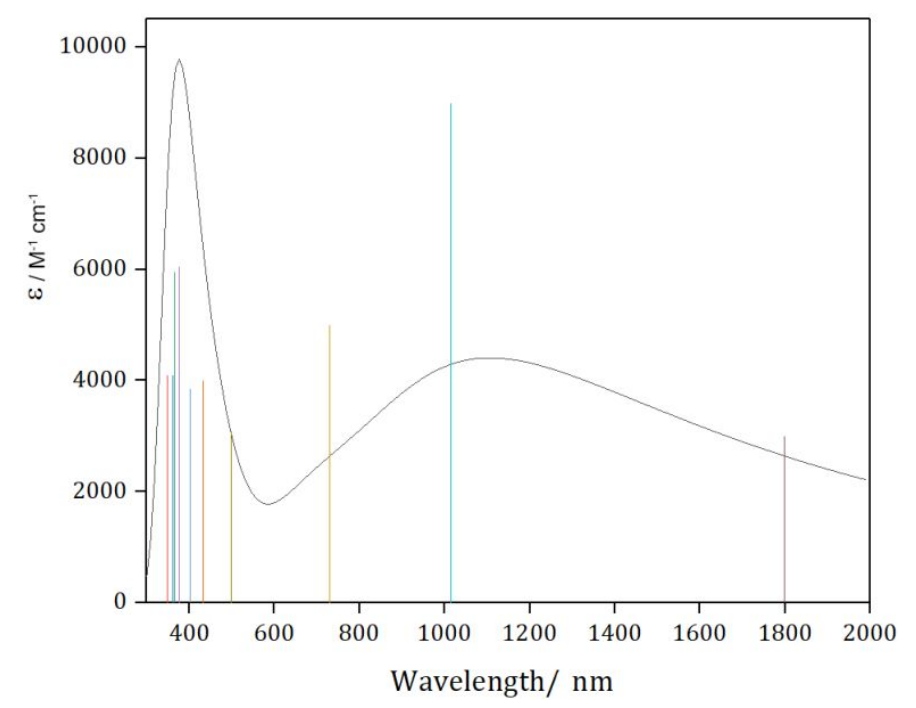

Figure S40. Calculated electronic absorption spectrum of 2.

\section{References}

1. Wickramasinghe, L. D.; Zhou, R.; Zong, R.; Vo, P.; Gagnon, K. J.; Thummel, R. P., Iron Complexes of Square Planar Tetradentate Polypyridyl-Type Ligands as Catalysts for Water Oxidation. J. Am. Chem. Soc. 2015, 137 (41), 13260-13263.

2. Coucouvanis, D., Useful Reagents and Ligands. In Inorganic Syntheses, John Wiley \& Sons, Inc.: 2002; pp 75-121.

3. Fulmer, G. R.; Miller, A. J. M.; Sherden, N. H.; Gottlieb, H. E.; Nudelman, A.; Stoltz, B. M.; Bercaw, J. E.; Goldberg, K. I., NMR Chemical Shifts of Trace Impurities: Common Laboratory Solvents, Organics, and Gases in Deuterated Solvents Relevant to the Organometallic Chemist. Organometallics 2010, 29 (9), 2176-2179.

4. Bain, G. A.; Berry, J. F., Diamagnetic corrections and Pascal's constants. Journal of Chemical Education 2008, 85 (4), 532-536.

5. Sheldrick, G., A short history of SHELX. Acta Crystallogr. Sect. A 2008, 64 (1), 112-122.

6. Dolomanov, O. V.; Bourhis, L. J.; Gildea, R. J.; Howard, J. A. K.; Puschmann, H., OLEX2: a complete structure solution, refinement and analysis program. Journal of Applied Crystallography 2009, 42 (2), 339-341.

7. Tong, L.; Zong, R.; Thummel, R. P., Visible light-driven hydrogen evolution from water catalyzed by a molecular cobalt complex. J. Am. Chem. Soc. 2014, 136 (13), 4881-4884.

8. Costentin, C.; Drouet, S.; Robert, M.; Saveant, J. M., Turnover numbers, turnover frequencies, and overpotential in molecular catalysis of electrochemical reactions. Cyclic voltammetry and preparative-scale electrolysis. J. Am. Chem. Soc. 2012, 134 (27), 11235-11242.

9. Costentin, C.; Savéant, J.-M., Multielectron, Multistep Molecular Catalysis of Electrochemical Reactions: Benchmarking of Homogeneous Catalysts. ChemElectroChem 2014, 1 (7), 1226-1236.

10. Artero, V.; Saveant, J.-M., Toward the rational benchmarking of homogeneous H2-evolving catalysts. Energ. Environ. Sci. 2014, 7 (11), 3808-3814. 
11. Rountree, E. S.; Martin, D. J.; McCarthy, B. D.; Dempsey, J. L., Linear Free Energy Relationships in the Hydrogen Evolution Reaction: Kinetic Analysis of a Cobaloxime Catalyst. ACS Catal. 2016, 6 (5), 33263335.

12. Queyriaux, N.; Sun, D.; Fize, J.; Pecaut, J.; Field, M. J.; Chavarot-Kerlidou, M.; Artero, V., Electrocatalytic Hydrogen Evolution with a Cobalt Complex Bearing Pendant Proton Relays: Acid Strength and Applied Potential Govern Mechanism and Stability. J. Am. Chem. Soc. 2020, 142 (1), 274282.

13. Costentin, C.; Robert, M.; Saveant, J. M., Catalysis of the electrochemical reduction of carbon dioxide. Chem. Soc. Rev. 2013, 42 (6), 2423-2436.

14. Costentin, C.; Drouet, S.; Robert, M.; Saveant, J. M., A local proton source enhances CO2 electroreduction to CO by a molecular Fe catalyst. Science 2012, 338 (6103), 90-94.

15. Becke, A. D., Density - functional thermochemistry. III. The role of exact exchange. J. Chem. Phys. 1993, 98 (7), 5648-5652.

16. Grimme, S.; Antony, J.; Ehrlich, S.; Krieg, H., A consistent and accurate ab initio parametrization of density functional dispersion correction (DFT-D) for the 94 elements H-Pu. J. Chem. Phys. 2010, 132 (15), 154104.

17. Frisch, M. J. T., G. W.; Schlegel, H. B.; Scuseria, G. E.; Robb, M. A.; Cheeseman, J. R.; Scalmani, G.; Barone, V.; Mennucci, B.; Petersson, G. A.; Nakatsuji, H.; Caricato, M.; Li, X.; Hratchian, H. P.; Izmaylov, A. F.; Bloino, J.; Zheng, G.; Sonnenberg, J. L.; Hada, M.; Ehara, M.; Toyota, K.; Fukuda, R.; Hasegawa, J.; Ishida, M.; Nakajima, T.; Honda, Y.; Kitao, O.; Nakai, H.; Vreven, T.; Montgomery, J. A., Jr.; Peralta, J. E.; Ogliaro, F.; Bearpark, M.; Heyd, J. J.; Brothers, E.; Kudin, K. N.; Staroverov, V. N.; Kobayashi, R.; Normand, J.; Raghavachari, K.; Rendell, A.; Burant, J. C.; Iyengar, S. S.; Tomasi, J.; Cossi, M.; Rega, N.; Millam, M. J.; Klene, M.; Knox, J. E.; Cross, J. B.; Bakken, V.; Adamo, C.; Jaramillo, J.; Gomperts, R.; Stratmann, R. E.; Yazyev, O.; Austin, A. J.; Cammi, R.; Pomelli, C.; Ochterski, J. W.; Martin, R. L.; Morokuma, K.; Zakrzewski, V. G.; Voth, G. A.; Salvador, P.; Dannenberg, J. J.;Dapprich, S.;Daniels,A.D.; Farkas,Ö.; Foresman, J. B.; Ortiz, J. V.; Cioslowski, J.; Fox, D. J., Gaussian 16, revision A.03; Gaussian, Inc.: Wallingford CT, . 2016.

18. Andrae, D.; U.Haubermann; Dolg, M.; Stoll, H.; PreuB, H., Energy-adjusted ab initio pseudopotentials for the second and third row transition elements. Theor. Chim. Acta 1990, 77, 123141.

19. Marenich, A. V.; Cramer, C. J.; Truhlar, D. G., Universal Solvation Model Based on Solute Electron Density and on a Continuum Model of the Solvent Defined by the Bulk Dielectric Constant and Atomic Surface Tensions. J. Phys. Chem. B 2009, 113, 6378-6396.

20. Li, Y.-Y.; Ye, K.; Siegbahn, P. E. M.; Liao, R.-Z., Mechanism of Water Oxidation Catalyzed by a Mononuclear Manganese Complex. ChemSusChem 2017, 10, 903-911.

21. Zhang, Y.-Q.; Liao, R.-Z., Reaction mechanism of hydrogen evolution catalysed by $\mathrm{Co}$ and $\mathrm{Fe}$ complexes containing a tetra-dentate phosphine ligand - a DFT study. Phys. Chem. Chem. Phys. 2017, 19 (48), 32589-32596.

22. Li, Y.-Y.; Tong, L.-P.; Liao, R.-Z., Mechanism of Water Oxidation Catalyzed by a Mononuclear Iron Complex with a Square Polypyridine Ligand: A DFT Study. Inorg. Chem. 2018, 57 (8), 4590-4601.

23. Zhang, Y.-Q.; Chen, J.-Y.; Siegbahn, P. E. M.; Liao, R.-Z., Harnessing Noninnocent Porphyrin Ligand to Circumvent Fe-Hydride Formation in the Selective Fe-Catalyzed CO2 Reduction in Aqueous Solution. ACS Catalysis 2020, 10 (11), 6332-6345.

24. Marenich, A. V.; Ho, J.; Coote, M. L.; Cramer, C. J.; Truhlar, D. G., Computational electrochemistry: prediction of liquid-phase reduction potentials. Phys. Chem. Chem. Phys. 2014, 16 (29), 15068-15106.

25. Liao, R.-Z.; Siegbahn, P. E. M., Quantum Chemical Modeling of Homogeneous Water Oxidation Catalysis. ChemSusChem 2017, 10, 4236-4263. 
26. Schilling, M.; Luber, S., Computational Modeling of Cobalt-Based Water Oxidation: Current Status and Future Challenges. Frontiers in chemistry 2018, 6, 100.

27. Himmel, D.; Radtke, V.; Butschke, B.; Krossing, I., Basic Remarks on Acidity. Angew. Chem. Int. Ed. 2018, 57 (16), 4386-4411.

28. Daniel Himmel; Valentin Radtke; BurkhardButschke; Krossing, I., Basic Remarks on Acidity. Angew.Chem.Int. Ed. 2018, 57, 4386-4411.

29. Morello, G. R.; Hopmann, K. H., A Dihydride Mechanism Can Explain the Intriguing Substrate Selectivity of Iron-PNP-Mediated Hydrogenation. ACS Catalysis 2017, 7 (9), 5847-5855. 


\section{Cartesian coordinates for all species}

$\mathrm{E}_{\text {opt }}\left({ }^{4}[\mathrm{Co}(\mathrm{ppq}) \mathrm{DMF}]^{2+}\right)=-1613.56875190$ Hartree

Center Atomic Atomic Coordinates (Angstroms)

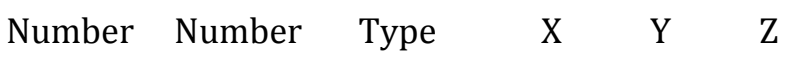

\begin{tabular}{|c|c|c|c|c|c|}
\hline 1 & 6 & 0 & -1.062784 & -3.340263 & -1.429847 \\
\hline 2 & 6 & 0 & -2.440342 & -3.374909 & -1.450415 \\
\hline 3 & 6 & 0 & -3.184351 & -2.322851 & -0.868409 \\
\hline 4 & 6 & 0 & -2.440794 & -1.244078 & -0.340246 \\
\hline 5 & 6 & 0 & -0.379005 & -2.249645 & -0.829203 \\
\hline 6 & 6 & 0 & -4.616258 & -2.304394 & -0.793504 \\
\hline 7 & 6 & 0 & -3.134240 & -0.138220 & 0.273022 \\
\hline 8 & 6 & 0 & -4.546358 & -0.166625 & 0.372534 \\
\hline 9 & 6 & 0 & -5.271208 & -1.271212 & -0.189263 \\
\hline 10 & 6 & 0 & -5.170665 & 0.911972 & 1.041924 \\
\hline 11 & 1 & 0 & -6.251957 & 0.927223 & 1.141945 \\
\hline 12 & 6 & 0 & -4.399007 & 1.928614 & 1.573789 \\
\hline 13 & 6 & 0 & -3.004169 & 1.881952 & 1.411203 \\
\hline 14 & 1 & 0 & -5.169763 & -3.137370 & -1.215187 \\
\hline 15 & 1 & 0 & -0.498009 & -4.138499 & -1.894512 \\
\hline 16 & 1 & 0 & -2.959539 & -4.209974 & -1.911461 \\
\hline 17 & 1 & 0 & -6.354294 & -1.270776 & -0.119037 \\
\hline 18 & 1 & 0 & -4.849338 & 2.757280 & 2.108297 \\
\hline 19 & 1 & 0 & -2.367536 & 2.662519 & 1.816664 \\
\hline 20 & 7 & 0 & -1.079315 & -1.213502 & -0.345280 \\
\hline 21 & 7 & 0 & -2.388095 & 0.890044 & 0.767659 \\
\hline 22 & 27 & 0 & -0.374410 & 0.657897 & 0.221747 \\
\hline 23 & 6 & 0 & 1.103873 & -2.279253 & -0.718010 \\
\hline 24 & 6 & 0 & 1.949903 & -1.119634 & -0.809657 \\
\hline
\end{tabular}




\begin{tabular}{|c|c|c|c|c|c|}
\hline 25 & 6 & 0 & 1.723238 & -3.516811 & -0.570657 \\
\hline 26 & 6 & 0 & 3.372332 & -1.291260 & -0.875474 \\
\hline 7 & 6 & 0 & 3.125835 & -3.673799 & -0.556606 \\
\hline 8 & 1 & 0 & 1.113355 & -4.405574 & -0.451403 \\
\hline 29 & 6 & 0 & 2.184557 & 1.200129 & -1.078874 \\
\hline 30 & 6 & 0 & 4.170968 & -0.139117 & -1.084061 \\
\hline 31 & 6 & 0 & 3.943021 & -2.581521 & -0.734691 \\
\hline 32 & 1 & 0 & 3.548469 & -4.665083 & -0.432640 \\
\hline 33 & 6 & 0 & 3.587751 & 1.099202 & -1.217647 \\
\hline 34 & 1 & 0 & 5.249896 & -0.248019 & -1.147000 \\
\hline 35 & 1 & 0 & 5.022556 & -2.691553 & -0.775165 \\
\hline 36 & 1 & 0 & 4.195418 & 1.979526 & -1.386667 \\
\hline 37 & 7 & 0 & 1.416130 & 0.133649 & -0.850159 \\
\hline 38 & 6 & 0 & 1.457117 & 2.492503 & -1.143958 \\
\hline 39 & 6 & 0 & 1.989354 & 3.648763 & -1.716392 \\
\hline 40 & 6 & 0 & 1.205951 & 4.802577 & -1.776590 \\
\hline 41 & 1 & 0 & 2.988119 & 3.648715 & -2.135998 \\
\hline 42 & 6 & 0 & -0.555242 & 3.583226 & -0.708335 \\
\hline 43 & 6 & 0 & -0.090881 & 4.771960 & -1.266837 \\
\hline 44 & 1 & 0 & 1.602100 & 5.707409 & -2.225946 \\
\hline 45 & 1 & 0 & -1.558416 & 3.503856 & -0.304927 \\
\hline 46 & 1 & 0 & -0.734577 & 5.643487 & -1.302352 \\
\hline 47 & 7 & 0 & 0.196441 & 2.473478 & -0.641724 \\
\hline 48 & 8 & 0 & 0.636007 & 0.543727 & 1.954549 \\
\hline 49 & 6 & 0 & 1.828433 & 0.703957 & 2.324389 \\
\hline 50 & 1 & 0 & 2.273993 & 1.706338 & 2.349501 \\
\hline 51 & 7 & 0 & 2.627277 & -0.275482 & 2.719457 \\
\hline 52 & 6 & 0 & 3.995929 & -0.014154 & 3.172775 \\
\hline 53 & 1 & 0 & 4.700936 & -0.561966 & 2.540659 \\
\hline 54 & 1 & 0 & 4.216177 & 1.053061 & 3.115327 \\
\hline
\end{tabular}




$\begin{array}{llllll}55 & 1 & 0 & 4.114508 & -0.346764 & 4.207551 \\ 56 & 6 & 0 & 2.177320 & -1.669995 & 2.750528 \\ 57 & 1 & 0 & 2.272263 & -2.058955 & 3.767919 \\ 58 & 1 & 0 & 1.137761 & -1.720569 & 2.433777 \\ 59 & 1 & 0 & 2.800179 & -2.267352 & 2.078478\end{array}$

$\mathrm{E}_{\text {opt }}\left({ }^{5}[\mathrm{Co}(\mathrm{ppq}) \mathrm{DMF}]^{+}\right)=-1613.830105$ Hartree

\begin{tabular}{|c|c|c|c|c|c|}
\hline \multirow{2}{*}{$\begin{array}{l}\text { Center } \\
\text { Number }\end{array}$} & \multicolumn{2}{|c|}{ Atomic } & \multirow{2}{*}{$\begin{array}{l}\text { Atomic } \\
\text { Type }\end{array}$} & \multicolumn{2}{|c|}{ Coordinates (Angstroms } \\
\hline & & umber & & $\mathrm{X}$ & $\mathrm{Z}$ \\
\hline 1 & 6 & 0 & -1.168831 & -3.410761 & -1.222674 \\
\hline 2 & 6 & 0 & -2.539853 & -3.411097 & -1.255307 \\
\hline 3 & 6 & 0 & -3.261901 & -2.289605 & -0.766171 \\
\hline 4 & 6 & 0 & -2.489763 & -1.195652 & -0.327111 \\
\hline 5 & 6 & 0 & -0.437138 & -2.292632 & -0.712092 \\
\hline 6 & 6 & 0 & -4.689367 & -2.224733 & -0.705149 \\
\hline 7 & 6 & 0 & -3.160320 & -0.031406 & 0.190412 \\
\hline 8 & 6 & 0 & -4.577146 & -0.006992 & 0.279338 \\
\hline 9 & 6 & 0 & -5.328298 & -1.128122 & -0.196329 \\
\hline 10 & 6 & 0 & -5.167693 & 1.140514 & 0.856151 \\
\hline 11 & 1 & 0 & -6.248914 & 1.197558 & 0.943397 \\
\hline 12 & 6 & 0 & -4.367745 & 2.169541 & 1.315583 \\
\hline 13 & 6 & 0 & -2.972784 & 2.063285 & 1.172419 \\
\hline 14 & 1 & 0 & -5.260610 & -3.076556 & -1.061974 \\
\hline 15 & 1 & 0 & -0.626543 & -4.256701 & -1.624512 \\
\hline 16 & 1 & 0 & -3.080205 & -4.262236 & -1.659109 \\
\hline 17 & 1 & 0 & -6.411597 & -1.094159 & -0.138256 \\
\hline 18 & 1 & 0 & -4.793974 & 3.051938 & 1.779205 \\
\hline 19 & 1 & 0 & -2.311461 & 2.849183 & 1.524071 \\
\hline
\end{tabular}




\begin{tabular}{|c|c|c|c|c|c|}
\hline 20 & 7 & 0 & -1.125906 & -1.192540 & -0.326112 \\
\hline 21 & 7 & 0 & -2.387094 & 1.008110 & 0.613727 \\
\hline 22 & 27 & & -0.357322 & 0.670789 & 0.112970 \\
\hline 23 & 6 & 0 & 1.020278 & -2.360773 & -0.609190 \\
\hline 24 & 6 & 0 & 1.908066 & -1.225318 & -0.696729 \\
\hline 25 & 6 & 0 & 1.602862 & -3.641364 & -0.443484 \\
\hline 26 & 6 & 0 & 3.330686 & -1.472231 & -0.762560 \\
\hline 27 & 6 & 0 & 2.975030 & -3.848051 & -0.422145 \\
\hline 8 & 1 & 0 & 0.954679 & -4.495803 & -0.286171 \\
\hline 29 & 6 & 0 & 2.278016 & 1.106318 & -0.975382 \\
\hline 30 & 6 & 0 & 4.191338 & -0.349612 & -0.976194 \\
\hline 31 & 6 & 0 & 3.838996 & -2.769420 & -0.609422 \\
\hline 32 & 1 & 0 & 3.369061 & -4.847644 & -0.271901 \\
\hline 33 & 6 & 0 & 3.671126 & 0.910932 & -1.110878 \\
\hline 34 & 1 & 0 & 5.261907 & -0.517478 & -1.045610 \\
\hline 35 & 1 & 0 & 4.914278 & -2.920575 & -0.641076 \\
\hline 36 & 1 & 0 & 4.328889 & 1.753632 & -1.288794 \\
\hline 37 & 7 & 0 & 1.439955 & 0.049067 & -0.733776 \\
\hline 38 & 6 & 0 & 1.645243 & 2.409483 & -1.038189 \\
\hline 39 & 6 & 0 & 2.290142 & 3.587426 & -1.475479 \\
\hline 40 & 6 & 0 & 1.585797 & 4.775530 & -1.544219 \\
\hline 41 & 1 & 0 & 3.327930 & 3.556002 & -1.784247 \\
\hline 42 & 6 & 0 & -0.350299 & 3.615285 & -0.755527 \\
\hline 43 & 6 & 0 & 0.226513 & 4.798685 & -1.182866 \\
\hline 44 & 1 & 0 & 2.077040 & 5.679435 & -1.890150 \\
\hline 45 & 1 & 0 & -1.396504 & 3.570540 & -0.472616 \\
\hline 46 & 1 & 0 & -0.361577 & 5.707102 & -1.237706 \\
\hline 47 & 7 & 0 & 0.326555 & 2.454643 & -0.666374 \\
\hline 48 & 8 & 0 & 0.479279 & 0.692961 & 2.008895 \\
\hline 49 & 6 & 0 & 1.716964 & 0.777404 & 2.200139 \\
\hline
\end{tabular}




$\begin{array}{llllll}50 & 1 & 0 & 2.236869 & 1.739253 & 2.098033 \\ 51 & 7 & 0 & 2.502118 & -0.245201 & 2.521803 \\ 52 & 6 & 0 & 3.941819 & -0.078777 & 2.700961 \\ 53 & 1 & 0 & 4.471269 & -0.693646 & 1.967494 \\ 54 & 1 & 0 & 4.220245 & 0.965929 & 2.552261 \\ 55 & 1 & 0 & 4.233215 & -0.387840 & 3.709338 \\ 56 & 6 & 0 & 1.970917 & -1.599217 & 2.683810 \\ 57 & 1 & 0 & 2.131346 & -1.932829 & 3.713773 \\ 58 & 1 & 0 & 0.906269 & -1.593650 & 2.459660 \\ 59 & 1 & 0 & 2.486499 & -2.276844 & 1.998372\end{array}$

$E_{\text {opt }}\left({ }^{4}[\mathrm{Co}(p p q) D M F]^{0}\right)=-1613.97520278$ Hartree

\begin{tabular}{ccccccc} 
Center & Atomic & \multicolumn{2}{l}{ Atomic } & \multicolumn{2}{c}{ Coordinates (Angstrom } \\
Number & Number & Type & $\mathrm{X}$ & $\mathrm{Y}$ & $\mathrm{Z}$ \\
\hline 1 & 6 & 0 & 1.061380 & 3.413558 & -1.198612 \\
2 & 6 & 0 & 2.445312 & 3.454379 & -1.256699 \\
3 & 6 & 0 & 3.189214 & 2.351225 & -0.783622 \\
4 & 6 & 0 & 2.456967 & 1.229183 & -0.331657 \\
5 & 6 & 0 & 0.365878 & 2.287320 & -0.701150 \\
6 & 6 & 0 & 4.621673 & 2.313281 & -0.737881 \\
7 & 6 & 0 & 3.155892 & 0.100478 & 0.174273 \\
8 & 6 & 0 & 4.580053 & 0.092451 & 0.247453 \\
9 & 6 & 0 & 5.295416 & 1.233344 & -0.240357 \\
10 & 6 & 0 & 5.200181 & -1.034268 & 0.811119 \\
11 & 1 & 0 & 6.283784 & -1.071153 & 0.883099 \\
12 & 6 & 0 & 4.416658 & -2.085372 & 1.284681 \\
13 & 6 & 0 & 3.025721 & -2.005247 & 1.159704 \\
14 & 1 & 0 & 5.168099 & 3.179593 & -1.102126
\end{tabular}




\begin{tabular}{|c|c|c|c|c|c|}
\hline 15 & 1 & 0 & 0.493003 & 4.253443 & -1.578743 \\
\hline 16 & 1 & 0 & 2.958204 & 4.321796 & -1.661624 \\
\hline 17 & 1 & 0 & 6.381096 & 1.225949 & -0.199240 \\
\hline 18 & 1 & 0 & 4.865053 & -2.960878 & 1.741571 \\
\hline 19 & 1 & 0 & 2.386456 & -2.807792 & 1.517577 \\
\hline 20 & 7 & 0 & 1.077638 & 1.171078 & -0.330514 \\
\hline 21 & 7 & 0 & 2.396430 & -0.965337 & 0.604800 \\
\hline 22 & 27 & 0 & 0.388603 & -0.645991 & 0.129127 \\
\hline 23 & 6 & 0 & -1.092851 & 2.325578 & -0.594212 \\
\hline 24 & 6 & 0 & -1.955569 & 1.167507 & -0.685068 \\
\hline 25 & 6 & 0 & -1.713655 & 3.589338 & -0.413410 \\
\hline 26 & 6 & 0 & -3.385411 & 1.381411 & -0.774560 \\
\hline 27 & 6 & 0 & -3.088749 & 3.761557 & -0.411865 \\
\hline 28 & 1 & 0 & -1.085338 & 4.453890 & -0.229845 \\
\hline 29 & 6 & 0 & -2.254011 & -1.179563 & -0.961235 \\
\hline 30 & 6 & 0 & -4.211038 & 0.228076 & -1.005805 \\
\hline 31 & 6 & 0 & -3.927087 & 2.660605 & -0.622053 \\
\hline 32 & 1 & 0 & -3.510583 & 4.749387 & -0.251396 \\
\hline 33 & 6 & 0 & -3.653295 & -1.013820 & -1.126415 \\
\hline 34 & 1 & 0 & -5.284626 & 0.367510 & -1.099880 \\
\hline 35 & 1 & 0 & -5.006259 & 2.785414 & -0.667679 \\
\hline 36 & 1 & 0 & -4.284654 & -1.873280 & -1.325827 \\
\hline 37 & 7 & 0 & -1.452184 & -0.090587 & -0.699829 \\
\hline 38 & 6 & 0 & -1.585696 & -2.448906 & -1.010775 \\
\hline 39 & 6 & 0 & -2.207278 & -3.677041 & -1.363750 \\
\hline 40 & 6 & 0 & -1.469826 & -4.839776 & -1.413216 \\
\hline 41 & 1 & 0 & -3.262021 & -3.695225 & -1.613370 \\
\hline 42 & 6 & 0 & 0.461037 & -3.585153 & -0.765523 \\
\hline 43 & 6 & 0 & -0.089169 & -4.805768 & -1.112707 \\
\hline 44 & 1 & 0 & -1.947241 & -5.774490 & -1.693464 \\
\hline
\end{tabular}




$\begin{array}{llllll}45 & 1 & 0 & 1.516964 & -3.492645 & -0.530238 \\ 46 & 1 & 0 & 0.527050 & -5.696431 & -1.155654 \\ 47 & 7 & 0 & -0.241033 & -2.439110 & -0.701137 \\ 48 & 8 & 0 & -0.522826 & -0.832568 & 2.073328 \\ 49 & 6 & 0 & -1.764703 & -0.803778 & 2.178869 \\ 50 & 1 & 0 & -2.371532 & -1.705603 & 2.010534 \\ 51 & 7 & 0 & -2.478723 & 0.286119 & 2.478368 \\ 52 & 6 & 0 & -3.932265 & 0.253731 & 2.555848 \\ 53 & 1 & 0 & -4.350603 & 0.957920 & 1.830835 \\ 54 & 1 & 0 & -4.295527 & -0.747441 & 2.316608 \\ 55 & 1 & 0 & -4.266694 & 0.528207 & 3.562937 \\ 56 & 6 & 0 & -1.832525 & 1.579776 & 2.684129 \\ 57 & 1 & 0 & -1.961692 & 1.898519 & 3.724826 \\ 58 & 1 & 0 & -0.772119 & 1.484488 & 2.456398 \\ 59 & 1 & 0 & -2.278907 & 2.321342 & 2.016813\end{array}$

$\mathrm{E}_{\text {opt }}\left({ }^{3}[\mathrm{Co}(\mathrm{ppq}) \mathrm{DMF}]^{-}\right)=-1614.00488706$ Hartree

\begin{tabular}{cccccc} 
Center & Atomic & Atomic & \multicolumn{2}{c}{ Coordinates (Angstrom } \\
Number & Number & Type & $\mathrm{X}$ & $\mathrm{Y}$ & $\mathrm{Z}$ \\
& & & & & \\
1 & 6 & 0 & 0.629687 & -3.512083 & -0.002479 \\
2 & 6 & 0 & 1.971886 & -3.644395 & 0.238966 \\
3 & 6 & 0 & 2.838381 & -2.532410 & 0.084965 \\
4 & 6 & 0 & 2.205070 & -1.296915 & -0.233075 \\
5 & 6 & 0 & 0.040941 & -2.255381 & -0.407275 \\
6 & 6 & 0 & 4.242784 & -2.548018 & 0.238479 \\
7 & 6 & 0 & 2.961787 & -0.119703 & -0.382901 \\
8 & 6 & 0 & 4.382509 & -0.151909 & -0.285812 \\
9 & 6 & 0 & 4.992710 & -1.399187 & 0.052346
\end{tabular}




\begin{tabular}{|c|c|c|c|c|c|}
\hline 10 & 6 & 0 & 5.080458 & 1.051227 & -0.550356 \\
\hline 11 & 1 & 0 & 6.164649 & 1.078570 & -0.491787 \\
\hline 12 & 6 & 0 & 4.335733 & 2.187299 & -0.946622 \\
\hline 13 & 6 & 0 & 2.958750 & 2.141160 & -1.004222 \\
\hline 14 & 1 & 0 & 4.730611 & -3.485392 & 0.499031 \\
\hline 15 & 1 & 0 & -0.017821 & -4.362787 & 0.161744 \\
\hline 16 & 1 & 0 & 2.380244 & -4.602802 & 0.554857 \\
\hline 17 & 1 & 0 & 6.074977 & -1.430656 & 0.157861 \\
\hline 18 & 1 & 0 & 4.841543 & 3.108232 & -1.224981 \\
\hline 19 & 1 & 0 & 2.375266 & 2.993343 & -1.331715 \\
\hline 20 & 7 & 0 & 0.844852 & -1.164377 & -0.439646 \\
\hline 21 & 7 & 0 & 2.241042 & 1.019735 & -0.668967 \\
\hline 22 & 27 & 0 & 0.329268 & 0.675830 & -0.487878 \\
\hline 23 & 6 & 0 & -1.361947 & -2.178418 & -0.753709 \\
\hline 24 & 6 & 0 & -2.111121 & -0.942127 & -0.860559 \\
\hline 25 & 6 & 0 & -2.055319 & -3.405971 & -1.021233 \\
\hline 26 & 6 & 0 & -3.541075 & -1.043017 & -1.122249 \\
\hline 27 & 6 & 0 & -3.400189 & -3.466584 & -1.290803 \\
\hline 28 & 1 & 0 & -1.483755 & -4.324866 & -1.065692 \\
\hline 29 & 6 & 0 & -2.331116 & 1.451847 & -0.636968 \\
\hline 30 & 6 & 0 & -4.313729 & 0.175393 & -1.147205 \\
\hline 31 & 6 & 0 & -4.151900 & -2.276598 & -1.316449 \\
\hline 32 & 1 & 0 & -3.874330 & -4.422326 & -1.500487 \\
\hline 33 & 6 & 0 & -3.720799 & 1.373961 & -0.893193 \\
\hline 34 & 1 & 0 & -5.380094 & 0.106932 & -1.347055 \\
\hline 35 & 1 & 0 & -5.222458 & -2.302669 & -1.509698 \\
\hline 36 & 1 & 0 & -4.311873 & 2.285243 & -0.885452 \\
\hline 37 & 7 & 0 & -1.539337 & 0.279360 & -0.678704 \\
\hline 38 & 6 & 0 & -1.640822 & 2.631384 & -0.322622 \\
\hline 39 & 6 & 0 & -2.217355 & 3.926055 & -0.126177 \\
\hline
\end{tabular}




\begin{tabular}{|c|c|c|c|c|c|}
\hline 40 & 6 & 0 & -1.457138 & 4.957421 & 0.360965 \\
\hline 41 & 1 & 0 & -3.272052 & 4.074051 & -0.335005 \\
\hline 42 & 6 & 0 & 0.440796 & 3.487619 & 0.407230 \\
\hline 43 & 6 & 0 & -0.088130 & 4.731008 & 0.680024 \\
\hline 44 & 1 & 0 & -1.904358 & 5.935619 & 0.522573 \\
\hline 45 & 1 & 0 & 1.475904 & 3.259235 & 0.629317 \\
\hline 46 & 1 & 0 & 0.532311 & 5.503614 & 1.120222 \\
\hline 47 & 7 & 0 & -0.263295 & 2.475652 & -0.148402 \\
\hline 48 & 8 & 0 & 0.434355 & 0.428063 & 2.464493 \\
\hline 49 & 6 & 0 & -0.786005 & 0.367781 & 2.333027 \\
\hline 50 & 1 & 0 & -1.389631 & 1.237190 & 2.022928 \\
\hline 51 & 7 & 0 & -1.543704 & -0.742930 & 2.538565 \\
\hline 52 & 6 & 0 & -2.976133 & -0.736177 & 2.307227 \\
\hline 53 & 1 & 0 & -3.529794 & -0.895897 & 3.243932 \\
\hline 54 & 1 & 0 & -3.275570 & 0.219110 & 1.869715 \\
\hline 55 & 1 & 0 & -3.249676 & -1.522415 & 1.596451 \\
\hline 56 & 6 & 0 & -0.918817 & -2.008395 & 2.878903 \\
\hline 57 & 1 & 0 & -1.187577 & -2.767248 & 2.137384 \\
\hline 58 & 1 & 0 & 0.162221 & -1.869448 & 2.869706 \\
\hline 59 & 1 & 0 & -1.240125 & -2.347821 & 3.873658 \\
\hline
\end{tabular}

$\mathrm{E}_{\mathrm{opt}}\left({ }^{3}[\mathrm{Co}(\mathrm{ppq})]^{-}\right)=-1365.45231238$ Hartree

Center Atomic Atomic Coordinates (Angstroms)

Number Number Type $\quad$ X $\quad$ Y $\quad$ Z

$\begin{array}{llllll}1 & 6 & 0 & 1.081148 & -3.434187 & 0.702988 \\ 2 & 6 & 0 & 2.450438 & -3.325800 & 0.842823 \\ 3 & 6 & 0 & 3.101248 & -2.113557 & 0.516136 \\ 4 & 6 & 0 & 2.261887 & -1.033358 & 0.141197\end{array}$




\begin{tabular}{|c|c|c|c|c|c|}
\hline 5 & 6 & 0 & $0.279391-$ & -2.345938 & 0.239721 \\
\hline 6 & 6 & 0 & $4.510483-$ & -1.905383 & 0.555221 \\
\hline 7 & 6 & 0 & 2.824411 & 0.223612 & -0.180884 \\
\hline 8 & 6 & 0 & 4.235536 & 0.412310 & -0.168813 \\
\hline 9 & 6 & 0 & $5.060532-$ & -0.692824 & 0.220660 \\
\hline 10 & 6 & 0 & 4.740459 & 1.673413 & -0.546131 \\
\hline 11 & 1 & 0 & 5.812456 & 1.850735 & -0.552657 \\
\hline 12 & 6 & 0 & 3.830851 & 2.676253 & -0.926973 \\
\hline 13 & 6 & 0 & 2.467335 & 2.423420 & -0.898890 \\
\hline 14 & 1 & 0 & 5.149226 & -2.735279 & 0.852207 \\
\hline 15 & 1 & 0 & 0.600277 & -4.362863 & 0.982011 \\
\hline 16 & 1 & 0 & 3.034540 & -4.169448 & 1.204717 \\
\hline 17 & 1 & 0 & 6.138610 & -0.549788 & 0.245498 \\
\hline 18 & 1 & 0 & 4.181769 & 3.654471 & -1.244009 \\
\hline 19 & 1 & 0 & 1.751051 & 3.185336 & -1.191288 \\
\hline 20 & 7 & 0 & 0.890228 & -1.134351 & 0.057932 \\
\hline 21 & 7 & 0 & 1.929088 & 1.237159 & -0.512508 \\
\hline 22 & 27 & 0 & 0.021704 & 0.656662 & -0.186049 \\
\hline 23 & 6 & 0 & -1.135972 & -2.533766 & -0.039098 \\
\hline 24 & 6 & 0 & -2.130015 & -1.475502 & -0.145170 \\
\hline 25 & 6 & 0 & -1.581659 & -3.881074 & -0.240557 \\
\hline 26 & 6 & 0 & -3.523412 & -1.878094 & -0.282526 \\
\hline 27 & 6 & 0 & -2.900945 & -4.223389 & -0.418509 \\
\hline 28 & 1 & 0 & -0.837735 & -4.666125 & -0.309432 \\
\hline 29 & 6 & 0 & -2.810197 & 0.834853 & -0.012058 \\
\hline 30 & 6 & 0 & -4.524610 & -0.840766 & -0.290403 \\
\hline 31 & 6 & 0 & -3.881302 & -3.216314 & -0.408480 \\
\hline 32 & 1 & 0 & -3.178778 & -5.261672 & -0.584708 \\
\hline 33 & 6 & 0 & -4.172888 & 0.465692 & -0.133442 \\
\hline 34 & 1 & 0 & -5.567166 & -1.131471 & -0.396509 \\
\hline
\end{tabular}




\begin{tabular}{|c|c|c|c|c|c|}
\hline 35 & 1 & 0 & -4.933762 & -3.466816 & -0.528426 \\
\hline 36 & 1 & 0 & -4.942489 & 1.231519 & -0.104719 \\
\hline 37 & 7 & 0 & -1.810239 & -0.151060 & -0.097240 \\
\hline 38 & 6 & 0 & -2.370160 & 2.161298 & 0.192706 \\
\hline 39 & 6 & 0 & -3.224702 & 3.301088 & 0.341267 \\
\hline 40 & 6 & 0 & -2.703459 & 4.541124 & 0.606967 \\
\hline 41 & 1 & 0 & -4.299259 & 3.175213 & 0.259288 \\
\hline 42 & 6 & 0 & -0.508770 & 3.584645 & 0.557728 \\
\hline 43 & 6 & 0 & -1.293237 & 4.702908 & 0.739074 \\
\hline 44 & 1 & 0 & -3.366475 & 5.395203 & 0.726817 \\
\hline 45 & 1 & 0 & 0.573601 & 3.641235 & 0.641530 \\
\hline 46 & 1 & 0 & -0.845376 & 5.664202 & 0.967249 \\
\hline 47 & 7 & 0 & -0.988443 & 2.356001 & 0.265520 \\
\hline
\end{tabular}

$E_{\text {opt }}(D M F)=-248.517668$ Hartree

\begin{tabular}{ccccccc} 
Center & Atomic & Atomic & \multicolumn{3}{c}{ Coordinates (Angstrom } \\
Number & Number & Type & $X$ & $Y$ & $Z$ \\
& & & & & \\
1 & 8 & 0 & 1.912282 & -0.206028 & 0.000345 \\
2 & 6 & 0 & 0.796634 & -0.704878 & -0.000551 \\
3 & 1 & 0 & 0.624465 & -1.801461 & 0.000245 \\
4 & 7 & 0 & -0.364195 & 0.005784 & -0.000284 \\
5 & 6 & 0 & -1.651718 & -0.682207 & 0.000201 \\
6 & 1 & 0 & -2.454104 & 0.056532 & 0.000673 \\
7 & 1 & 0 & -1.777145 & -1.311062 & -0.889220 \\
8 & 1 & 0 & -1.776384 & -1.311331 & 0.889537 \\
9 & 6 & 0 & -0.258769 & 1.462813 & -0.000003 \\
10 & 1 & 0 & 0.286443 & 1.810036 & 0.883614 \\
11 & 1 & 0 & 0.288808 & 1.809950 & -0.882164
\end{tabular}


$\begin{array}{llllll}12 & 1 & 0 & -1.257849 & 1.900708 & -0.001338\end{array}$

$E_{\text {opt }}\left(\mathrm{Et}_{3} \mathrm{NH}^{+}\right)=-292.706036548$ Hartree

\begin{tabular}{|c|c|c|c|c|c|}
\hline Center & & tomic & Atomic & Coordinate & es (Angstrom \\
\hline Number & & Numbe & Type & $\mathrm{X}$ & $\mathrm{Z}$ \\
\hline 1 & 7 & 0 & -0.036284 & 0.003303 & 0.015413 \\
\hline 2 & 6 & 0 & 1.080041 & -0.930678 & -0.462715 \\
\hline 3 & 1 & 0 & 0.852638 & -1.157621 & -1.507199 \\
\hline 4 & 1 & 0 & 2.002108 & -0.348163 & -0.434818 \\
\hline 5 & 6 & 0 & 1.207039 & -2.188328 & 0.383645 \\
\hline 6 & 1 & 0 & 2.033979 & -2.785888 & -0.009311 \\
\hline 7 & 1 & 0 & 1.444527 & -1.954829 & 1.427007 \\
\hline 8 & 1 & 0 & 0.313362 & -2.815930 & 0.354597 \\
\hline 9 & 6 & 0 & 0.249786 & 1.440328 & -0.404524 \\
\hline 10 & 6 & 0 & 1.438246 & 2.041759 & 0.363189 \\
\hline 11 & 1 & 0 & 1.204305 & 3.057548 & 0.687584 \\
\hline 12 & 1 & 0 & 1.680171 & 1.466574 & 1.264627 \\
\hline 13 & 1 & 0 & 2.339948 & 2.088390 & -0.250394 \\
\hline 14 & 6 & 0 & -1.412342 & -0.475764 & -0.425943 \\
\hline 15 & 1 & 0 & -1.403792 & -1.561426 & -0.321713 \\
\hline 16 & 1 & 0 & -1.485348 & -0.234229 & -1.489055 \\
\hline 17 & 6 & 0 & -2.545646 & 0.123931 & 0.392433 \\
\hline 18 & 1 & 0 & -2.466178 & -0.149121 & 1.449343 \\
\hline 19 & 1 & 0 & -2.612774 & 1.210856 & 0.312849 \\
\hline 20 & 1 & 0 & -3.489032 & -0.282958 & 0.018860 \\
\hline 21 & 1 & 0 & -0.668456 & 2.004475 & -0.244978 \\
\hline 22 & 1 & 0 & 0.426611 & 1.395888 & -1.481767 \\
\hline 23 & 1 & 0 & -0.020819 & -0.024173 & 1.039970 \\
\hline
\end{tabular}


$E_{\text {opt }}\left(E_{3} N\right)=-292.446846177$ Hartree

Center Atomic Atomic Coordinates (Angstroms)

$\begin{array}{llllll}\text { Number Number } & \text { Type } & \text { X } & \text { Y } & \text { Z }\end{array}$

\begin{tabular}{|c|c|c|c|c|c|}
\hline 1 & 7 & 0 & -0.000002 & -0.000013 & 0.028465 \\
\hline 2 & 6 & 0 & 1.218846 & -0.698960 & 0.452595 \\
\hline 3 & 1 & 0 & 1.464295 & -0.475063 & 1.509388 \\
\hline 4 & 1 & 0 & 1.026643 & -1.775459 & 0.410416 \\
\hline 5 & 6 & 0 & 2.418247 & -0.391083 & -0.445916 \\
\hline 6 & 1 & 0 & 3.299149 & -0.953189 & -0.117397 \\
\hline 7 & 1 & 0 & 2.191602 & -0.664587 & -1.480558 \\
\hline 8 & 1 & 0 & 2.681484 & 0.671381 & -0.431081 \\
\hline 9 & 6 & 0 & -1.214640 & -0.706152 & 0.452713 \\
\hline 10 & 6 & 0 & -1.547940 & -1.898543 & -0.446046 \\
\hline 11 & 1 & 0 & -2.475434 & -2.380114 & -0.117843 \\
\hline 12 & 1 & 0 & -1.671071 & -1.565242 & -1.480651 \\
\hline 13 & 1 & 0 & -0.759709 & -2.658021 & -0.431139 \\
\hline 14 & 6 & 0 & -0.004141 & 1.404892 & 0.453011 \\
\hline 15 & 1 & 0 & 1.024250 & 1.776679 & 0.411081 \\
\hline 16 & 1 & 0 & -0.320850 & 1.505211 & 1.509800 \\
\hline 17 & 6 & 0 & -0.870385 & 2.289849 & -0.445387 \\
\hline 18 & 1 & 0 & -0.520279 & 2.230211 & -1.480051 \\
\hline 19 & 1 & 0 & -1.922177 & 1.986767 & -0.430462 \\
\hline 20 & 1 & 0 & -0.823839 & 3.333780 & -0.116880 \\
\hline 21 & 1 & 0 & -2.050769 & -0.001377 & 0.410892 \\
\hline 22 & 1 & 0 & -1.143205 & -1.030899 & 1.509415 \\
\hline
\end{tabular}

$E_{\text {opt }}(T S)=-1658.914241$ Hartree 


\begin{tabular}{|c|c|c|c|c|c|}
\hline Center & & omic & Atomic & Coordinate & es (Angstrom \\
\hline Number & & Jumbe & Type & $\mathrm{X}$ & $\mathrm{Z}$ \\
\hline 1 & 6 & 0 & 1.333223 & 3.617110 & -0.957276 \\
\hline 2 & 6 & 0 & 2.708281 & 3.494125 & -1.071935 \\
\hline 3 & 6 & 0 & 3.309453 & 2.235966 & -0.852310 \\
\hline 4 & 6 & 0 & 2.442288 & 1.144206 & -0.617946 \\
\hline 5 & 6 & 0 & 0.504716 & 2.511235 & -0.649027 \\
\hline 6 & 6 & 0 & 4.725519 & 2.013137 & -0.856674 \\
\hline 7 & 6 & 0 & 2.990259 & -0.140682 & -0.370601 \\
\hline 8 & 6 & 0 & 4.403203 & -0.339506 & -0.338779 \\
\hline 9 & 6 & 0 & 5.256592 & 0.779470 & -0.605230 \\
\hline 10 & 6 & 0 & 4.880600 & -1.623746 & -0.035489 \\
\hline 11 & 1 & 0 & 5.951114 & -1.806398 & -0.001653 \\
\hline 12 & 6 & 0 & 3.970031 & -2.646634 & 0.228803 \\
\hline 13 & 6 & 0 & 2.601012 & -2.371259 & 0.162118 \\
\hline 14 & 1 & 0 & 5.376964 & 2.860574 & -1.054856 \\
\hline 15 & 1 & 0 & 0.877484 & 4.582039 & -1.138976 \\
\hline 16 & 1 & 0 & 3.322874 & 4.353936 & -1.321868 \\
\hline 17 & 1 & 0 & 6.332508 & 0.628052 & -0.599058 \\
\hline 18 & 1 & 0 & 4.303517 & -3.648478 & 0.477254 \\
\hline 19 & 1 & 0 & 1.873371 & -3.151505 & 0.362912 \\
\hline 20 & 7 & 0 & 1.066510 & 1.260184 & -0.577576 \\
\hline 21 & 7 & 0 & 2.097401 & -1.170148 & -0.145111 \\
\hline 22 & 27 & 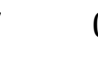 & 0.151297 & $7 \quad-0.496387$ & $\begin{array}{ll}7 & -0.450309\end{array}$ \\
\hline 23 & 6 & 0 & -0.925768 & 2.712903 & -0.424955 \\
\hline 24 & 6 & 0 & -1.952009 & 1.706235 & -0.601323 \\
\hline 25 & 6 & 0 & -1.346347 & 4.008537 & -0.021933 \\
\hline 26 & 6 & 0 & -3.336010 & 2.133193 & -0.558752 \\
\hline
\end{tabular}




\begin{tabular}{|c|c|c|c|c|c|}
\hline 27 & 6 & 0 & -2.677555 & 4.375635 & 0.078660 \\
\hline 28 & 1 & 0 & -0.592185 & 4.738947 & 0.246575 \\
\hline 29 & 6 & 0 & -2.639315 & -0.520489 & -1.114217 \\
\hline 30 & 6 & 0 & -4.348776 & 1.156427 & -0.841392 \\
\hline 31 & 6 & 0 & -3.673865 & 3.447870 & -0.224305 \\
\hline 32 & 1 & 0 & -2.939553 & 5.380220 & 0.397866 \\
\hline 33 & 6 & 0 & -4.004053 & -0.131061 & -1.127125 \\
\hline 34 & 1 & 0 & -5.389637 & 1.466746 & -0.825629 \\
\hline 35 & 1 & 0 & -4.724219 & 3.723216 & -0.174762 \\
\hline 36 & 1 & 0 & -4.774088 & -0.859361 & -1.356826 \\
\hline 37 & 7 & 0 & -1.648910 & 0.391913 & -0.813143 \\
\hline 38 & 6 & 0 & -2.197349 & -1.856049 & -1.376151 \\
\hline 39 & 6 & 0 & -3.050051 & -2.943244 & -1.712748 \\
\hline 40 & 6 & 0 & -2.522864 & -4.187098 & -1.975419 \\
\hline 41 & 1 & 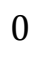 & -4.121294 & -2.789097 & -1.772501 \\
\hline 42 & 6 & 0 & -0.339752 & -3.293466 & -1.572441 \\
\hline 43 & 6 & 0 & -1.120140 & -4.377520 & -1.917401 \\
\hline 44 & 1 & 0 & -3.178414 & -5.012556 & -2.237542 \\
\hline 45 & & 0 & 0.741787 & -3.373337 & -1.525690 \\
\hline 46 & 1 & 0 & -0.664637 & -5.334512 & -2.145603 \\
\hline 47 & 7 & 4 & -0.835083 & -2.070440 & -1.282167 \\
\hline 48 & 7 & 0 & -0.677138 & -0.704961 & 2.550307 \\
\hline 49 & 0 & 0 & 0.197754 & -1.837031 & 2.924742 \\
\hline 50 & 6 & 0 & -0.223075 & -3.168010 & 2.301513 \\
\hline 51 & 1 & 0 & 0.239343 & -1.920498 & 4.023010 \\
\hline 52 & 1 & 0 & 1.200057 & -1.593239 & 2.568505 \\
\hline 53 & 1 & 0 & 0.577112 & -3.899486 & 2.449745 \\
\hline 54 & 1 & 0 & -1.130231 & -3.578895 & 2.751297 \\
\hline 55 & 1 & 0 & -0.392701 & -3.054647 & 1.227012 \\
\hline 56 & 6 & 0 & -2.113054 & -1.011647 & 2.7617 \\
\hline
\end{tabular}




$\begin{array}{lllrll}57 & 6 & 0 & -3.060543 & 0.161189 & 2.531681 \\ 58 & 1 & 0 & -2.243671 & -1.409302 & 3.782311 \\ 59 & 1 & 0 & -2.370485 & -1.808423 & 2.060653 \\ 60 & 1 & 0 & -4.088734 & -0.211594 & 2.539940 \\ 61 & 1 & 0 & -2.979416 & 0.926819 & 3.307464 \\ 62 & 1 & 0 & -2.885877 & 0.624047 & 1.561760 \\ 63 & 6 & 0 & -0.256668 & 0.582513 & 3.152257 \\ 64 & 6 & 0 & 1.226101 & 0.901857 & 2.969242 \\ 65 & 1 & 0 & -0.524569 & 0.587337 & 4.221647 \\ 66 & 1 & 0 & -0.838617 & 1.362846 & 2.658082 \\ 67 & 1 & 0 & 1.400066 & 1.941375 & 3.262102 \\ 68 & 1 & 0 & 1.874739 & 0.272118 & 3.583949 \\ 69 & 1 & 0 & 1.512404 & 0.793641 & 1.921740 \\ 70 & 1 & 0 & -0.420512 & -0.538953 & 1.059400\end{array}$

$\mathrm{E}_{\mathrm{opt}}\left({ }^{3}[\mathrm{CoH}(\mathrm{ppq})]^{0}\right)=-1365.99969712$ Hartree

Center Atomic Atomic Coordinates (Angstroms)

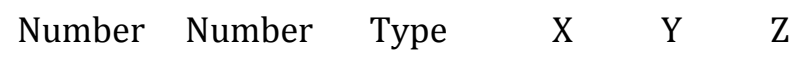

$\begin{array}{cccccc}1 & 6 & 0 & -0.524855 & -3.451813 & -0.793893 \\ 2 & 6 & 0 & -1.862224 & -3.479056 & -1.099323 \\ 3 & 6 & 0 & -2.675295 & -2.361256 & -0.785396 \\ 4 & 6 & 0 & -2.021467 & -1.247765 & -0.211019 \\ 5 & 6 & 0 & 0.073371 & -2.314984 & -0.169623 \\ 6 & 6 & 0 & -4.086063 & -2.319780 & -1.016784 \\ 7 & 6 & 0 & -2.805621 & -0.092793 & 0.146798 \\ 8 & 6 & 0 & -4.214630 & -0.096327 & -0.050850 \\ 9 & 6 & 0 & -4.834233 & -1.232965 & -0.659903 \\ 10 & 6 & 0 & -4.929574 & 1.042164 & 0.382170\end{array}$




\begin{tabular}{|c|c|c|c|c|c|}
\hline 11 & 1 & 0 & -6.006839 & 1.080794 & 0.244249 \\
\hline 12 & 6 & 0 & -4.253749 & 2.081926 & 0.991921 \\
\hline 13 & 6 & 0 & -2.857198 & 1.989326 & 1.144512 \\
\hline & 1 & 0 & -4.557690 & -3.186049 & -1.472998 \\
\hline 15 & 1 & 0 & 0.101474 & -4.291607 & -1.066083 \\
\hline 16 & 1 & 0 & -2.301677 & -4.344623 & -1.587376 \\
\hline 17 & 1 & 0 & -5.907817 & -1.218465 & -0.824325 \\
\hline 18 & 1 & 0 & -4.777932 & 2.960165 & 1.353724 \\
\hline 19 & 1 & 0 & -2.290531 & 2.771030 & 1.642312 \\
\hline 20 & 7 & 0 & -0.688726 & -1.218741 & 0.069582 \\
\hline 21 & 7 & 0 & -2.151829 & 0.952628 & 0.712265 \\
\hline 22 & 27 & & 0.040249 & 0.581893 & 0.849368 \\
\hline 23 & 6 & 0 & 1.503029 & -2.357237 & 0.158181 \\
\hline 24 & 6 & 0 & 2.370524 & -1.205888 & 0.147994 \\
\hline 25 & 6 & 0 & 2.095763 & -3.617699 & 0.399704 \\
\hline 26 & 6 & 0 & 3.797017 & -1.411501 & 0.175929 \\
\hline 27 & 6 & 0 & 3.470313 & -3.787724 & 0.524043 \\
\hline 28 & 1 & 0 & 1.455944 & -4.485466 & 0.517023 \\
\hline 29 & 6 & 0 & 2.672755 & 1.121474 & -0.182290 \\
\hline 30 & 6 & 0 & 4.631426 & -0.265199 & -0.002540 \\
\hline 31 & 6 & 0 & 4.322526 & -2.697526 & 0.374837 \\
\hline 32 & 1 & 0 & 3.874293 & -4.775079 & 0.726199 \\
\hline 33 & 6 & 0 & 4.077470 & 0.970544 & -0.220183 \\
\hline 34 & 1 & 0 & 5.709639 & -0.395254 & 0.014638 \\
\hline 35 & 1 & 0 & 5.400661 & -2.823714 & 0.426573 \\
\hline 36 & 1 & 0 & 4.717655 & 1.829007 & -0.388967 \\
\hline 37 & 7 & 0 & 1.863977 & 0.053000 & 0.075637 \\
\hline 38 & 6 & 0 & 1.984748 & 2.385404 & -0.377529 \\
\hline 39 & 6 & 0 & 2.629361 & 3.577814 & -0.777027 \\
\hline & 6 & 0 & 1.888683 & 4.724484 & -0.994059 \\
\hline
\end{tabular}




$\begin{array}{llllll}41 & 1 & 0 & 3.701877 & 3.589244 & -0.931006 \\ 42 & 6 & 0 & -0.074212 & 3.492280 & -0.403322 \\ 43 & 6 & 0 & 0.494479 & 4.686777 & -0.814610 \\ 44 & 1 & 0 & 2.380056 & 5.640185 & -1.309373 \\ 45 & 1 & 0 & -1.144150 & 3.408424 & -0.246421 \\ 46 & 1 & 0 & -0.125800 & 5.559209 & -0.987544 \\ 47 & 7 & 0 & 0.629467 & 2.370590 & -0.176055 \\ 48 & 1 & 0 & -0.024483 & 0.850059 & 2.433916\end{array}$

$E_{\text {opt }}\left({ }^{4}[\mathrm{Co}(p p q)]^{2+}\right)=-1364.97412904$ Hartree

\begin{tabular}{|c|c|c|c|c|c|}
\hline \multirow{2}{*}{$\begin{array}{l}\text { Center } \\
\text { Number }\end{array}$} & \multicolumn{2}{|c|}{ Atomic } & \multirow{2}{*}{$\begin{array}{l}\text { Atomic } \\
\text { Type }\end{array}$} & \multicolumn{2}{|c|}{ Coordinates (Angstrom } \\
\hline & & Jumber & & Y & $\mathrm{Z}$ \\
\hline 1 & 6 & 0 & -0.803676 & -3.438556 & -0.797723 \\
\hline 2 & 6 & 0 & -2.173307 & -3.413617 & -0.944765 \\
\hline 3 & 6 & 0 & -2.912893 & -2.271135 & -0.553222 \\
\hline 4 & 6 & 0 & -2.158250 & -1.171485 & -0.100052 \\
\hline 5 & 6 & 0 & -0.109364 & -2.324353 & -0.247790 \\
\hline 6 & 6 & 0 & -4.342372 & -2.175672 & -0.603964 \\
\hline 7 & 6 & 0 & -2.827122 & 0.037756 & 0.297088 \\
\hline 8 & 6 & 0 & -4.240656 & 0.094671 & 0.277537 \\
\hline 9 & 6 & 0 & -4.981935 & -1.040652 & -0.194200 \\
\hline 10 & 6 & 0 & -4.844809 & 1.287677 & 0.740282 \\
\hline 11 & 1 & 0 & -5.927448 & 1.373667 & 0.746848 \\
\hline 12 & 6 & 0 & -4.053618 & 2.330311 & 1.189914 \\
\hline 13 & 6 & 0 & -2.656755 & 2.194650 & 1.154059 \\
\hline 14 & 1 & 0 & -4.909493 & -3.028866 & -0.962223 \\
\hline 15 & 1 & 0 & -0.252490 & -4.311156 & -1.122087 \\
\hline 16 & 1 & 0 & -2.691349 & -4.273138 & -1.359917 \\
\hline
\end{tabular}




\begin{tabular}{|c|c|c|c|c|c|}
\hline 17 & 1 & 0 & -6.065304 & -0.980458 & -0.216947 \\
\hline 18 & 1 & 0 & -4.492011 & 3.247885 & 1.565430 \\
\hline 19 & 1 & & -2.008872 & 2.994648 & 1.498133 \\
\hline 20 & 7 & 0 & -0.799458 & -1.203247 & 0.021187 \\
\hline 21 & 7 & & -2.054754 & 1.087837 & 0.708944 \\
\hline 22 & 27 & & -0.071521 & 0.670709 & 0.269050 \\
\hline 23 & 6 & & 1.338818 & -2.414680 & 0.067531 \\
\hline 24 & 6 & & 2.259102 & -1.306941 & 0.141680 \\
\hline 25 & 6 & & 1.852877 & -3.688558 & 0.315270 \\
\hline 26 & 6 & 0 & 3.655538 & -1.581431 & 0.341102 \\
\hline 27 & 6 & & 3.213806 & -3.943314 & 0.569989 \\
\hline 28 & 1 & & 1.178556 & -4.536175 & 0.335460 \\
\hline 29 & 6 & & 2.742728 & 1.004659 & -0.045948 \\
\hline 30 & 6 & & 4.565031 & -0.499934 & 0.316822 \\
\hline 31 & 6 & & 4.112766 & -2.905608 & 0.558043 \\
\hline 32 & 1 & & 3.540284 & -4.959649 & 0.760647 \\
\hline 33 & 6 & & 4.123935 & 0.785349 & 0.099273 \\
\hline 34 & 1 & 0 & 5.622744 & -0.696951 & 0.464550 \\
\hline 35 & 1 & 0 & 5.172065 & -3.078874 & 0.720088 \\
\hline 36 & 1 & 0 & 4.828020 & 1.606272 & 0.069029 \\
\hline 37 & 7 & 0 & 1.852010 & -0.003127 & 0.011141 \\
\hline 38 & 6 & 0 & 2.172468 & 2.356284 & -0.285430 \\
\hline 39 & 6 & 0 & 2.943152 & 3.486973 & -0.558889 \\
\hline 40 & 6 & 0 & 2.307478 & 4.701094 & -0.826089 \\
\hline 41 & 1 & 0 & 4.023989 & 3.431627 & -0.582811 \\
\hline 42 & 6 & 0 & 0.204946 & 3.598319 & -0.540136 \\
\hline 43 & 6 & 0 & 0.914318 & 4.761109 & -0.823525 \\
\hline 44 & 1 & 0 & 2.897204 & 5.586064 & -1.042270 \\
\hline 45 & 1 & 0 & -0.879183 & 3.582884 & -0.534081 \\
\hline 46 & 1 & 0 & 0.385594 & 5.682544 & -1.039157 \\
\hline
\end{tabular}


$\begin{array}{llllll}47 & 7 & 0 & 0.815154 & 2.431141 & -0.269562\end{array}$

$\mathrm{E}_{\text {opt }}\left({ }^{4}\left[\mathrm{Co}(\mathrm{ppq})\left(\mathrm{PPh}_{3}\right)\right]^{2+}\right)=-2401.435703$ Hartree

Center Atomic Atomic Coordinates (Angstroms)

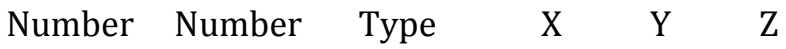

$\begin{array}{llllll}1 & 6 & 0 & -1.764903 & -4.093273 & -0.774246 \\ 2 & 6 & 0 & -3.129659 & -3.937183 & -0.863812 \\ 3 & 6 & 0 & -3.697517 & -2.642240 & -0.826689 \\ 4 & 6 & 0 & -2.792563 & -1.560623 & -0.753223 \\ 5 & 6 & 0 & -0.913252 & -2.961173 & -0.643956 \\ 6 & 6 & 0 & -5.108765 & -2.391027 & -0.856649 \\ 7 & 6 & 0 & -3.307055 & -0.214486 & -0.695021 \\ 8 & 6 & 0 & -4.706613 & 0.003027 & -0.675982 \\ 9 & 6 & 0 & -5.595630 & -1.118766 & -0.776329 \\ 10 & 6 & 0 & -5.152570 & 1.339097 & -0.541728 \\ 11 & 1 & 0 & -6.218133 & 1.548213 & -0.522555 \\ 12 & 6 & 0 & -4.230522 & 2.362259 & -0.420952 \\ 13 & 6 & 0 & -2.859483 & 2.056387 & -0.463713 \\ 14 & 1 & 0 & -5.785208 & -3.236816 & -0.929282 \\ 15 & 1 & 0 & -1.333638 & -5.084479 & -0.829419 \\ 16 & 1 & 0 & -3.774811 & -4.805023 & -0.964329 \\ 17 & 1 & 0 & -6.665460 & -0.935782 & -0.780396 \\ 18 & 1 & 0 & -4.545030 & 3.392100 & -0.295800 \\ 21 & 1 & 0 & -2.105048 & 2.830870 & -0.362257 \\ 23 & 6 & 0 & 0.547783 & -3.164607 & -0.469705\end{array}$




\begin{tabular}{|c|c|c|c|c|c|}
\hline 24 & 6 & 0 & 1.558798 & -2.294735 & -1.009038 \\
\hline 25 & 6 & 0 & 0.973365 & -4.317400 & 0.185217 \\
\hline 26 & 6 & 0 & 2.926589 & -2.722537 & -0.998793 \\
\hline 27 & 6 & & 2.331180 & -4.688915 & 0.272766 \\
\hline 88 & 1 & 0 & 0.239887 & -4.963956 & 0.654270 \\
\hline 29 & 6 & 0 & 2.150256 & -0.329635 & -2.141304 \\
\hline 30 & 6 & & 3.888462 & -1.890709 & -1.621537 \\
\hline 31 & 6 & 0 & 3.293199 & -3.924814 & -0.345488 \\
\hline 32 & 1 & 0 & 2.601614 & -5.595123 & 0.803789 \\
\hline 33 & 6 & 0 & 3.507456 & -0.712343 & -2.215889 \\
\hline 34 & 1 & 0 & 4.930879 & -2.193713 & -1.618918 \\
\hline 35 & 1 & 0 & 4.337367 & -4.222198 & -0.331798 \\
\hline 36 & 1 & 0 & 4.241699 & -0.075117 & -2.691557 \\
\hline 37 & 7 & 0 & 1.230192 & -1.081176 & -1.531774 \\
\hline 38 & 6 & 0 & 1.633350 & 0.928182 & -2.733045 \\
\hline 39 & 6 & 0 & 2.353865 & 1.718378 & -3.632058 \\
\hline 40 & 6 & 0 & 1.746553 & 2.842283 & -4.192464 \\
\hline 41 & 1 & 0 & 3.365038 & 1.453134 & -3.914492 \\
\hline 42 & 6 & 0 & -0.223436 & 2.326254 & -2.937349 \\
\hline 43 & 6 & 0 & 0.429593 & 3.149156 & -3.849922 \\
\hline 44 & 1 & 0 & 2.291976 & 3.460278 & -4.898326 \\
\hline 45 & 1 & 0 & -1.243451 & 2.522199 & -2.627609 \\
\hline 46 & 1 & 0 & -0.083843 & 4.002385 & -4.278328 \\
\hline 47 & 7 & 0 & 0.363292 & 1.253034 & -2.383849 \\
\hline 48 & 15 & 0 & 0.629094 & 0.830573 & 1.185030 \\
\hline 49 & 6 & 0 & 0.202903 & 2.607104 & 1.324445 \\
\hline 50 & 6 & 0 & -0.517728 & 3.105578 & 2.420395 \\
\hline 51 & 6 & 0 & 0.503747 & 3.467329 & 0.250862 \\
\hline 52 & 6 & 0 & -0.927325 & 4.441201 & 2.440270 \\
\hline 5 & 1 & 0 & -0.760340 & 2.457033 & 3.25537 \\
\hline
\end{tabular}




\begin{tabular}{|c|c|c|c|c|c|}
\hline 54 & 6 & 0 & 0.098107 & 4.801697 & 0.279599 \\
\hline 55 & 1 & 0 & 1.061729 & 3.098942 & -0.603808 \\
\hline 56 & 6 & 0 & -0.623854 & 5.289565 & 1.373502 \\
\hline 57 & 1 & 0 & -1.478686 & 4.819229 & 3.295540 \\
\hline 58 & 1 & 0 & 0.347866 & 5.460349 & -0.546744 \\
\hline 59 & 1 & 0 & -0.940721 & 6.327456 & 1.396382 \\
\hline 60 & 6 & 0 & 2.446241 & 0.665385 & 1.290918 \\
\hline 61 & 6 & 0 & 2.975043 & -0.612296 & 1.546319 \\
\hline 62 & 6 & 0 & 3.321168 & 1.742778 & 1.081902 \\
\hline 63 & 6 & 0 & 4.354337 & -0.803973 & 1.596521 \\
\hline 64 & 1 & 0 & 2.311138 & -1.453071 & 1.725063 \\
\hline 65 & 6 & 0 & 4.702459 & 1.540365 & 1.122178 \\
\hline 66 & 1 & 0 & 2.935604 & 2.742341 & 0.914166 \\
\hline 67 & 6 & 0 & 5.221538 & 0.269978 & 1.378897 \\
\hline 68 & 1 & 0 & 4.750902 & -1.791455 & 1.812189 \\
\hline 69 & 1 & 0 & 5.371664 & 2.382000 & 0.972789 \\
\hline 70 & 1 & 0 & 6.295791 & 0.120710 & 1.424738 \\
\hline 71 & 6 & 0 & -0.032034 & 0.025509 & 2.679704 \\
\hline 72 & 6 & 0 & -1.317961 & -0.537147 & 2.633540 \\
\hline 73 & 6 & 0 & 0.688677 & 0.008198 & 3.885954 \\
\hline 74 & 6 & 0 & -1.875679 & -1.110940 & 3.775900 \\
\hline 75 & 1 & 0 & -1.884649 & -0.518421 & 1.709422 \\
\hline 76 & 6 & 0 & 0.127575 & -0.571339 & 5.023886 \\
\hline 77 & 1 & 0 & 1.683688 & 0.438804 & 3.935373 \\
\hline 78 & 6 & 0 & -1.152355 & -1.130709 & 4.970767 \\
\hline 79 & 1 & 0 & -2.871141 & -1.542417 & 3.734703 \\
\hline 80 & 1 & 0 & 0.688006 & -0.582081 & 5.953369 \\
\hline 81 & 1 & 0 & -1.584554 & -1.579237 & 5.859751 \\
\hline
\end{tabular}

